\title{
Hot Water Electric Energy Use in Single-Family Residences in the Pacific Northwest
}

Regional End-Use Metering Project (REMP/ELCAP)

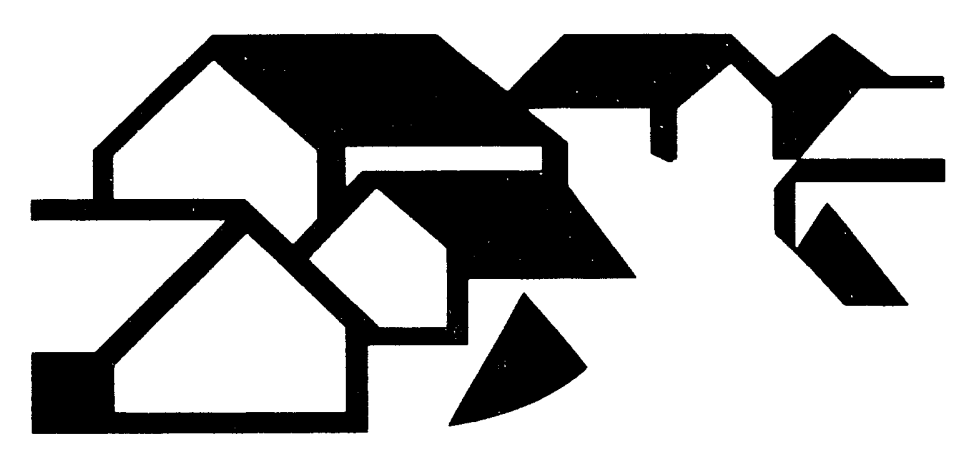

DISTRIBUTION OF THIS DOCUMENT IS UNILIMITED 


\section{DISCLAIMER}

The report was prepared by the U.S. Department of Energy, Bonneville Power Administration. Neither the U.S. Department of Energy nor any agency thereof, nor any of their employees, makes any warranty, express or implied, or assumes any legal liability or responsibility for the accuracy, completeness, or usefulness of any information, apparatus, product, or process disclosed, or represents that its use would not infringe on privately owned rights. Reference herein to any specific commercial product, process, or service by trade name, trademark, manufacturer, or otherwise, does not necessarily constitute or imply its endorsement, recommendation, or favoring by the U.S. Department of Energy or any agency thereof. The views and opinions of authors expressed herein do not necessarily state or reflest those of the U.S. Department of Energy or any agency thereof. 


\section{HOT WATER ELECTRIC ENERGY USE IN SINGLE-FAMILY RESIDENCES IN THE PACIFIC NORTHWEST}

REGIONAL END-USE METERING PROJECT (REMP)

Prepared By

M.E. Taylor

K.G. Ritland*

R.G. Pratt**

September 1991

Office of Energy Resources

Bonneville Power Administration

Portland, Oregon

*K.G. Ritland is employed by Ritland Associates, Stattle, Washington

**R.G. Pratt is employed by Pacific Northwest Laboratories, Richland, Washington 


\title{
FOREWORD
}

The Office of Energy Resources of the Bonneville Power Administration carries out generation and conservation resource planning. The analysis of historical trends in and determinants of energy consumption is carried out by the office's End-Use Research Section. The End-Use Research Section operates a comprehensive data collection program to provide pertinent information to support demand-side conservation planning, load forecasting, and conservation program development and delivery. Part of this on-going program, commonly known as the End-Use Load and Consumer Assessment Program (ELCAP), was recently renamed the Regional End-Use Metering Project (REMP) to reflect an emphasis on metering rather than analytical activities. REMP is designed to collect electricity usage data through direct monitoring of end-use loads in buildings in the residential and commercial sectors and is conducted for Bonneville by Pacific Northwest Laboratories (Battelle).

The detailed summary information in this report is on energy used for water heaters in the residential sector and is based on data collected from September 1985 through December 1990 for 336 of the 499 REMP metered homes. Specific information is provided on annual loads averaged over the years and their variation across residences. Descriptions are given of use as associated with demographic and energy-related characteristics. Summaries are also provided for electricity use by each year, month, and daytype, as well as at peak hot water load and peak system times.

This is the second residential report. The first report, Description of Electric Energy Use in Single-Family Residences in the Pacific Northwest (ELCAP) (1989), provides extensive background information on residential metering and serves as a sourcebook of summarized residential data for every end use metered. This second report focuses on a specific end use and adds detail to the first report. Subsequent reports are planned on other individual end uses or sets of end uses.

Comments regarding the interpretation of the data presented, requests for additional useful data summaries, or requests for an electronic version of the data summaries should be directed to:

\author{
Residential Analyst \\ End-Use Research Section \\ Bonneville Power Administration \\ P.O. Box 3621 - RPEE \\ (503) 230-5856
}




\section{ACKNOWLEDGMENTS}

This report was made possible by the efforts of many people in the Bonneville Power Administration. Special thanks to David Mills and Jim Cahill for their contribution and responsiveness when help was needed, Mary Lange for her map of the region, and the Bonneville Writer/Editor Pool for editing expertise. 


\section{CONTENTS}

Section 1 - Introduction ....................................................

Section 2 - Key Observations.......................................... 2-1

Section 3 - Background .................................................... $3-1$

The Hot Water End Use ..................................... 3-1

How a Water Heater Functions............................. 3-1

Section 4 - Residential Hot Water Activities ................................ 4-1

Conservation Measures and Programs........................ 4-1

Other Work ................................................. 4-1

Section 5 - Description of the REMP Studies............................... $5-1$

Existing Homes: Base and Post-1978 Homes.................... 5-1

New Homes: MCS and Control Homes ...................... 5-2

Section 6 - Key Characteristics of Homes ................................... 6-1

Key Home Characteristics.................................... 6-1

Number of Sites Represented ................................ 6-10

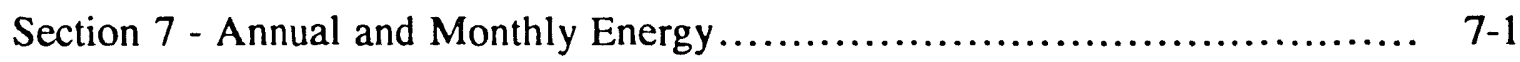

Annual Energy Use.......................................... 7-1

Year-To-Year Trends ...................................... 7-7

Monthly Energy Use ...................................... 7-10

Section 8 - Average Hot Water Load Profiles .............................. 8-1

Weekend and Weekday Load Profiles ......................... 8-1

January and July Load Profiles .............................. 8-5

Section 9 - Peak Day Load Characteristics ................................. 9-1

Annual Peak ................................................... 9-2

Monthly Peak Profiles ...................................... 9-3

Seasonal Peak Day Profiles ...................................... 9-5

Contribution To Bonneville System Peak ......................... 9-11

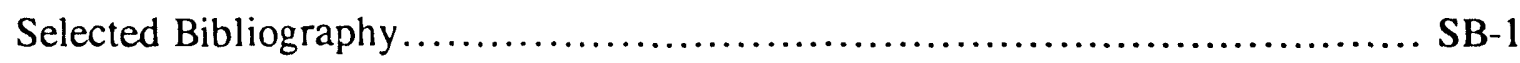

Appendix A - Temporal and Cross-Site Aggregation Methodology .............. $:-1$

Appendix B - Companion Data Tables ................................... B-1 


\section{LIST OF FIGURES}

1.1 Bonneville Power Administration Service Area Boundaries ............. 1-1

7.1 Estimated Actual Annual End-Use Load Distribution for 1990 in a Single-Family Electrically Heated Home .................... 7-3

7.2 Measured REMP Residential Annual End-Use Load Distribution for an Average Single-Family Home With Electric Space Heating 7-3

7.3 Average REMP End-Use Load Distribution for an MCS Home ......... 7-4

7.4 Residential Hot Water Mean Annual Loads by Type of Home ........... 7-7

7.5 Mean Residential Hot Water Loads by Year and Type of Home Using the Clustered Weighting Method with All Sites........... 7-8

7.6 Mean Residential Hot Water Monthly Loads by Study ................. 7-11

7.7 Mean Residential Hot Water Daily Load by Month for the Base Study ............................................... 7-14

7.8 Mean Residential Hot Water Daily Load by Month for the Post-1978 Study......................................... 7-14

7.9 Mean Residential Hot Water Daily Load by Month for the MCS Study

7.10 Mean Residential Hot Water Daily Load by Month for the Control Study

8.1 Mean Residential Hourly Hot Water Annual Load Profile for Base Homes

8.2 Mean Residential Hourly Hot Water Annual Load Profile for Post-1978 Homes

8.3 Mean Residential Hourly Hot Water Annual Load Profile for MCS Homes............................................. 8-4

8.4 Mean Residential Hourly Hot Water Annual Load Profile for Control Homes......................................... 8-4

8.5 Mean Residential Hot Water Weekend Load Profile for Base Homes.... 8-6

8.6 Mean Residential Hot Water Weekday Load Profile for Base Homes.... 8-7 
9.1 Mean Monthly Residential Hot Water Coincident Peak Load, Average Load, and Load Factor for Base Homes

9.2 Mean Monthly Residential Hot Water Coincident Peak Load, Average Load, and Load Factor for Post-1978 Homes

9.3 Mean Monthly Residential Hot Water Coincident Peak Load, Average Load, and Load Factor for MCS Homes.

9.4 Mean Monthly Residential Hot Water Coincident Peak Load, Average Load, and Load Factor for Control Homes.

9.5 Winter Peak Day Hourly Load Profiles for December 17, 1987 for Base Homes

9.6 Winter Peak Day Hourly Load Profiles for December 17, 1987 for Post-1978 Homes

9.7 Winter Peak Day Hourly Load Profiles for December 17, 1987 for MCS Homes.

9.8 Winter Peak Day Hourly Load Profile for December 17, 1987 for Control Homes....

9.9 Summer Peak Day Hourly Load Profile for August 31, 1987 for Base Homes

9.10 Summer Peak Day Hourly Load Profile for August 31, 1987 for Post-1978 Homes

9.11 Summer Peak Day Hourly Load Profile for August 31, 1987 for MCS Homes

9.12 Summer Peak Day Hourly Load Profile for August 31, 1987 for Control Homes. 


\section{LIST OF TABLES}

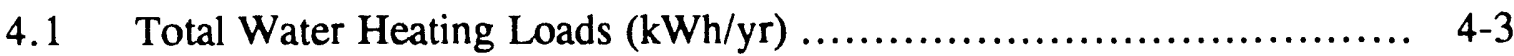

6.1 REMP and PNWRES83 Demographic and Energy-Related Characteristics............................................... 6-2

6.2 Change Over Time in REMP Study Characteristics.................... 6-7

6.3 REMP Study Water Heater Characteristics............................. 6-9

6.4 Number of Sites in the Studies Represented in this Report.............. 6-10

7.1 Average kWh Per Site Using Sites With Data for Every Year .......... 7-9

7.2 Annual Trends in Hot Water Energy Consumption Using the Scorekeeping Method .................................... 7-10

7.3 Number of Homes with Well Pumps in Each Study ................... 7-13

9.1 Annual Hot Water Peak Averages and Load Factor..................... 9-2

9.2 Contribution to Bonneville System Peak ............................. 9-11 


\section{SECTION 1 - INTRODUCTION}

The Bonneville Power Administration (Bonneville) began a program in 1983 to collect detailed, reliable end-use data on how electricity is used in Pacific Northwest homes. This data supports demand-side planning, forecasting, and conservation program development. In 1990 the name of this program was changed from the EndUse Load and Consumer Assessment Program (ELCAP) to the Regional End-Use Metering Project (REMP) to reflect a shift in program direction toward metered and characteristics data collection.

REMP is conducted in Bonneville's service territory by the Pacific Northwest Laboratory (PNL). ${ }^{1}$ This territory, shown in Figure 1.1, primarily covers Oregon, Washington, Idaho, and Montana west of the Continental Divide, and includes the portions of Nevada, Utah and Wyoming that lie within the Columbia River drainage basin.

FIGURE 1.1

Bonneville Power Administration

Service Area Boundaries

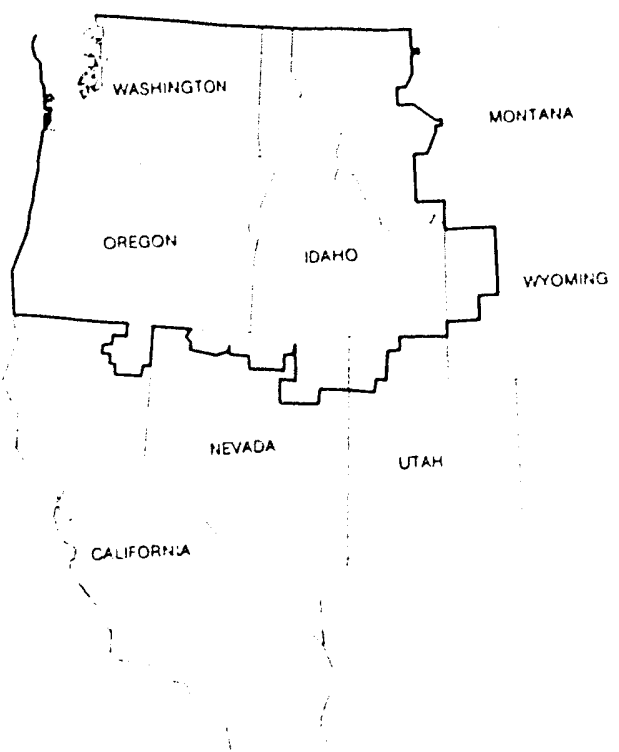

\footnotetext{
${ }^{1}$ A government laboratory managed by Battelle Memorial Institute.
} 
Bonneville and PNL published an end-use summary report in 1989, titled Description of Electric Energy Use in Single-Family Residences in the Pacific Northwest (ELCAP) (Pratt et al., 1989), that includes a sourcebook of summarized data from residential end-use metering. To supplentent the very general information in that report, Bonneville will provide reports for each different end use or set of end uses. This hot water report is the first in this supplemental series.

The hot water report provides a detailed look at electricity consumption by hot water heaters in the residential sector. The data show that the hot water load comprises a significant portion of the electric energy consumption in the residential sector and plays an important part in our region's conservation potential. The Northwest Power Planning Council (Council) and Bonneville estimate the residential hot water load represents $20 \%$ of total residential electricity consumption--second only to space heating (see Figure 7.1). The Council identifies about 190 average megawatts of conservation potential in their regional medium forecast through more efficient appliances that use hot water, such as hot water tanks, clothes washers, and dishwashers (Northwest Power Planning Council, 1991).

The data summaries presented here, based on metered data collected from September 1985 through December 1990, are for groups of homes in four studies, not for individual sites. Several different levels of data aggregation were performed across homes to produce annual, monthly, and hourly energy summaries as well as peak usage time profiles. Most of the end-use information is in graphic form.

Key observations about electricity use for heating water in the REMP residences are presented in Section 2. Section 3 provides background information on water heaters and their use. Section 4 describes a planned conservation program, and also reports on related work. Section 5 describes the four REMP studies whose loads are reported on here. Section 6 gives the number of sites represented in the data for each study, and provides some comparisons of demographic and energy-related 
characteristics across studies. Section 7 presents annual and monthly energy summaries, and Sectior 8 looks at average load profiles by weekend and weekday (daytypes) and year-to-year trends. Section 9 presents a variety of profiles depicting the hot water load at peak usage times. Sections 7-9 also offer some views on how the analytic results might be interpreted. Appendix A provides detailed information on the methodology applied in creating the averages used in the data summaries and Appendix B contains companion data tables for the data summaries in this report. 


\section{SECTION 2 - KEY OBSERVATIONS}

The primary purpose of collecting and analyzing residential end-use data is to provide useful information on how much electric energy is consumed at the end-use level and to learn more about factors which affect usage and how they do so. A number of key observations about water heating have been made possible by the data aggregations summarized in this report. These observations are based on average electricity consumption for a home in the four residential REMP studies--Base, Post1978, MCS, and Control.

- Average annual hot water energy consumption in the four residential REMP studies is $4747 \mathrm{kWh}$, or $23 \%$ of total average annual energy use by residential single-family homes with permanently installed electric space heating equipment. (Figure 7.2)

- Post-1978 homes, a subset of the Base study homes, use about $10 \%$ (about $500 \mathrm{kWh}$ ) more average annual energy than the other Base study homes. The average loads in the MCS and Control homes are virtually equal, and about $15 \%$ (750 kWh) lower than the Post-1978 homes. (Figure 7.4)

- Annual hot water usage in REMP homes from 1986 through 1990 varied from year to year, but does not show a statistically significant trend over time. (Figure 7.5)

- $\quad$ Monthly hot water usage in REMP decreases an average of $20-25 \%$ (88$108 \mathrm{kWh}$ ) from winter to summer months. (Figure 7.6)

- Average weekday and weekend daily hot water load shapes follow the typical residential total household profile where there is a peak in the morning and a lesser peak in the evening. The weekday load shape shows the peak load at the hour ending 8:00 a.m., and a lower peak in the evening around 8:00 p.m. The weekend load shape peaks later in the morning (11:00 a.m.) than the weekday, but has an evening peak around the same time as on the weekdays. (Figures 8.1-8.4)

- The morning peak for hot water usage in Base homes is on average $30 \%$ higher in January than in July. (Figures 8.5-8.6)

- Base, Post-1978, MCS, and Control homes show similar average load shapes and magnitudes when compared to each other in $b$ th the month of January and the month of July. 
- Hot water annual coincident peak load is about $1.6 \mathrm{kWh}$ for Base study homes, and about 1.8-2.1 kWh for Post-1978, MCS, and Control homes. (Table 9.1)

- The hot water monthly coincident peak is higher in winter months than in the summer, in proportion to average monthly energy use. Thus, the monthiy load factor is relatively constant throughout the year. (Figures 9.1-9.4)

- The timing of the daily hot water peak is coincident with the Bonneville system peak during the winter season. However, the magnitude of hot water use on Bonneville peak days is no higher than on non-peak days, thus the hot water end use, while a substantial contributor to Bonneville system load is not responsible for increased system loads on system peak days. (Figures 9.5-9.12)

- Hot water comprises $20-30 \%$ of the residential load on the winter peak hour, and is $15-19 \%$ of the daily load on that day. (Table 9.2)

- Hot water comprises $39-49 \%$ of the residential load on the summer peak hour, and $24-34 \%$ of the daily load on that day. (Table 9.2) 


\section{SECTION 3 - BACKGROUND}

An important part of interpreting data summaries is understanding how the data were collected and other variables affecting the data. This section provides such pertinent information as the definition of the hot water end use, and the operation of the hot water tank as well as factors affecting its use.

\section{THE HOT WATER END USE}

While other metering approaches typically allow for measuring usage at the appliance level, meters in REMP sites measure individual circuits at the breaker panel. The end-use definitions in REMP are therefore dependent on the circuitry in home wiring systems. If an end use can be isolated at the circuit level, then it is referred to as "pure". If the circuit includes any other, small loads, the end use is referred to as "mixed". The hot water load in REMP is a pure end use. There are, however, some auxiliary instantaneous water heaters (1-10 gallons) that may be metered as part of the lights and conveniences end use in REMP and not included in the hot water end use.

The hot water end use includes the energy used to supply hot water, but not the energy to run appliances in which the water is used. For example, the energy to run the clothes washer is attributed to the clothes washing end use. Only the energy to heat the water in the hot water tank is part of the hot water end use.

\section{HOW A WATER HEATER FUNCTIONS}

A water heater contains one or two electrical resistance heaters. One is always located near the bottom of the tank, and a second is often located in the middle of the tank. Both are controlled by temperature sensors. Cold water enters at the bottom of the tank and hot water leaves from the top of the tank. 
The heating elements are activated when the sensor indicates that the water temperature has dropped below the bottom of the set point temperature range, and heat the water until the temperature reaches the top of the set point range (Pratt and Ross, 1991).

There are two reasons a water heater might drop below its set point temperature: 1) hot water is being used and the tank is refilled with cold water (demand load), and/or 2) tank insulation cannot keep the colder ambient air from reducing the tank water temperature (standby load). As a result of demand and standby loads, energy is required to reheat the water.

According to Measured Electric Hot Water Standby and Demand Loads from Pacific Northwest Homes (REMP) (Pratt and Ross, 1991), standby losses account for approximately $23-26 \%$ of an average water heater's electricity consumption. 


\section{SECTION 4 - RESIDENTIAL HOT WATER ACTIVITIES}

Hot water use and its conservation potential continues to be a common topic in today's energy environment. This section discusses Bonneville's current water heating conservation activities, and provides an overview of other related residential hot water work and results.

\section{CONSERVATION MEASURES AND PROGRAMS}

Conservation programs targeted at reducing standby loss of water heaters may encourage use of more tank insulation, tank wraps, pipe insulation, or bottom boards. Programs aimed at reducing demand may foster installation of low flow shower heads, efficient clothes and dish washing appliances, or water heater load control devices that reheat water during hours of the day when demand for electricity is generally low.

Bonneville is currently in the process of implementing a water heater program aimed at encouraging the installation of energy-efficient water heaters and low flow shower heads. According to Strategy for Establishing an Energy Efficient Water Heater Program (Draft) (Bonneville, 1990), this program will go into effect in 1992. Key elements involve a marketing campaign to promote utility rebates, utility loans, an information program, and a shower head study intended to rate shower heads in terms of flow rate and perceived comfort.

\section{OTHER WORK}

Other work besides this hot water report has been done on energy consumption by residential hot water heaters in the Pacific Northwest. This work includes regional forecasts and assessments of the conservation potential for residential water heaters.

Bonneville and the Council joint forecast of electricity consumption for water heating begins with the number of households equipped with electric water heating 
equipment. Then, taking the number of occupants per household and the number of hot water consuming devices present, the average current electricity consumption for water heating per home is estimated. The data necessary to make the estimates are derived from regional surveys of household and occupant characteristics.

For assessing the potential conservation available from residential water heaters in the region, consumption is estimated by Bonneville and the Council as the sum of two components: 1) heat losses from the hot water in the tank to the surrounding air (referred to here as the standby load) 2) the energy required to heat the cold water that replaces the hot water withdrawn from the tank (the demand load). In its analysis Bonneville uses the conservation measure costs and savings provided by the Northwest Power Planning Council (1989).

Key assumptions for the total, standby, and demand hot vater loads (including the assumed measure costs and impacts) used in deriving furecasting and conservation potential estimates are summarized below.

\section{Total Water Heating Load}

Monthly loads and hourly load shapes for REMP homes for various daytypes can be found in the 1989 report, Description of Electric Energy Use in Single-Family Residences in the Pacific Northwest (ELCAP) (Pratt et al., 1989). Metered total water heating loads (standby and demand loads combined) are available from three projects that metered large numbers of single family homes: the Hood River Project, the Residential Standards Demonstration Project (RSDP), and REMP. Table 4.1 shows the loads for homes split by number of occupants for the three projects.

\section{Standby Loads}

In the regional planning process, standby loads of the current population of water heaters are assumed to equal $1610 \mathrm{kWh} / \mathrm{yr}$. This standby load is the average of 


\section{TABLE 4.1 \\ TOTAL WATER HEATING LOADS \\ (KWH/YR)}

Number of

Occupants

$\begin{array}{cc}1 & 2843(n=25) \\ 2 & 4173(n=78) \\ 3 & 5756(n=26) \\ 4 & 6253(n=35) \\ 5 & 7582(n=9) \\ 6 & 9504(n=6) \\ 7 & --\end{array}$

$\underline{\text { RSDP }}$

$2764(n=30)$

$3812(n=109)$

$4817(n=93)$

$5541(n=133)$

$5688(n=34)$

$6730(n=18)$

$8143(n=8)$

\section{$\underline{\text { REMPa }}^{a}$}

$2714(n=4)$

$3506(n=106)$

$5152(n=42)$

$5446(n=56)$

$6589^{\mathrm{b}}(\mathrm{n}=33)$

a Pratt and Ross, 1991.

b Average for homes with five or more occupants.

estimates from six studies of water heater performance (Northwest Power Planning Council, 1991).

In a 1980 study, standby hot water consumption for the average hot water tank sold between 1960 and 1980 was estimated as $1375 \mathrm{kWh} / \mathrm{yr}$ (Clear and Goldstein, 1980). Estimates of standby loads were obtained by the Council using water heater consumption data from three studies. These standby loads were estimated from the $y$-axis intercept of a linear relationship (from a least square's regression) of consumption as a function of number of occupants in the home. The average standby load was estimated as the total load predicted for zero occupants. This produced estimates of $1610 \mathrm{kWh} / \mathrm{yr}, 1995 \mathrm{kWh} / \mathrm{yr}$, and $1731 \mathrm{kWh} / \mathrm{yr}$ from the three studies, respectively. Two lower estimates, $1375 \mathrm{kWh} / \mathrm{yr}$ and $1483 \mathrm{kWh} / \mathrm{yr}$, were obtained by laboratory testing of one tank representative of those sold just prior to the adoption of the efficiency standards. A high efficiency tank was also tested in each of the 
laboratory tests and these results are being updated by a set of similar tests currently underway at Bonneville.

Recently, standby loads have also been directly estimated from REMP metered data (Pratt and Ross, 1991) using periods of time when the occupants were determined to be on vacation. This estimate is somewhat lower than the laboratory tests, averaging $1191 \mathrm{kWh} /$ year for the Base study. This lower estimate was attributed to a non-linear relationship of total hot water load to number of occupants as discussed in the next section.

It is expected that the Federal appliance efficiency standards (Federal Register, 1977) on electric water heaters will greatly reduce standby losses. Water heaters are replaced as they wear out and begin to leak, having an average lifetime of about 12 years (Bonneville Power Administration, 1990). Thus, in the course of the region's 20-year planning horizon, all water heaters will be replaced by new, more efficient models.

The Federal standards are based on laboratory tests of heat losses, and are projected to lower standby losses to $1290 \mathrm{kWh} / \mathrm{yr}$ (Geller and Morrill 1988), although the laboratory tests conducted by Bonneville of high efficiency tanks that meet the new standards showed even lower consumption (800 kWh/yr) (Ek, 1982; Ek and Auberg, 1984). The reason for the discrepancy is not known.

Other key Bonneville and Council assumptions about both existing and new hot water heaters are that the typical tank is 52 gallons, that there is a 70 degrees 1 temperature difference between the hot water and the air surrounding the tank. Water tanks in heated spaces are therefore assumed to have, on average, temperatures of about 140 degrees. The effect of conservation measures (R-11 wraps, thermal traps/pipe insulation, and bottom boards) on standby loads for tanks that meet Federal standards

1 All references to degrees are in degrees Fahrenheit. 
are based on the average of the Reese and Wall (1981) field study and the laboratory testing of Ek and Auberg (1984). Finally, savings from conservation measures and the Federal Standards are reduced to reflect additional space heating requirements resulting from the lower level of internal heat gain as hot water tank standby heat losses are reduced.

\section{Demand Loads}

Demand loads in the regional planning process are based on an assuription of 2.7 occupants per household, using an average of $1310 \mathrm{kWh}$ per occupant (Northwest Power Planning Council, 1989). This corresponds to an estimated 6775 gal/occupantyear (18.6 gal/occupant-day) if the temperature difference between the cold inlet water and hot water in the tank is assumed to be 80 degrees.

The demand load assumption is supported by several studies that estimated demand loads. Clear and Goldstein (1980) and the Natural Resources Defense Council (1982) calculated consumption per occupant at 5582 and 5411 gallons per occupant per year, respectively. These studies used a 90 degree temperature difference. Estimates developed from metered data in four other studies ranged from 6019 to 7680 gallons/occupant-year. The average of the six estimates, 6429 gal/occupant-year, corresponds to $1243 \mathrm{kWh}$ /occupant-year if an 80 degree temperature difference is assumed, or $1399 \mathrm{kWh}$ if 90 degrees is assumed. This 6429 gal/occupant-year average is close to the Council's assumption of $6775 \mathrm{gal} /$ occupant-year.

Pratt and Ross (1991) recently analyzed hot water demand loads as a function of number of occupants of four age groups in the REMP homes. The demand loads were estimated by subtracting the standby loads (estimated using vacancy periods) from the total loads. This work suggests that demand loads are not linear with the number of occupants, but instead the first adult (18-65 years old) uses nearly three times as much hot water as each additional adult. This may be the result of fixed water consumption 
required for cleaning, and running dishwashers and clothes washers. Children under 6 years old and adults over 65 years old appear to use less than half as much hot water as other occupants. This effect was shown to cause $y$-axis intercepts of regressions of total hot water loads versus number of occupants that are higher than the vacancy standby loads, resulting in high standby loads estimates when the regression technique is used. It can be speculated that both use less hot water for showers and clothes washing; elderly because of lower frequencies and children because of their small size. Savings for measures that reduce hot water demand by clothes washers and dishwashers are derived from data developed to support the Federal appliance standards (U.S. Department of Energy, 1989). Savings due to low flow showerheads are derived from a survey of hot water use for showers in Oregon (Council, 1989). This study indicated showers had a duration of 10 minutes and used approximately equal parts hot and cold water. Savings are based on lowering shower flow rates from 3.0 gallons per minute (gpm) to $2.3 \mathrm{gpm}$ (Council, 1989) or $2.5 \mathrm{gpm}$ (Bonneville, 1990). Assuming $2.5 \mathrm{gpm}$, this translates to current hot water demands of 15 gallons per shower, and a reduction to 12.5 gallons per shower, for a savings of 2.5 gallons as a result of low flow shower heads. 


\section{SECTION 5 - DESCRIPTION OF THE REMP STUDIES}

This section briefly describes the types of homes included in Bonneville's residential end-use metering program. This program was designed to meter singlefamily, owner-occupied, site-built electrically heated homes built prior to 1984. A subset of the Base study is homes constructed after 1978 (referred to as Post-1978 study homes). The same metering process was also used to measure the effect of residential energy codes in two groups of newly constructed homes: homes built to a specific set of energy efficiency codes promoted by the Northwest Power Planning Council (Council)--the Model Conservation Standards (MCS), and homes constructed to current building practice codes (Control). (More information on these studies may be found in Description of Electricity Use in Single-Family Residences in the Pacific Northwest (1989).)

\section{EXISTING HOMES: BASE AND POST-1978 HOMES}

The Base study homes were randomly selected from respondents to the 1983 Pacific Northwest Residential Energy Survey (PNWRES83).1 PNWRES83 was an onsite inspection and occupant survey conducted on more than 4,700 homes randomly drawn from the Bonneville service territory.

The Base study selection process was stratified to provide adequate representation of demographics for five criteria: climate zone, utility type (publiclyowned and privately-owned), construction vintage, occupant income, and presence of wood-heating equipment. Because the number of metered homes has declined over time due to metering failures and/or household turnover, any original demographic

1 Regional residential surveys, designed by Bonneville, were conducted in both 1979 (PNWRES79) and 1983 (PNWRES83). 
representation has been reduced and it is therefore difficult to extend observations based on the studies to the Bonneville service territory as a whole.

\section{NEW HOMES: MCS AND CONTROL HOMES}

The MCS homes were built to the Model Conservation Standards developed by the Council. These standards are appropriate to geographic location and include measures such as high levels of insulation in the walls, floors, and ceilings in cold climates. The Control homes were built to current construction standards.

Although matched pairs of MCS and Control homes were intended, many Control homes were not built in time for inclusion in REMP. In this report we do not distinguish between the matched and unmatched MCS and Control homes, but describe the results from each group in its entirety. (For more specific information about the MCS and Control homes see Windell, (1987).) 


\section{SECTION 6 -KEY CHARACTERISTICS OF HOMES}

This section provides information important to interpreting the water heating data summaries. Included are demographic and energy-related characteristics for the groups of homes in REMP and PNWRES83, changes in the REMP study characteristics over time, characteristics of water heaters in the study homes, and the number of sites represented in this report. Some comparisons of the key characteristics across studies are offered that may help explain differences in the summary profiles presented in other sections of the report.

\section{KEY HOME CHARACTERISTICS}

Tables 6.1-6.3 provide characteristics information on the homes in each of four REMP studies--Base, Post-1978 (Post-1978 homes are a subset of the Base homes), MCS, and Control.

\section{Demographic Comparisons}

Table 6.1 compares some key demographic and energy-related characteristics in the homes in the REMP studies to PNWRES83 homes. PNWRES83 is a 1983 on-site inspection, conducted randomly on over 4,700 homes in Bonneville's service territory, from which the existing (Base and Post-1978) REMP homes were selected.

Comparisons of the REMP homes and PNWRES83 homes provide a framework for understanding how representative the REMP study homes are of the Bonneville service territory (region). For example, a primary difference between the samples in the REMP studies and the entire PNWRES83 population (POP) is that the latter includes manufactured and multifamily homes.

Comparisons of characteristics of the Base study homes with PNWRES83 single-family homes with permanently installed space heating equipment (SF PESHE) 


\begin{tabular}{|c|c|c|c|c|c|c|}
\hline $\begin{array}{r}\text { REN } \\
\text { E }\end{array}$ & $\begin{array}{l}\text { P AND } \\
\text { JERGY }\end{array}$ & $\begin{array}{r}\text { TA } \\
\text { RWRES } \\
\text { RELATE }\end{array}$ & $\begin{array}{l}6.1 \\
\text { DEMO } \\
\text { HARA }\end{array}$ & $\begin{array}{l}\text { APHIC } \\
\text { ERISTI }\end{array}$ & & \\
\hline Variable & & EMP Studies & weighted) & & _PNWRES83 & ighted) \\
\hline & Base & Post-1978 & Control & $\underline{\mathrm{MCS}}$ & SF PESHE & $\underline{P O P}$ \\
\hline Floor Area (conditioned) & 1807 & 1994 & 1510 & 1812 & 1751 & 1495 \\
\hline Number of Occupants & 3.08 & 3.17 & 3.04 & 2.85 & 2.87 & 2.68 \\
\hline Age Distribution (\# per hshld) & & & & & & \\
\hline Less than 6 & .27 & .40 & .73 & .46 & .24 & .24 \\
\hline $6-18$ years & .70 & .67 & .37 & .42 & .61 & .52 \\
\hline $19-64$ years & 1.78 & 1.87 & 1.95 & 1.96 & 1.67 & 1.57 \\
\hline 65 and over & .34 & .23 & .00 & .02 & .34 & .33 \\
\hline Income (1986 annual) & & & & & & \\
\hline Less than $\$ 8,000$ & $4.1 \%$ & $3.4 \%$ & $0 \%$ & $0 \%$ & $9.0 \%$ & $15.8 \%$ \\
\hline$\$ 8,000-\$ 15,999$ & $15.3 \%$ & $10.3 \%$ & $9.1 \%$ & $0 \%$ & $20.7 \%$ & $26.2 \%$ \\
\hline$\$ 16,000-\$ 24,999$ & $18.8 \%$ & $24.1 \%$ & $18.2 \%$ & $15.6 \%$ & $21.5 \%$ & $23.0 \%$ \\
\hline$\$ 25,000-\$ 34,999$ & $22.9 \%$ & $17.3 \%$ & $31.8 \%$ & $24.4 \%$ & $23.7 \%$ & $18.4 \%$ \\
\hline$\$ 35,000-\$ 59,000$ & $26.5 \%$ & $17.3 \%$ & $40.9 \%$ & $53.3 \%$ & $20.4 \%$ & $126 \%$ \\
\hline$\$ 60,000$ and over & $12.4 \%$ & $27.6 \%$ & $0 \%$ & $6.7 \%$ & $4.7 \%$ & $3.0 \%$ \\
\hline Number of Respondents & $n=170$ & $\mathrm{n}=29$ & $\mathrm{n}=22$ & $n=45$ & $\mathrm{n}=1251$ & $n=4104$ \\
\hline Utility Type & & & & & & \\
\hline Public & $63.6 \%$ & $58.0 \%$ & $50.0 \%$ & $37.0 \%$ & $43.7 \%$ & $60.0 \%$ \\
\hline Private & $36.4 \%$ & $42.0 \%$ & $50.0 \%$ & $63.0 \%$ & $56.3 \%$ & $40.0 \%$ \\
\hline Year Built & & & & & & \\
\hline Before 1950 & $22.2 \%$ & $0.0 \%$ & $0.0 \%$ & $0.0 \%$ & $31.5 \%$ & $32.2 \%$ \\
\hline $1950-1969$ & $26.3 \%$ & $0.0 \%$ & $0.0 \%$ & $0.0 \%$ & $26.1 \%$ & $30.1 \%$ \\
\hline $1970-1978$ & $36.6 \%$ & $0.0 \%$ & $0.0 \%$ & $0.0 \%$ & $31.8 \%$ & $27.1 \%$ \\
\hline $1979-1983$ & $14.9 \%$ & $100.0 \%$ & $100.0 \%$ & $100.0 \%$ & $10.6 \%$ & $10.6 \%$ \\
\hline 1984 and after & $0.0 \%$ & $0.0 \%$ & $0.0 \%$ & $0.0 \%$ & $0.0 \%$ & $0.0 \%$ \\
\hline Geographical Location & & & & & & \\
\hline E. Washington & $22.6 \%$ & $24.2 \%$ & $4.2 \%$ & $15.5 \%$ & $15.7 \%$ & $12.5 \%$ \\
\hline W. Washington & $21.7 \%$ & $12.1 \%$ & $41.6 \%$ & $32.8 \%$ & $41.3 \%$ & $39.8 \%$ \\
\hline E. Oregon & $11.8 \%$ & $6.1 \%$ & $0.0 \%$ & $3.4 \%$ & $4.6 \%$ & $4.5 \%$ \\
\hline W. Oregon & $22.2 \%$ & $24.2 \%$ & $4.2 \%$ & $17.2 \%$ & $22.5 \%$ & $28.1 \%$ \\
\hline Montana & $10.4 \%$ & $18.2 \%$ & $20.8 \%$ & $12.1 \%$ & $3.4 \%$ & $3.4 \%$ \\
\hline Idaho & $10.4 \%$ & $12.1 \%$ & $29.2 \%$ & $19.0 \%$ & $12.5 \%$ & $11.7 \%$ \\
\hline Wyoming & $.9 \%$ & $3.1 \%$ & $0.0 \%$ & $0.0 \%$ & & \\
\hline Heating Systems Available & & & & & & \\
\hline Electric & $100.0 \%$ & $100.0 \%$ & $100.0 \%$ & $100.0 \%$ & $100.0 \%$ & $62.6 \%$ \\
\hline Gas & $1.4 \%$ & $0 \%$ & $0 \%$ & $0 \%$ & $5.3 \%$ & $23.9 \%$ \\
\hline Oil & $2.9 \%$ & $0 \%$ & $0 \%$ & $0 \%$ & $5.1 \%$ & $14.7 \%$ \\
\hline Other & $1.4 \%$ & $0 \%$ & $0 \%$ & $0 \%$ & $2.2 \%$ & $3.2 \%$ \\
\hline Wood (only) & $0 \%$ & $0 \%$ & $0 \%$ & $0 \%$ & $0 \%$ & $5.3 \%$ \\
\hline Wood (supplemented) & $83.3 \%$ & $87.1 \%$ & $45.8 \%$ & $58.5 \%$ & $58.7 \%$ & $41.9 \%$ \\
\hline Number of Respondents & $\mathrm{n}=209$ & $\mathrm{n}=31$ & $n=24$ & $\mathrm{n}=53$ & $n=1445$ & $n=4697$ \\
\hline Number of Respondents (Total) & 221 & 33 & 24 & 58 & 1445 & 4703 \\
\hline
\end{tabular}


help provide a regional context for examining hot water consumption in the Base homes. Comparisons of the characteristics of the other studies and PNWRES83 help clarify some differences that may be seen in hot water energy consumption summaries as do comparisons between the groups of homes in the different REMP studies.

Floor area is an important characterization of a home. The larger the homes the more likely the home is to have more occupants and bathrooms than a smaller home, both of which directly relate to the amount of hot water a horne uses. As shown in Table 6.1, the average conditioned floor area in the Base homes is about equal to the PNWRES83 SF PESHE homes. Square footage in the homes in the Base and MCS studies are about the same. The Control homes on average are smaller and closer to the POP than the average of homes in the other studies. The Post-1978 home are significantly larger (about 200 square feet) than homes in any of the other studies.

The number of occupants in a home is a key indicator of hot water energy use. The more people in a home, the more activities there are that use hot water, such as bathing, clothes washing, and dish washing. Base homes have on average $6 \%$ more occupants than PNWRES SF PESHE homes. MCS homes are about equal to PNWRES83 SF PESHE homes, and both have 7-10\% fewer occupants than Post-1978 and Control homes. Other studies indicate that the first person in a home appeared to use over twice as much hot water as each additional adult (Pratt and Ross, 1991).

People use hot water differently according to their age. The age distribution of the Base home is approximately equal to the SF PESHE PNWRES83 homes. The Post-1978, Control, and MCS homes have one-and-a-half to three times as many children under six compared to the PNWRES83 and Base homes. The MCS and Control homes have almost no residents over 65 . Children under 6 and adults over 65 use much less hot water than other age groups, and ages 6-18 use slightly more than adults between 19 and 65 (Pratt and Ross, 1991). 
It is often supposed by utility economists that income level can affect electricity consumption. For example, it is often conjectured that occupants of households with incomes of $\$ 60,000$ and over may tend not to conserve. However, it's also possible that working adults in households with such incomes also may be likely to have more education and may be more energy conscious for non-financial reasons.

The income distribution in SF PESHE PNWRES83 homes and Base homes is similar except the Base study has fewer poor households and more in the wealthy category. About three quarters of residents in the newest homes, Control and MCS, have fairly high incomes $(\$ 25,000-\$ 59,000)$. Also there are virtually no low income families in the Control and MCS homes compared to about $20 \%$ and $30 \%$ of households earning below $\$ 16,020$ a year in the Base study and SF PESHE PNWRES83 residences, respectively. More families in Base and Post-1978 homes, $12.4 \%$ and $27.6 \%$ respectively, have incomes of $\$ 60,000$ and above than in other FFMP studies and PNWRES83.

Much like income, it is often thought that the price of electricity may affect the way people use their energy. With public utilities charging less than privately owned ones, it seems likely that residents of homes served by public utilities will be less energy conscious than those people in homes served by private utilities. The distribution of utility ownership for the homes in the Base and Post-1978 studies (about $60 \%$ public and about $40 \%$ privately served) looks much like the entire region while the utility distribution for SF PESHE PNWRES 83 homes does not (about $44 \%$ public and about $56 \%$ privately served). The MCS distribution (37\% public and $53 \%$ private) resembles the distribution of SF PESHE in PNWRES83 homes. The Control study is evenly split, with half of the homes served by public utilities and half served by privately owned utilities.

Vintage, the year a home was built, can be a good indicator of the age of appliances, including the hot water tank. While about $30 \%$ of the PNWRES83 homes 
are pre-1950, the Base study homes shows about $20 \%$ in the same vintage category. By definition the Post-1978, MCS, and Control homes are newer and built after 1978.

Locations of the homes are reported here as percentages of each sample situated in each of seven geographical parts in Bonneville's service territory. In the milder, western area of the region (western Washington and western Oregon), cold water inlet temperature tends to be warmer than in the five eastern parts of the region where air temperatures (and hence ground temperatures) are much colder. The colder the inlet water the more energy required to heat the water tank to the set point. About $44 \%$ of the Base homes and about $64 \%$ of SF PESHE PNWRES83 homes are in western areas. About $46 \%$ of the MCS and $50 \%$ of the Control homes are in the western part of the region. About $36 \%$ of the homes in the Post-1978 study are in the west.

Space heating does not directly affect hot water energy consumption. However, knowing about a home's heating system does provide some indication of fuel availability and preference, and if fuel switching becomes a recognized method of conservation it may be useful to review the conservation potential in these homes.

Although all of the REMP homes (100\%) have electric space heating as a requirement for inclusion in REMP, this does not necessarily mean that electricity is the only fuel used in the homes. Other fuels available are listed in Table 6.2, along with wood as a sole source and wood as a supplementary source of heating. About $5.2 \%$ of the SF PESHE PNWRES83 homes have gas and oil available. About onethird more of the Base homes than the SF PESHE homes report supplementing their primary heating fuel with wood.

\section{Change Over Time}

For dynamic variables--the number of household occupants, income, age distribution, and square footage--relating significantly to hot water use, Table 6.2 provides the average change over time in each REMP study. The information reported 
is from the 1986 REMP on-site residential inspection and the 1988, REMP mail survey.

The small changes shown in Table 6.2 demonstrate the stability of the REMP samples. However, whether or not those changes are considered significant depends on the perspective and issues being considered.

Hot water consumption in homes may be expected to fluctuate with changes in the number of occupants. Except for the Base study, the REMP studies show a definite change in the average number of occupants per household. The Post-1978 homes decreased an average of .29 people per household, and the MCS and Control homes increased by .30 and .16 respectively.

Base and Post-1978 homes show some small shifts over time from below to above $\$ 25,000$ average income earnings per year which may be accounted for by the rate of inflation. The MCS and Control household income changes are more obvious. In the Control study, $20.8 \%$ less of the homes reported earnings in the $\$ 25,000$ $\$ 34,999$ a year range in 1986 than in 1988 , and $14.7 \%$ more reported earning in the $\$ 35,000-\$ 59,000$ range. In the MCS study there was a decrease of $22.6 \%$ in the number of homes with lower to middle incomes, $\$ 8,000-\$ 24,999$, and an increase of $18.2 \%$ in the $\$ 35,000$ and over category.

Redistribution to higher age categories is clearly seen in the Base and Post-1978 homes, but not in the Control and MCS homes. The Control homes gained an average of .27 children per home under the age 6 , and the MCS homes lost an average of .1 of their occupants aged 19 and over.

\section{Water Heater Characteristics}

Table 6.3 reports characteristics associated with hot water heaters, such as tank capacities, temperature, and tank locations. The table provides this information for each study, and on both main and auxiliary water heaters although this hot water end- 


\begin{tabular}{|c|c|c|c|c|}
\hline \multicolumn{5}{|c|}{$\begin{array}{c}\text { TABLE } 6.2 \\
\text { CHANGE OVER TIME IN REMP STUDY CHARACTERISTICS } \\
(1986-1988)\end{array}$} \\
\hline \multirow[t]{2}{*}{$\underline{\text { Variable }}$} & \multicolumn{4}{|c|}{ REMP Studies (Not weighted) } \\
\hline & Base & Post-1978 & Control & $\underline{\mathrm{MCS}}$ \\
\hline \multicolumn{5}{|l|}{ Floor Area Additions } \\
\hline Avg Square Ft. per Addition & 396 & 424 & 1100 & 1000 \\
\hline Number of Additions & 12 & 4 & 1 & 2 \\
\hline Incr in Study Avg Floor Area & 22 & 51 & 46 & 34 \\
\hline Number of Occupants & -0.05 & -0.29 & 0.16 & .30 \\
\hline \multicolumn{5}{|l|}{ Age Distribution (\# per hshld) } \\
\hline Less than 6 & -.11 & -.25 & .27 & -.08 \\
\hline $6-18$ years & .02 & -.09 & -.05 & .26 \\
\hline $19-64$ years & -.03 & -.10 & -.06 & .06 \\
\hline 65 and over & .07 & .15 & 0 & .06 \\
\hline \multicolumn{5}{|l|}{ Income (1986 annual) } \\
\hline Less than $\$ 8,000$ & $-1.9 \%$ & $-3.4 \%$ & $0.0 \%$ & $0.0 \%$ \\
\hline$\$ 8,000-\$ 15,999$ & $-2.2 \%$ & $-6.5 \%$ & $-9.1 \%$ & $4.4 \%$ \\
\hline$\$ 16,000-\$ 24,999$ & $-2.4 \%$ & $-4.9 \%$ & $9.6 \%$ & $-13.4 \%$ \\
\hline$\$ 25,000-\$ 34,999$ & $5.0 \%$ & $5.8 \%$ & $-20.8 \%$ & $-9.2 \%$ \\
\hline$\$ 35,000-\$ 59,000$ & $0.8 \%$ & $1.9 \%$ & $14.7 \%$ & $9.7 \%$ \\
\hline$\$ 60,000$ and over & $0.7 \%$ & $7.1 \%$ & $5.6 \%$ & $8.5 \%$ \\
\hline Number of Respondents & $\mathrm{n}=183$ & $n=26$ & $n=18$ & $\mathrm{n}=46$ \\
\hline
\end{tabular}

use report focuses on the main water heater. Energy use for heating the auxiliary tanks under 30 gallons is a part of the REMP end-use called 'other'. The hot water averages derived in this report therefore include 14 auxiliary water heaters in the 30-52 gallon tank range.

Capacity of a water heater tank in a home can be a major factor in hot water energy consumption. The larger the tank the more energy it uses because more energy is required to keep the water at a set point temperature when there is a larger surface for heat to escape. At least $79 \%$ of the main water tanks in the REMP studies hold 5055 gallons. There are very few tanks below 50 gallons. $11 \%$ of Base and $6 \%$ of MCS 
homes have 56-70 gallon tanks. There are quite a few homes with 71-85 gallon tanks $7 \%$ in the Base, $12 \%$ in Post-1978, and $9 \%$ in MCS homes.

The set point temperature of a water heater is an important variable in the use of energy to heat water. The higher the set point, the more energy it takes to heat the cold inlet water after water has been drained from the tank. And the more energy is needed to replace heat lost to the air surrounding the tank.

In comparison to the Control and MCS homes, the Base and Post-1978 homes generally have lower tank temperatures (tap temperatures). Over three-quarters of the tap temperatures in the Base and Post-1978 homes are concentrated in the middle ranges, from 120 to 149 degrees Fahrenheit, ${ }^{1}$ and the rest are primarily above 150 degrees. While homes in the Control and MCS studies also concentrate in the middle temperature ranges they differ from the Base and Post-1978 studies in that there are $14 \%$ Control and 6\% MCS homes with tank temperatures under 120 degrees.

Listed in Table 6.3 are conservation measures and the percentage of homes in each study with those measures. These conservation measures are aimed at reducing hot water standby loads, with the exception of flow restrictors. Flow restrictors are aimed at reducing the demand for hot water.

Tank wraps and flow restrictors are the most common hot water energy reducing features. More tank wraps were found in the Base (46\%) and Post-1978 (57\%) homes than in the Control (39\%) and MCS (36\%) homes. Flow restrictors are most common in the MCS homes $(63 \%)$ and least common in the Control homes (11\%). In the Base and Post-1978 studies, flow restrictors are in $42 \%$ and $50 \%$ of the homes, respectively.

The definition used in REMP surveys of what constitutes an 'efficient' tank is an insulation level of $\mathrm{R}-3$ or above. As seen in Table 6.3 , there are significantly more

1 All references to degrees are in degrees Fahrenheit. 


\begin{tabular}{|c|c|c|c|c|}
\hline \multirow[t]{3}{*}{ REMP STUDY WA } & \multicolumn{4}{|c|}{ TABLE 6.3} \\
\hline & \multicolumn{4}{|c|}{ REMP Studies (Not weighted) } \\
\hline & Base & Post-1978 & Control & $\underline{\mathrm{MCS}}$ \\
\hline \multicolumn{5}{|c|}{ MAIN WATER HEATER (largest electric tank) } \\
\hline \multicolumn{5}{|l|}{ Capacity } \\
\hline Under $50 \mathrm{Gal}$. & $3 \%$ & $0 \%$ & $0 \%$ & $2 \%$ \\
\hline $50-55$ gal. & $79 \%$ & $88 \%$ & $100 \%$ & $83 \%$ \\
\hline $56-70 \mathrm{gal}$. & $11 \%$ & $0 \%$ & $0 \%$ & $6 \%$ \\
\hline $71-85 \mathrm{gal}$. & $7 \%$ & $12 \%$ & $0 \%$ & $9 \%$ \\
\hline Number of Respondents & $n=165$ & $n=24$ & $n=21$ & $\mathrm{n}=47$ \\
\hline \multicolumn{5}{|l|}{ Tap Temperature } \\
\hline Under $120 \operatorname{deg} F$. & $3 \%$ & $0 \%$ & $14 \%$ & $6 \%$ \\
\hline $120-129 \operatorname{deg} F$ & $12 \%$ & $17 \%$ & $32 \%$ & $26 \%$ \\
\hline $130-139 \operatorname{deg} F$ & $28 \%$ & $23 \%$ & $13 \%$ & $32 \%$ \\
\hline $140-149$ deg F. & $42 \%$ & $37 \%$ & $32 \%$ & $36 \%$ \\
\hline $150-159 \operatorname{deg} F$. & $11 \%$ & $20 \%$ & $8 \%$ & $0 \%$ \\
\hline $160-185 \operatorname{deg} F$ & $4 \%$ & $3 \%$ & $0 \%$ & $0 \%$ \\
\hline Number of Respondents & $n=196$ & $\mathrm{n}=30$ & $\mathrm{n}=\mathbf{2 2}$ & $\mathbf{n}=50$ \\
\hline \multicolumn{5}{|l|}{ Tanks with Conservation Measures } \\
\hline Tank Wrap & $46 \%$ & $57 \%$ & $39 \%$ & $36 \%$ \\
\hline Efficient Unwrapped Tank $(\mathrm{R}>3)$ & $10 \%$ & $7 \%$ & $22 \%$ & $46 \%$ \\
\hline Pipe Insulation & $18 \%$ & $13 \%$ & $0 \%$ & $13 \%$ \\
\hline Flow Restrictor & $42 \%$ & $50 \%$ & $11 \%$ & $63 \%$ \\
\hline Solar Assistance & $2 \%$ & $0 \%$ & $0 \%$ & $2 \%$ \\
\hline Bottom Board & $9 \%$ & $20 \%$ & $5 \%$ & $7 \%$ \\
\hline Timer & $3 \%$ & $3 \%$ & $4 \%$ & $4 \%$ \\
\hline Thermal Trap & $2 \%$ & $3 \%$ & $4 \%$ & $6 \%$ \\
\hline \multicolumn{5}{|l|}{ Tank Location } \\
\hline Conditioned Space & $62 \%$ & $65 \%$ & $71 \%$ & $71 \%$ \\
\hline Unconditioned Space & $38 \%$ & $35 \%$ & $29 \%$ & $29 \%$ \\
\hline Number of Respondents (Total) & $n=208$ & $n=30$ & $n=24$ & $n=53$ \\
\hline \multicolumn{5}{|l|}{ AUXILIARY WATER HEATERS } \\
\hline \multicolumn{5}{|c|}{ Homes With An Additional Water Heaters That Uses: } \\
\hline Electric & $6 \%$ & $6 \%$ & $0 \%$ & $6 \%$ \\
\hline Gas & $0.5 \%$ & $0 \%$ & $0 \%$ & $0 \%$ \\
\hline Wood & $0.5 \%$ & $3 \%$ & $0 \%$ & $0 \%$ \\
\hline \multicolumn{5}{|l|}{ Tank Capacity (number of tanks) } \\
\hline 1 gal. & 0 & 0 & 0 & 2 \\
\hline $10 \mathrm{gal}$. & 1 & 0 & 0 & 1 \\
\hline $30-52 \mathrm{gal}$. & 10 & 3 & 0 & 1 \\
\hline Unknown & 4 & 1 & 0 & 0 \\
\hline \multicolumn{5}{|l|}{ Tap Temperature } \\
\hline Under 120 deg $F$. & $0 \%$ & $0 \%$ & $0 \%$ & $25 \%$ \\
\hline $120-139 \mathrm{deg} F$ & $43 \%$ & $25 \%$ & $0 \%$ & $0 \%$ \\
\hline $140-159$ deg $F$ & $50 \%$ & $50 \%$ & $0 \%$ & $25 \%$ \\
\hline $160-185 \operatorname{deg} F$. & $7 \%$ & $25 \%$ & $0 \%$ & $0 \%$ \\
\hline 190-195 deg F. & $0 \%$ & $0 \%$ & $0 \%$ & $50 \%$ \\
\hline \multicolumn{5}{|l|}{ Water Using Features (number per site) } \\
\hline Shower/Bath & 1.67 & 1.97 & 1.75 & 1.94 \\
\hline Clothes Washer & .99 & .97 & .92 & .98 \\
\hline Dish Washer & .99 & .90 & .92 & .89 \\
\hline
\end{tabular}


efficient water tanks in the Control (22\%) and MCS (46\%) homes than in the Base (10\%) and Post-1978 (7\%) homes. $20 \%$ of the Post-1978 homes have bottom boards to keep the heat from escaping through the bottom of the tank compared to less than $9 \%$ in the Base, Control, and MCS studies. Less than $6 \%$ of any of the homes in the REMP studies have solar assistance, timers, or thermal traps.

The ambient air temperature surrounding a water heater dictates the level to which the hot water in a tank will drop in standby loss, and therefore the energy required to reheat it to the tank's set temperature. Whether a water heater is located in a conditioned or unconditioned area of a home thus plays an important part in hot water energy consumption. In the REMP studies, $60-70 \%$ of the water heaters in homes are located in a conditioned space, while the remaining $30-40 \%$ are water heaters in an unconditioned area. The location of tanks in unconditioned areas are broken down further by Pratt and Ross (1991).

\section{NUMBER OF SITES REPRESENTED}

The number of sites with data represented in the summaries in this report are listed in Table 6.4. Each graph in this report lists either in the title or the legend the

\begin{tabular}{|c|c|}
\hline \multicolumn{2}{|c|}{$\begin{array}{c}\text { TABLE } 6.4 \\
\text { NUMBER OF SITES IN THE } \\
\text { STUDIES REPRESENTED IN } \\
\text { THIS REPORT }\end{array}$} \\
\hline Study & Metered Sites \\
\hline Base & 221 \\
\hline Post -1978 & 33 \\
\hline MCS & 58 \\
\hline Control & 24 \\
\hline
\end{tabular}


number of sites from which data was used to create the graph. This number may not equal the number of metered sites listed above. Due to incomplete data from individual sites it is possible that any one site may have enough data to be included the annual summaries, but may not meet the criteria for inclusion in a given monthly aggregation. Appendix A contains the methodology for developing the data summaries. 


\section{SECTION 7 - ANNUAL AND MONTHLY ENERGY}

This section looks at average annual and monthly hot water loads in singlefamily homes with permanently installed electric space heating equipment (PESHE). Using the REMP metered water heating data, comparisons of actual annual and monthly energy consumption are made to the forecasts of energy consumption in the Bonneville service territory in 1990. Average annual and monthly energy is presented across studies, by years and daytypes (weekends and weekdays). For homes with reliable data, averages are presented across all years and sites for the Base, Post-1978, MCS, and Control studies. (See Appendix A for aggregation methods used to produce these averages.)

The analysis of year-to-year annual usage using three different methods is also summarized. In addition, some possible reasons are given for the level of energy consumption in specific groups of homes and for differences in energy consumption across groups.

\section{ANNUAL ENERGY USE}

Hot water loads are a significant portion of residential energy consumption in single-family homes with electric space heating equipment, as REMP metered data and the Bonneville forecast loads for 1990 both illustrate. While not implying that the REMP homes are regionally representative, comparisons between these two sets of information provide an interesting perspective.

\section{Metered and Forecast Hot Water Annual Energy Comparisons}

Figure 7.1 shows the 1990 estimated actual forecast of end-use energy consumption for single-family homes in Bonneville's service territory heating with 
electricity. These estimated actual numbers ${ }^{1}$ are associated with the 1991 Northwest Conservation and Electric Power Plan, Volume II, (Northwest Power Planning Council, 1991). Figure 7.2 shows the actual consumption for REMP homes with permanently installed electric space heating equipment (PESHE).

The pie charts display the importance of hot water energy consumption in Bonneville's service territory and the REMP homes relative to space heating and other end uses. The charts report average annual $\mathrm{kWh}$ consumption and the percentage share of end-use consumption for hot water, heating, and all other end-uses.

Overall, the forecast for an electrically heated single-family residence is on average $21,533 \mathrm{kWh}$ per year. This estimate is approximately $5 \%$ (about $1,100 \mathrm{kWh}$ ) higher than the metered average in REMP of $20,724 \mathrm{kWh}$ per year. Broken down for hot water, REMP is about $8 \%(380 \mathrm{kWh})$ higher than the forecast. In Figure 7.1 and Figure 7.2, energy for heating water is about one fifth of the total consumption, making it a significant determinant of conservation potential.

While REMP includes all homes that have installed electric space heating equipment, the forecast includes those homes that report using electric space heating. This discrepancy in definition may affect the interpretation of the numbers since there may be some REMP homes with electric space heating equipment installed but not used.

Another difference between the two charts is that the load forecast projects the space heat end use separate from the air conditioning end use, while the plot of REMP data presents heating, ventilation, and air conditioning together (HVAC end use). However, since Pacific Northwest residences require only moderate cooling due to the mild summer climate, the cooling component is small (.4\%), and it is reasonable to compare space heating to HVAC.

\footnotetext{
${ }^{1}$ Estimated actuals are derived from actual annual sales data using historical shares to calculate the distribution by end use.
} 
FIGURE 7.1

Estimated Actual Annual End-Use Load Distribution for 1990 in a Single-Family Electrically Heated Home ${ }^{2}$

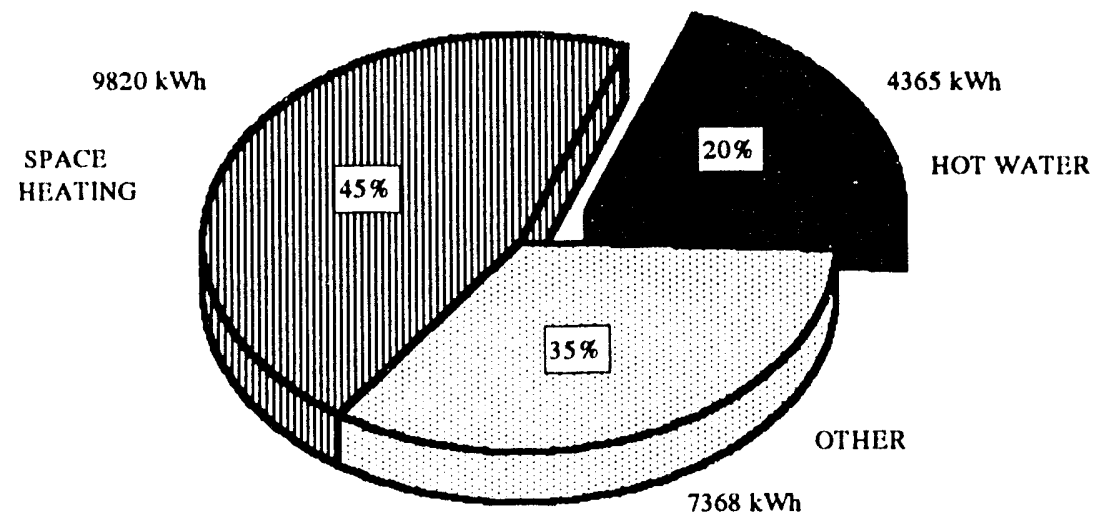

FIGURE 7.2

Measured REMP Residential Annual End-Use Load Distribution for an Average Single-Family Home with Electric Space Heating $(1986-1990)^{3}$

$($ Number of Sites $=336)$

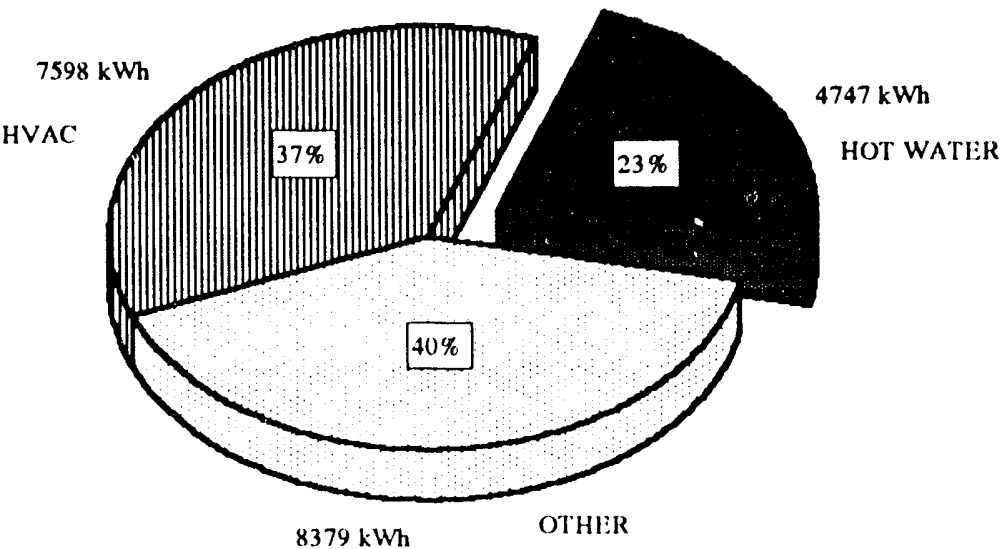

2 Bonneville Power Administration, 1990 Estimated Actuals.

$3.4 \%$ of HVAC is air conditioning. 
A third difference is that REMP is not a statistical sample of the Bonneville service territory, and the REMP numbers presented in Figure 7.2 are not sample weighted averages. Section 6 discusses some of the differences between the REMP homes and the homes in PNWRES83. (PNWRES83 is statistically representative of the Bonneville service territory in terms of demographics.)

\section{Hot Water Shares}

The average annual $\mathrm{kWh}$ of electric energy used for HVAC, hot water, and all other end uses is broken out for the MCS study in Figure 7.3. Figure 7.3 also shows the shares of residential electricity consumption. A comparison of Figures 7.1, 7.2,

FIGURE 7.3

Average REMP End-Use Load Distribution for an MCS Home (1986-1990) ${ }^{4}$

(Number of Sites $=58)$

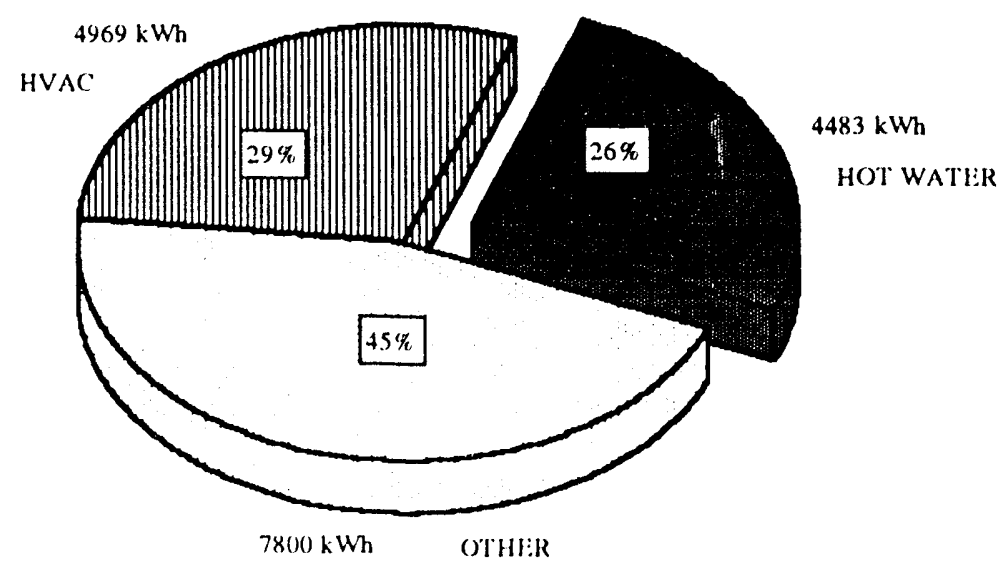

${ }^{4} 7.0 \%$ of $\mathrm{HVAC}$ is air conditioning. 
and 7.3 shows that total usage in MCS homes is lower, and the hot water share is a larger portion of total consumption than in the other REMP studies.

If all other usage factors remain the same, the space heating requirements in homes built in compliance with newly adopted codes in Washington and Oregon can be expected to decrease, with water heating accounting for a higher share of total electricity use than the current hot water share in non-REMP metered homes. Thus, water heating can be expected to play an even more significant role in determining residential sector energy consumption, residential conservation potential, and residential load shapes in the future as more homes are built to MCS.

\section{Study Group Comparisons}

Figure 7.4 displays the differences between the average annual hot water loads in the four types of REMP homes. When interpreting the energy loads in these four types of homes, remember that the Post-1978 homes are a subset of the Base study.

Loads are highest in Post-1978 homes, which use about 10\% more energy $(500 \mathrm{kWh})$ than the second highest, Base study homes. The loads in the new MCS and Control homes are virtually equal, and lower than the Base and Post-1978 homes. The Base and MCS homes differ by about $6 \%(280 \mathrm{kWh})$.

The results are not surprising for MCS and Control homes in relation to Base homes, if the average life of a water heater is assumed to be about 12 years (Bonneville, 1990). MCS and Control homes are no more than 8 years old at the time of data collection, while it is assumed that the average age of water heaters in the Base study is about 12 years. Therefore it would be reasonable to suppose that the water heaters are more efficient in the MCS and Control homes than in the Base homes, which could explain a difference in loads.

However, water heater efficiency does not explain the higher Post-1978 hot water loads in relation to homes in the other three studies. Since Post-1978 homes are 
less than 10 years old at the midpoint (November 1988) of the data collection period analyzed (September 1985 through December 1990), none of the water heaters is more than 10 years old--well within the assumed average water heater life. It would be reasonable, then, tc expect Post-1978 hot water loads to be less than Base hot water loads and closer to MCS and Control hot water loads.

Perhaps water heater efficiency would explain differences in hot water loads if all other variables matched across studies, but they do not. The Post-1978's higner loads may be due to several contributing factors.

One contributing factor is that the number of occupants per household affects the hot water consumption since more people generally corresponds with more showers and baths, as well as more clothes and dishes to wash. Post-1978 homes on average have 3.17 occupants per household while Base homes have on average 3.08 occupants per household, MCS homes have 2.85, and Control homes have 3.04 (see Table 6.1).

Also, more residents in the Post-1978 homes than in the Base, MCS, or Control homes have incomes of $\$ 60,000$ and above. Post-1978 homes may, therefore, be more likely to consume more energy for hot water since households with higher incomes have more disposable income and hence may be less responsive to energy costs.

Another characteristic of the Post-1978 study that may account for part of the consumption difference seen in Figure 7.4 is the number of homes with 'efficient' water tanks. Table 6.3 breaks down this hot water tank characteristic by study and shows more efficient ianks 1 , MCS and Control homes than in the Base and Post-1978 homes.

The approximately $6 \%(280 \mathrm{kWh})$ per home difference in electricity usage for hot water between MCS and Base homes could be explained by occupancy rates alone. The average of 2.90 occupants per MCS home and approximately 3.17 per Base home would explain a differential of about $330 \mathrm{kWh}(7 \%)$. 
FIGURE 7.4

Residential Hot Water Mean Annual Loads by Type of Home (1986-1990)

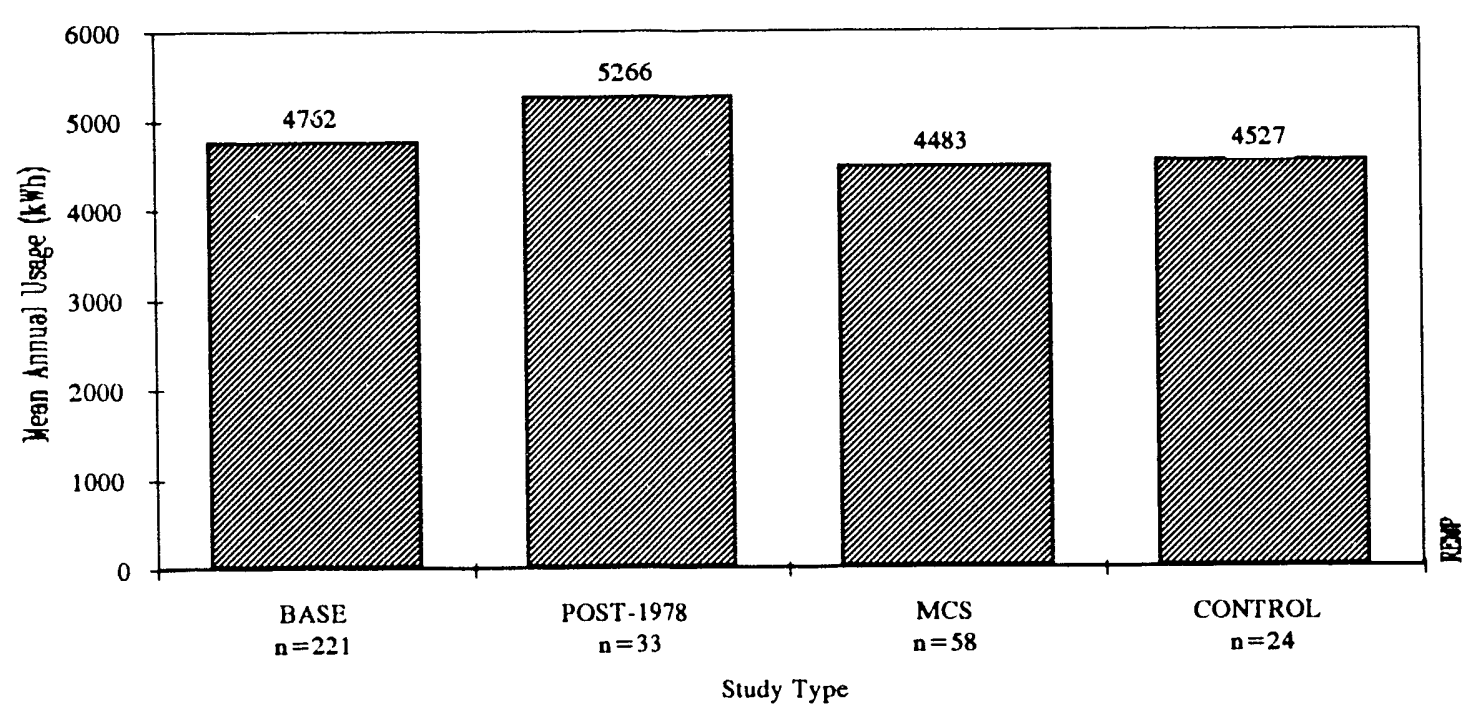

\section{YEAR-TO-YEAR TRENDS}

Knowing year-to-year trends can be helpful to program designers and forecasters. Analysis of REMP data was done for changes in hot water loads from year to year. The results of this analysis do not conclusively show year-to-year trends. However, such trends are difficult to measure, primarily due to the attrition of participating households over time and incomplete usage data from a number of sites.

Three approaches were taken to detect year-to-year water heating trends in the four studies: 1) cross-site aggregation and clustered weighting using all sites, 2) crosssite aggregation and clustered weighting : sing sites with data for every year, and 3) a scorekeeping method.

\section{Cross Site Aggregation and Clustered Weighting with All Sites}

Figure 7.5 shows the year-to-year mean annual usage for homes in each study, 
using the aggregation method described in Appendix A. The study sizes vary from year to year due to study attrition and metering difficulties. The annual average is calculated for all sites with data in each calendar year. The clustered weighting method attempts to correct for shifts in annual $\mathrm{kWh}$ by stratifying household use into three categories--high, medium, and low users--and maintaining the same ratio of each category in the overall average of each study despite changing sample size within each category.

FIGURE 7.5

Mean Residential Hot Water Loads by Year and

Type of Home Using the Clustered Weighting Method with All Sites

(1986-1990)

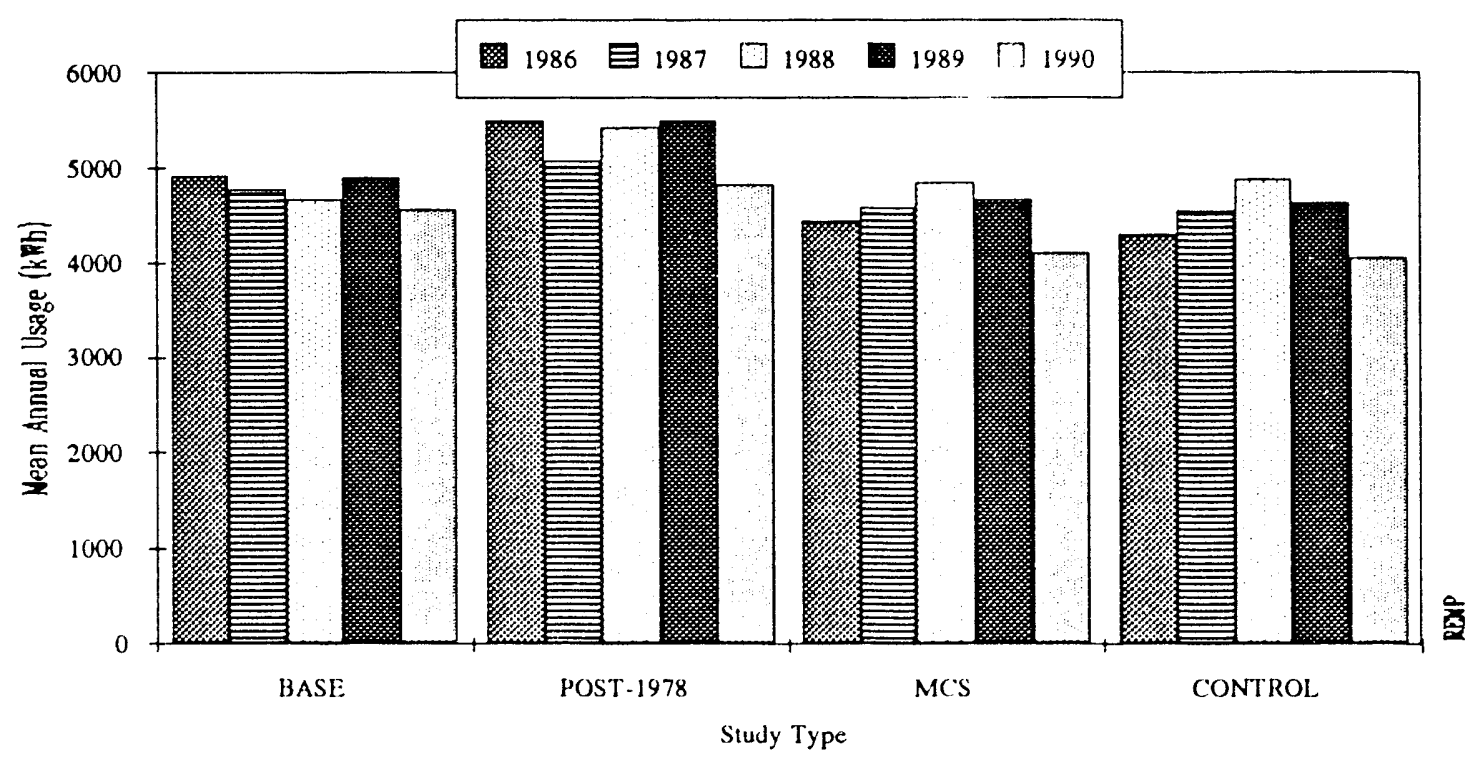

Any trend in annual usage is not clear from this analysis. Usage in 1990 is uniformly lower than that measured in 1986, but the level of usage in other years does not suggest a downward trend. However, analysis of the data is difficult due to the small study sizes and their variance from year to year. Two other methods of measuring annual trends were tested in an effort to overcome these difficulties. 


\section{Cross-Site Aggregation and Clustered Weighting Using Sites with Data For Every Year}

Using the cross-site aggregation and clustered weighting method, annual averages were calculated for each year, using only sites with data for all of the years. In Table 7.1, Post-1978 and Control homes show an increase over the first three years and then a decrease in average consumption in the fourth. None of the studies show a consistent trend for the four years.

Study attrition, discussed earlier in Section 7, not only significantly reduces the study size for this method, but it may bias the results toward stable sites. Stable sites may tend to have lower than average consumption because there is less household turnover, fewer occupant additions, older occupants, and smaller household size. All of these qualities imply less possibility of disruptions to the metering hardware and consequently less data loss. This effect brings doubt to any trend seen in three of the studies when using this method.

\begin{tabular}{|c|c|c|c|c|}
\hline \multirow{3}{*}{ Study } & \multicolumn{3}{|c|}{$\begin{array}{c}\text { TABLE } 7.1 \\
\text { GE KWH PER SITE USING SITES WITH } \\
\text { DATA FOR EVERY YEAR }\end{array}$} & \multirow[b]{3}{*}{1990} \\
\hline & \multicolumn{3}{|c|}{ Year } & \\
\hline & 1987 & $\underline{1988}$ & 1989 & \\
\hline Base $(n=51)$ & 5003 & 4848 & 4879 & 4475 \\
\hline Post-1978 $(n=7)$ & 5728 & 5758 & 5807 & 5440 \\
\hline $\operatorname{MCS}(n=18)$ & 4350 & 4410 & 4323 & 4310 \\
\hline Control $(n=5)$ & 3235 & 3854 & 3856 & 3731 \\
\hline
\end{tabular}




\section{Scorekeeping Method}

The third trend analysis method was a scorekeeping procedure, in which each site was examined for rate of change in annual usage. The rate of change was measured in $\mathrm{kWh}$ per year. The observed trends (or scores) for each site were then tallied to determine the aggregate trend in annual usage. The advantage of the scorekeeping method is that it only requires annual $\mathrm{kWh}$ values in any two years in order to measure a trend. The results, in Table 7.2, suggest that any trend is well within the standard deviation and is not statistically significant.

TABLE 7.2

ANNUAL TRENDS IN HOT WATER ENERGY CONSUMPTION USING THE SCOREKEEPING METHOD

$\underline{\text { Study }}$ Annual Rate of Change $\underline{\text { Kwh/Yr }} \quad \underline{\text { Standard Deviation }} \quad \underline{\text { Number of Sites }}$

Base $-135$

670 201

Post-1978 14 532 29

MCS 8

515 54

Control 292

615

\section{MONTHLY ENERGY USE}

Monthly patterns of usage are important to power resource planning. At Bonneville, seasonal effects are increasingly important to planning for sales of power outside the region. In this section are weekend and weekday mean monthly hot water loads by study. 


\section{Comparison of Energy Use Across Studies}

Figure 7.6 shows mean monthly hot water loads for the different types of REMP homes. As indicated by the chart, there is a $20-25 \%(88-108 \mathrm{kWh})$ decrease in energy consumption from winter to summer levels. Two seasonal effects could account for this drop: outside temperature and change in hot water demand.

Water inlet temperature varies with outside temperature. During the colder winter months, more energy is required to heat water to the set point of the water heater if the outside water source is a lake or river. This effect is negligible for water heaters in homes with well pumps since the incoming water temperature remains fairly consistent throughout the year.

FIGURE 7.6

Mean Residential Hot Water Monthly Loads by Study

(1986-1990)

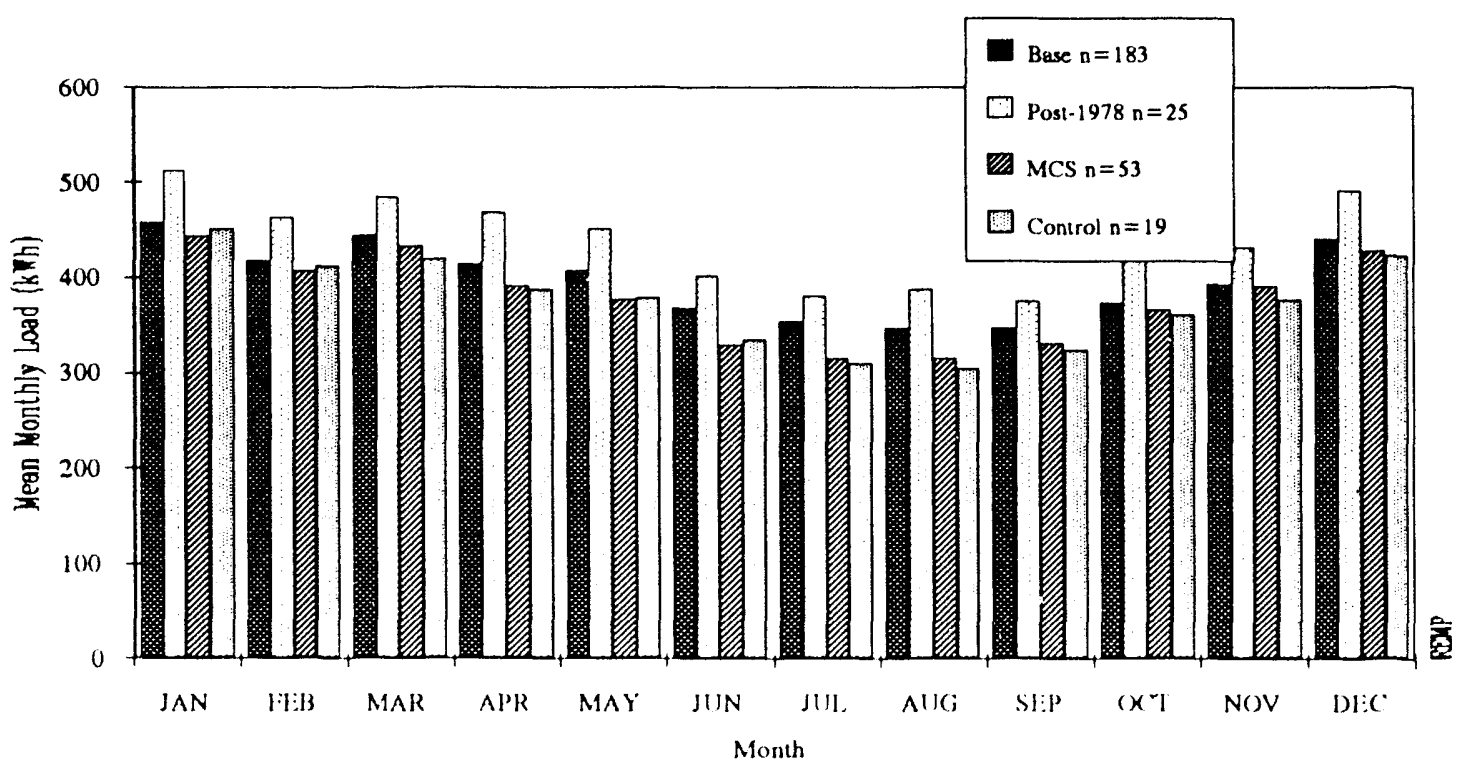

Decreased demand for hot water is another reason for seasonal variation in hot water energy use. Residential hot water demand is fundamentally affected by dish washing, clothes washing, and bathing, three uses that change from winter to summer.

Warmer temperatures in the summer generally reduce the amount of indoor 
cooking. Activities reducing the dish washing required, such as barbecues and picnics, become more common.

Summertime also means a decrease in the number of loads of laundry. People wear less clothes (shorts, sleeveless shirts) made of lightweight fabrics that don't take up much room in the washing machine. In contrast, in the colder winter, people wear more and heavier clothes that take up a lot of room in the washing machine and this results in more loads of laundry.

Bathing habits also may change with seasons. It seems reasonable that cooler showers are taken in the warmer summer than are taken in the colder winter.

Still another reason for decreased summer hot water loads is that summer is vacation season. When people are away from home, hot water isn't being used and the load can be expected to decrease to the standby load, $23-26 \%$ of the average (or zero if the tank is turned off, as reported by Pratt and Ross, 1991)

A comparison of the energy loads in different types of homes, in Figure 7.6, shows that the Post-1978 homes consistently have higher hot water use during the year than homes in the other three studies. Hot water usage in the Post-1978, Control, and MCS homes varies according to season by about the same energy level. Since these homes are newer, there is a greater likelihood they are in suburban areas where water tends to come from a lake or river, so the water inlet temperature is more variable.

Table 7.3 shows the number and percentage of homes with well pumps in each study, but does not account for municipal systems with well water sources. Base and Post-1978 homes have the same percentage of homes with well pumps, so the water inlet idea doesn't seem a likely explanation of why Base homes do not show as much variation in water heating loads from winter to summer as homes in the other studies. 
TABLE 7.3

NUMBER OF HOMES WITH WELL PUMPS IN

EACH STUDY

Study $\quad$ Number of Homes $\quad$ Percentage $\quad$ Number of Sites

Base

48

23

209

Post-1978

7

23

31

MCS

10

18

54

Control

1

4

24

\section{Mean Monthly Loads by Daytype}

Presented in Figures 7.7-7.10 are the mean daily hot water loads by month for weekdays and weekends (daytypes) for the four studies. The weekend loads are much closer in magnitude to the weekday loads in the Base homes than they are in the Post1978, MCS, and Control homes. The weekend/weekday difference could be the result of more dual wage earning families in the Post-1978, MCS, and Control homes. Households in these studies report much higher incomes than the Base households.

The weekend and weekday loads both exhibit seasonal patterns similar to the patterns seen in Figure 7.6, where the hot water energy use is higher in the winter than summer months. Average consumption per home on winter weekends in the Base (Figure 7.7) and Post-1978 (Figure 7.8) studies is about 5\% (.8 kWh) more than on weekdays, and on weekends is slightly lower than on summer weekdays. This change in weekend and weekday consumption between the winter and summer months may be a result of more dish and clothes washing and cleaning during the weekends in winter, and more summer weekends away from home.

The MCS (Figure 7.9) and Control (Figure 7.10) homes show an average winter weekend load per home of abol't 10\% (1.2 kWh) higher than their winter weekday load. This difference diminishes slightly in the summer. 
FIGURE 7.7

Mean Residential Hot Water

Daily Load by Month for the Base Study

(1986-1990)

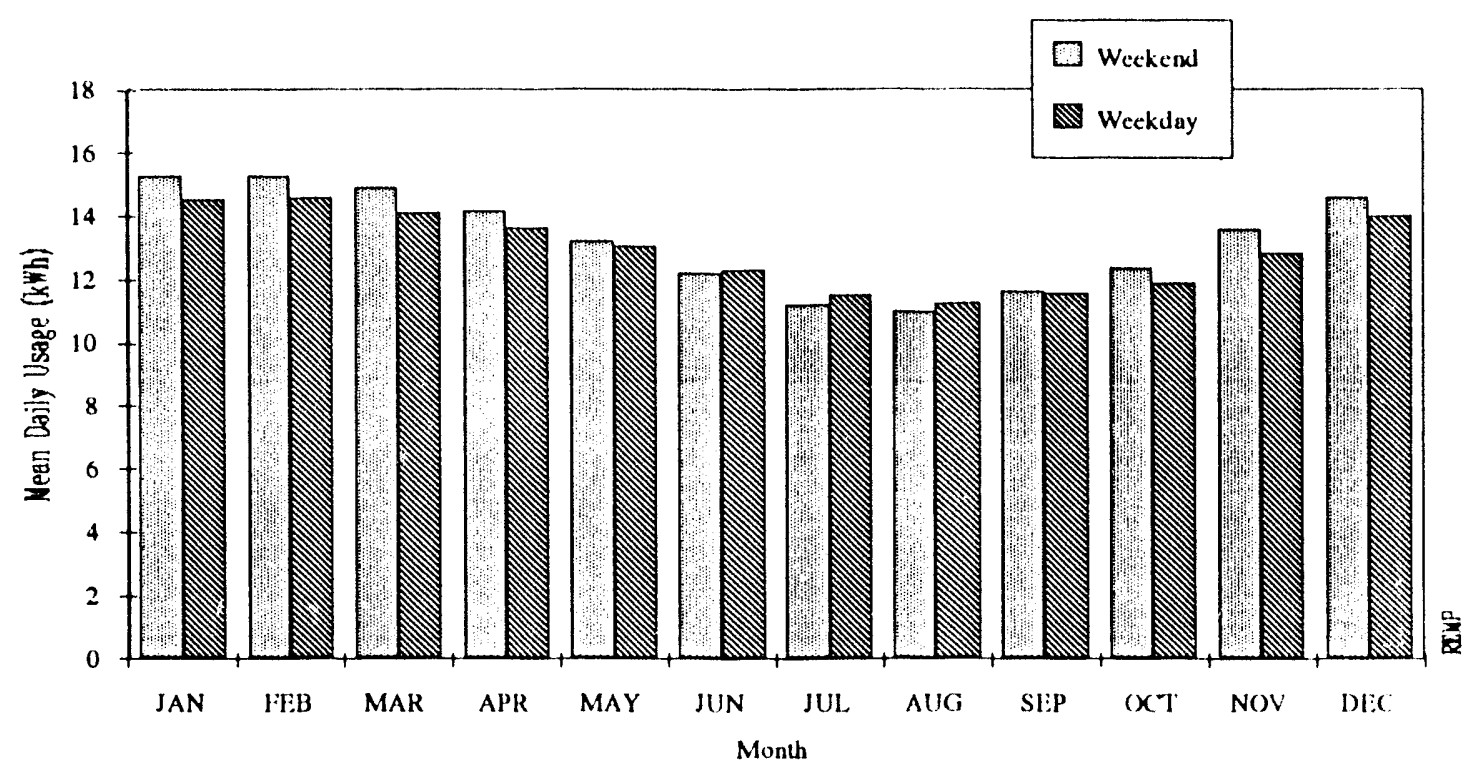

FIGURE 7.8

Mean Residential Hot Water

Daily Load by Month for the Post-1978 Study

(1986-1990)

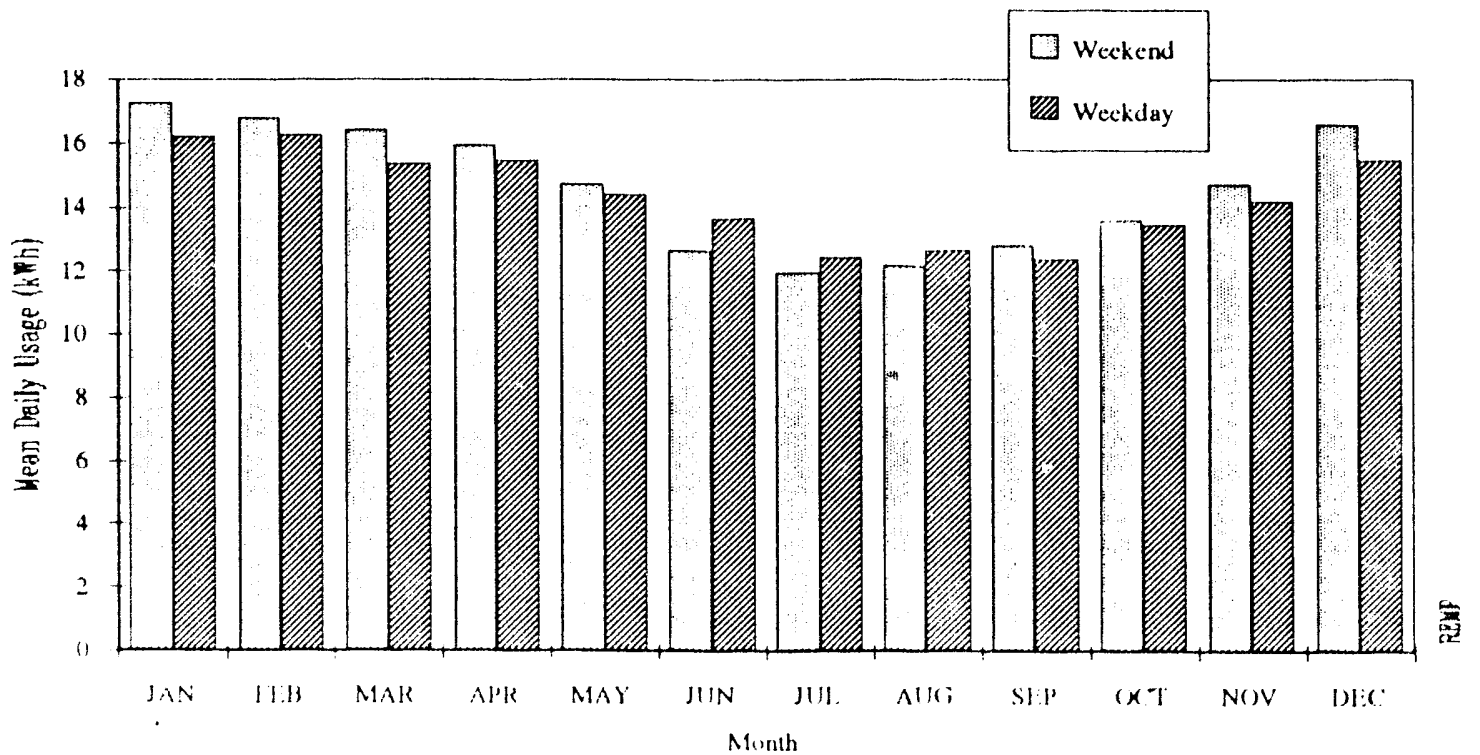


FIGURE 7.9

Mean Residential Hot Water

Daily Load by Month for the MCS Study

(1986-1990)

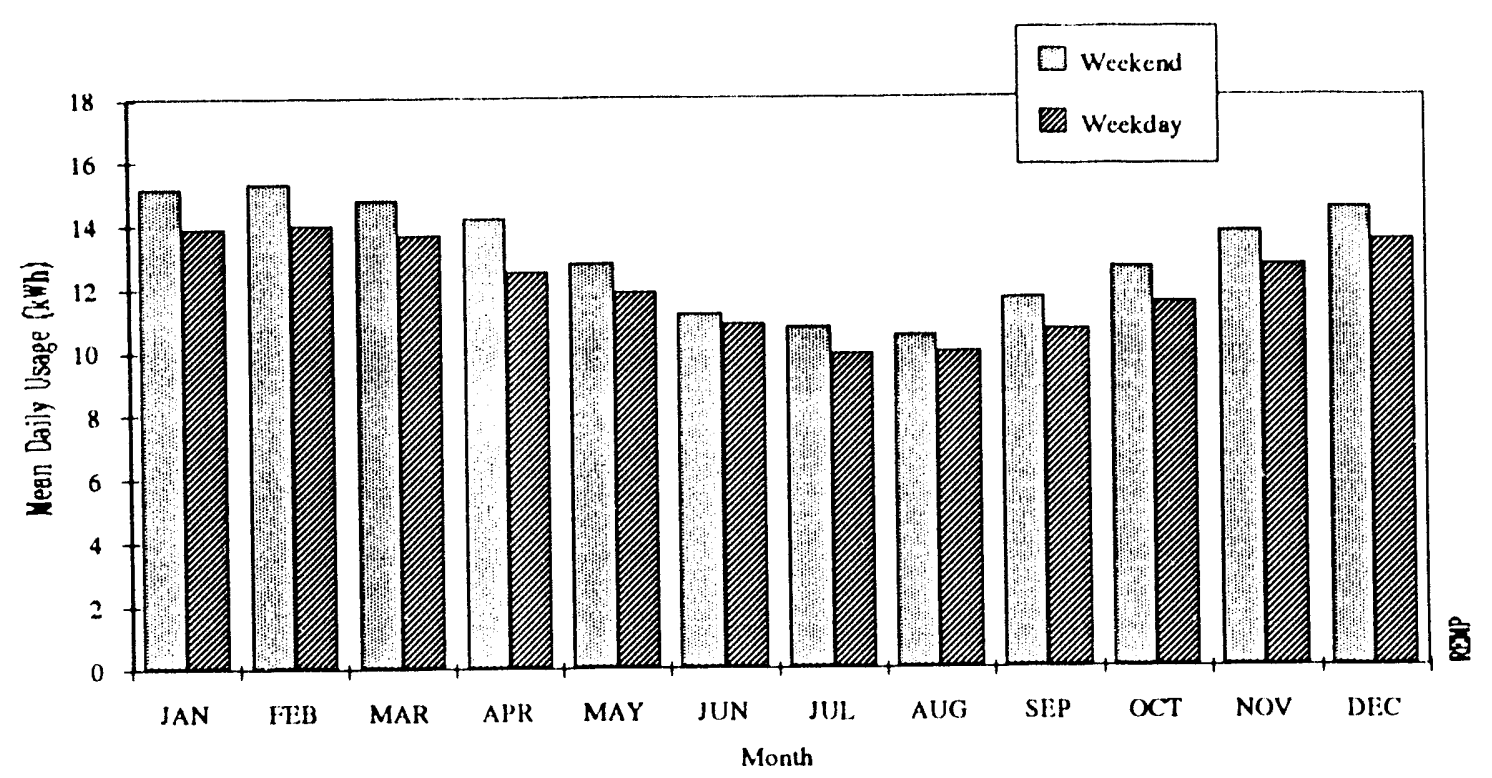

FIGURE 7.10

Mean Residential Hot Water

Daily Load by Month for the Control Study

(1986-1990)

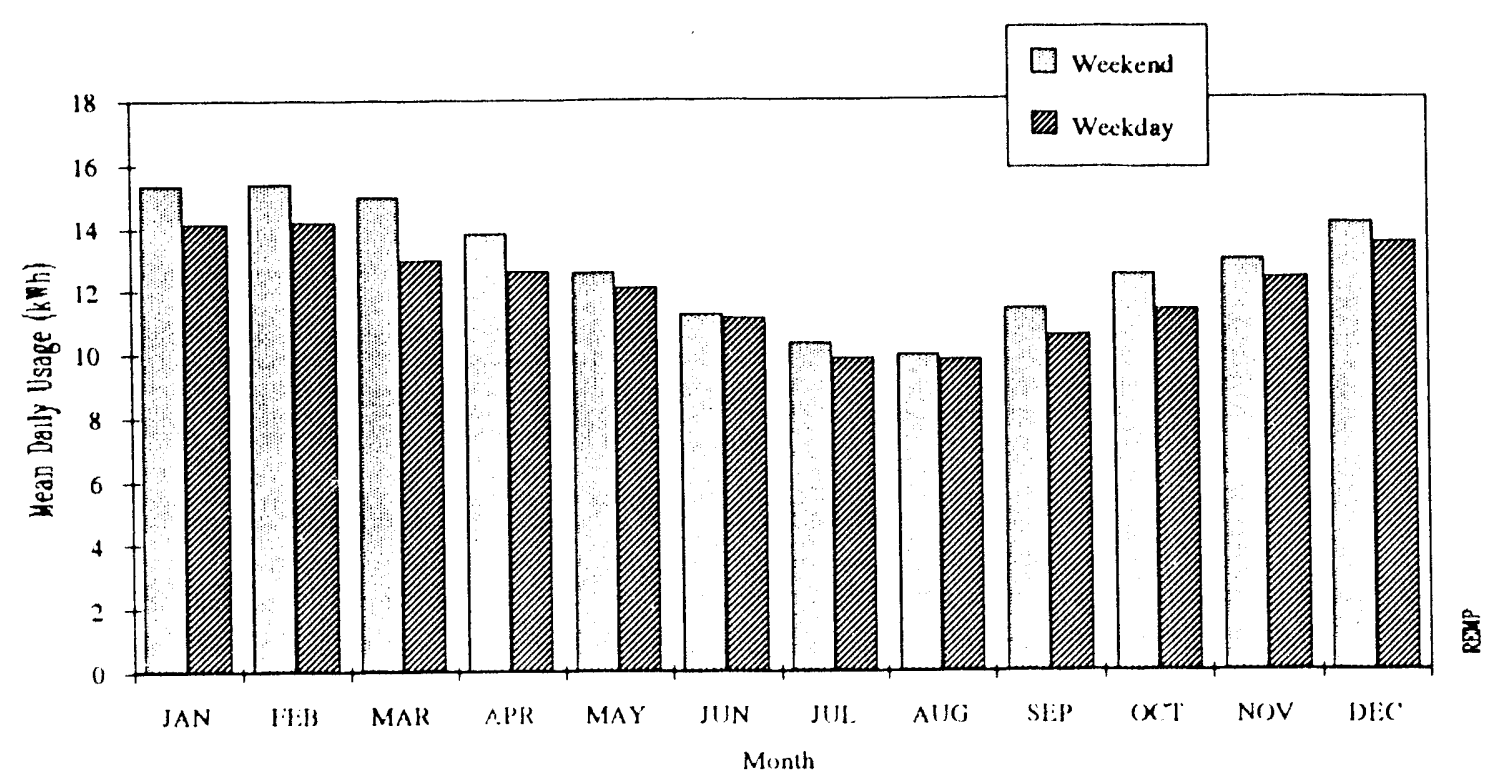




\section{SECTION 8 - AVERAGE HOT WATER LOAD PROFILES}

This section looks at various average annual 24-hour hot water load shapes and gives some possible explanations for the load shapes for specific time periods. It is important to note that these profiles do not represent an actual end-use load. They represent the average of all sites for each hour in a day and hours within a given time period. Each hour is the sum of the 60 minutes prior to that hour. For example, the energy use for 8:00 a.m. is the sum of the 60 minutes between 7:00 a.m.and 8:00 a.m.

Hot water load shapes presented in this section may be useful in targeting loadmanagement strategies that most contribute to reducing system peaks. Load profiles are presented for the months of January and July along with weekends and weekdays.

It is important to note that the average annual 24-hour load profiles, like the average annual and monthly loads, represent the average of all sites for each hour in a day and hours within a given time period. The average loads therefore do not represent actual end-use loads from single homes, which show much more hour to hour and day to day variation.

\section{WEEKEND AND WEEKDAY LOAD PROFILES}

Figures 8.1-8.4 are average annual weekend and weekday load profiles for each type of home (Base, Post-1978, MCS, and Control). These plots illustrate the effect of daytype on the hot water end use and how consumption differs between home types.

\section{Load Shape Comparisons Between Daytypes}

Each weekend and weekday load shape shows the typical diurnal peaks, one in the morning and another, lesser peak in the evening. However, the timing of the peaks varies for the two daytypes. 
The weekend morning peak occurs at the hour ending 10:00 a.m.; the weekday morning peak occurs between 7:00 a.m. and 8:00 a.m. The fact that more people shower around 7:00 a.m. or 8:00 a.m. on typical working days (Monday-Friday) and later on weekends may explain this daytype variation in morning peaks.

Each weekend load shape shows a higher hot water consumption during the afternoon hours than does each weekday load shape. This weekend afternoon consumption may occur because more working people commonly clean house, wash dishes, and wash clothes during weekend afternoons than on weekday afternoons. Hot water consumption levels on weekend evenings are about equal to weekday evening levels. This suggests that evening hot water usage patterns are similar across daytypes.

Figures 8.1-8.4 also show that the hot water load in the early morning (1:00 a.m.-4:00 a.m.) is small on both weekends and weekdays. In all types of homes, the lowest hot water load is at 4:00 a.m. According to Pratt and Ross (1991), the average 4:00 a.m. load provides a good estimate for the average standby load. However, if the 4:00 a.m. consumption level is taken as the standby load, then what explains the small hot water demand seen in hours 1:00 a.m.-3:00 a.m.? A likely explanation is that the small load in the very early morning hours is a result of earlier, small late evening loads (hands and face washing, for example) that only partially deplete the hot water tanks, causing the tanks to reheat sooner than they would under normal standby conditions but not immediately.

\section{Comparison Across Studies}

In Figures 8.1-8.4, the Base, MCS, and Control homes all peak in the morning at about the same level (1.05 kWh-1.13 kWh) with Post-1978 homes 10-20\% higher $(1.25 \mathrm{kWh})$. The Base and Control homes have a sharper weekday morning peak, concentrated in the 8:00 a.m. hour, while the weekday peak in the other types of homes is spread out over about two hours. 
FIGURE 8.1

Mean Residential Hourly Hot Water Annual

Load Profile for Base Homes

(1986-1990)

(Number of Sites $=183$ )

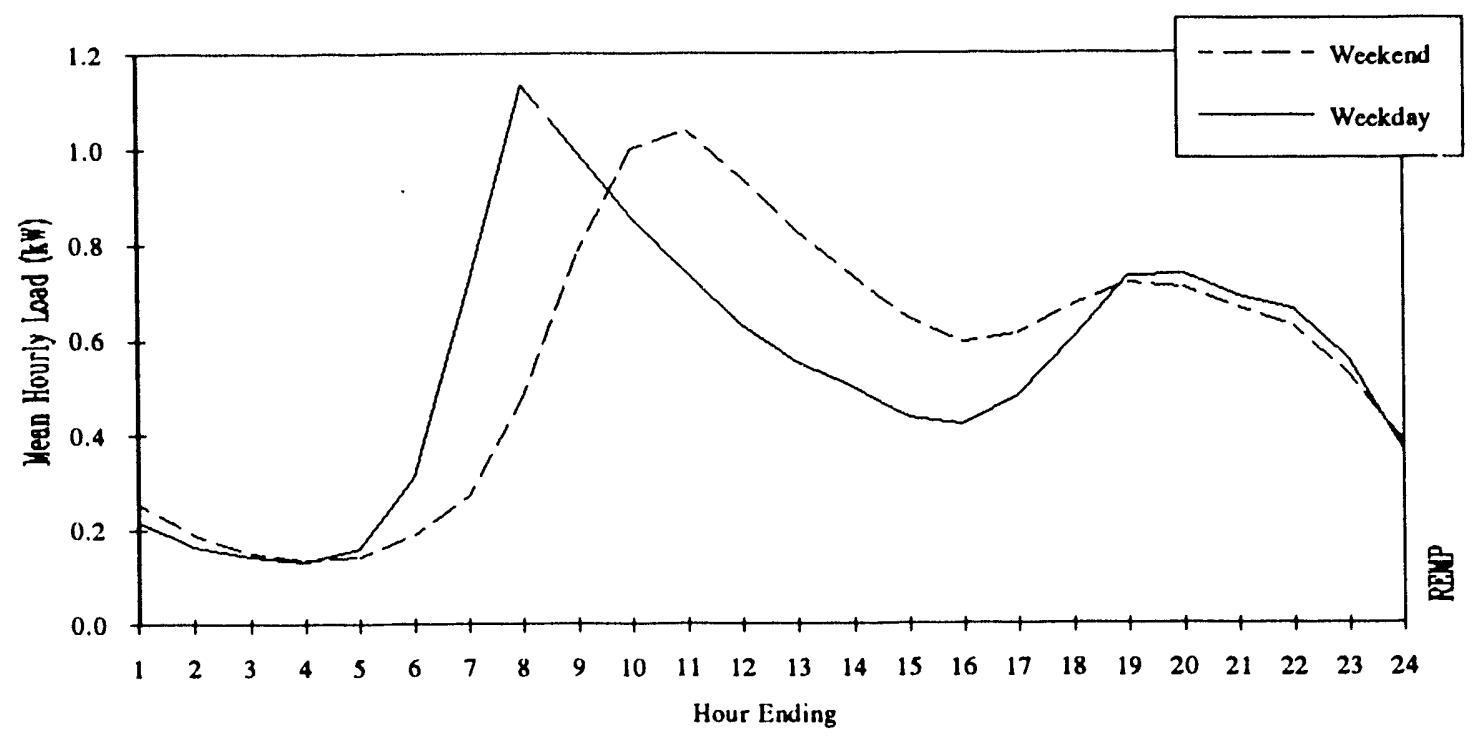

FIGURE 8.2

Mean Residential Hourly Hot Water Annual

Load Profile for Post-1978 Homes

(1986-1990)

(Number of Sites $=25$ )

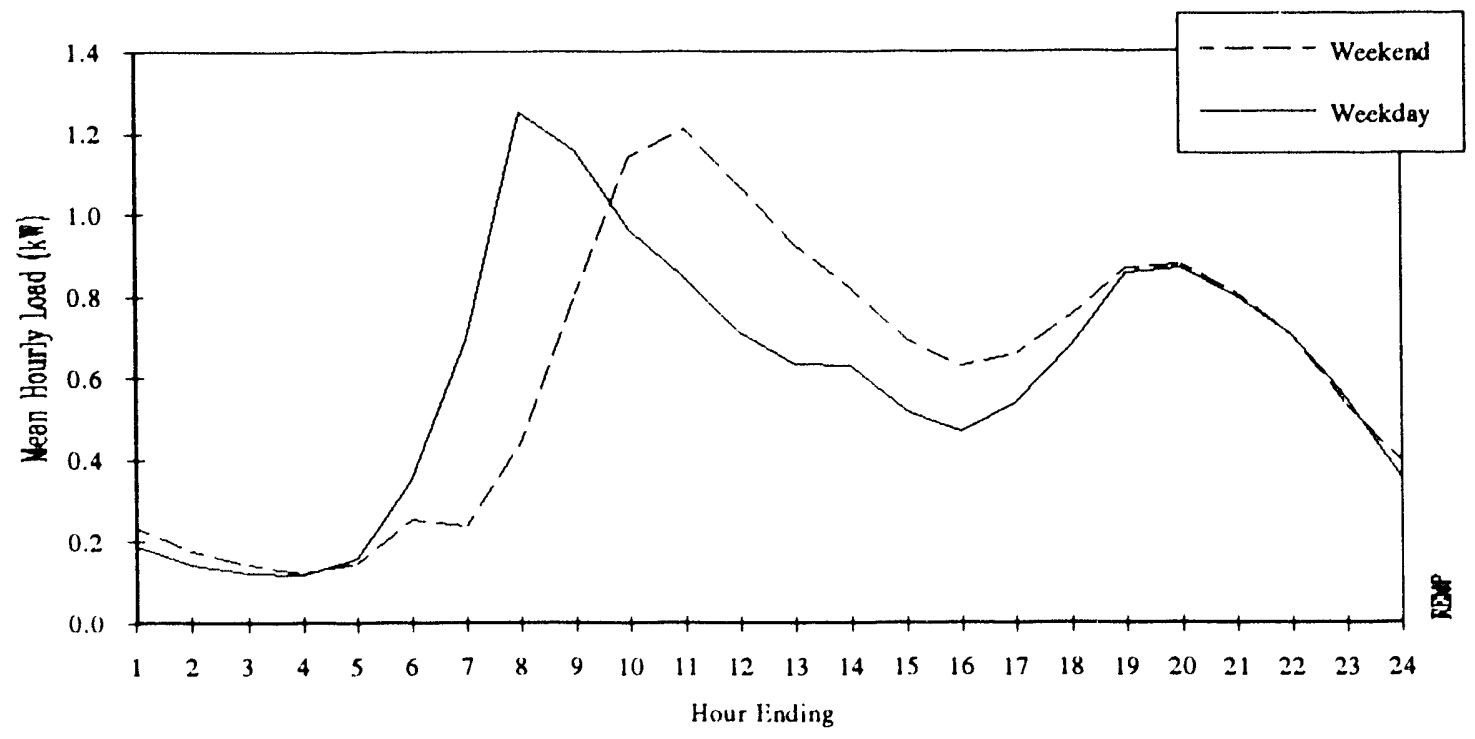


FIGURE 8.3

Mean Residential Hourly Hot Water Annual

Load Profile for MCS Homes

(1986-1990)

(Number of Sites $=53$ )

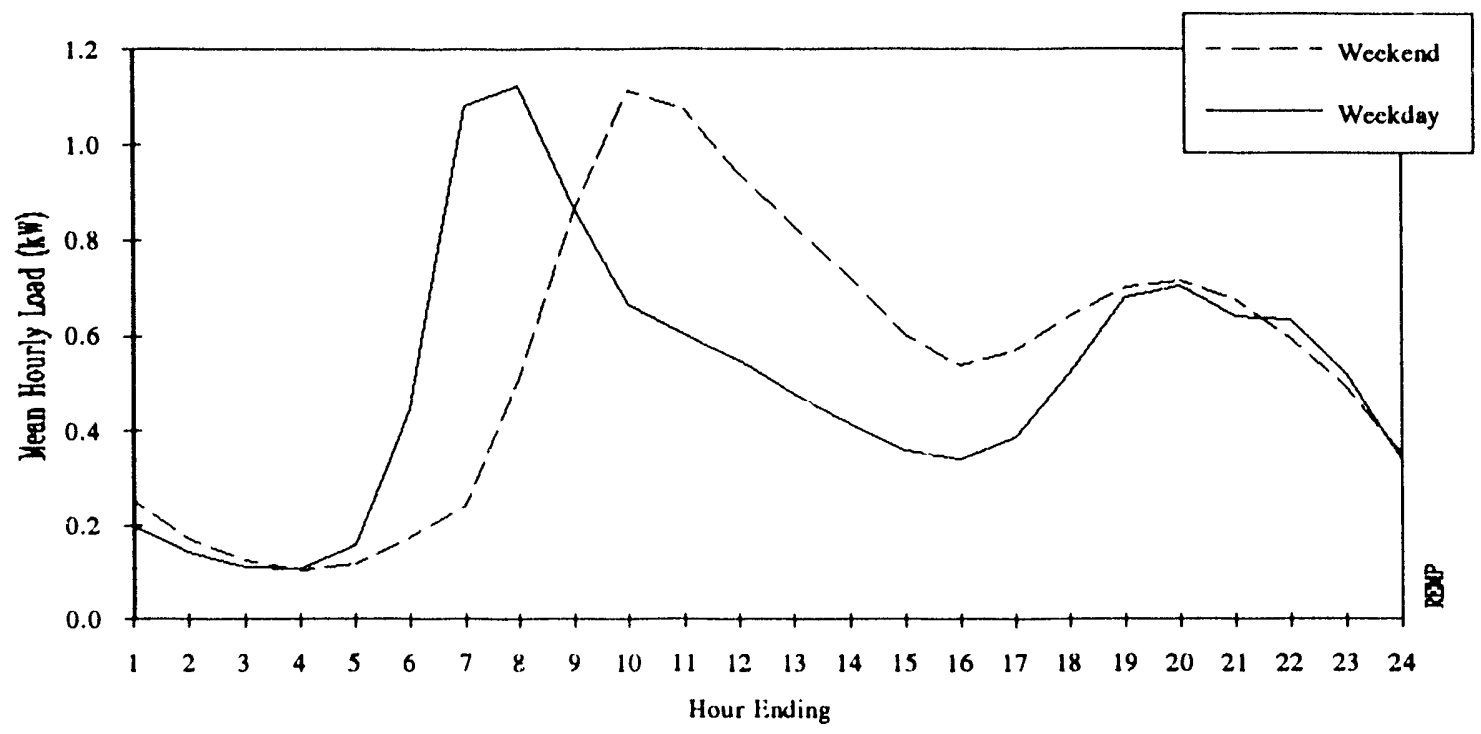

FIGURE 8.4

Mean Residential Hourly Hot Water Annual

Load Profile for Control Homes

(1986-1990)

(Number of Sites $=19)$

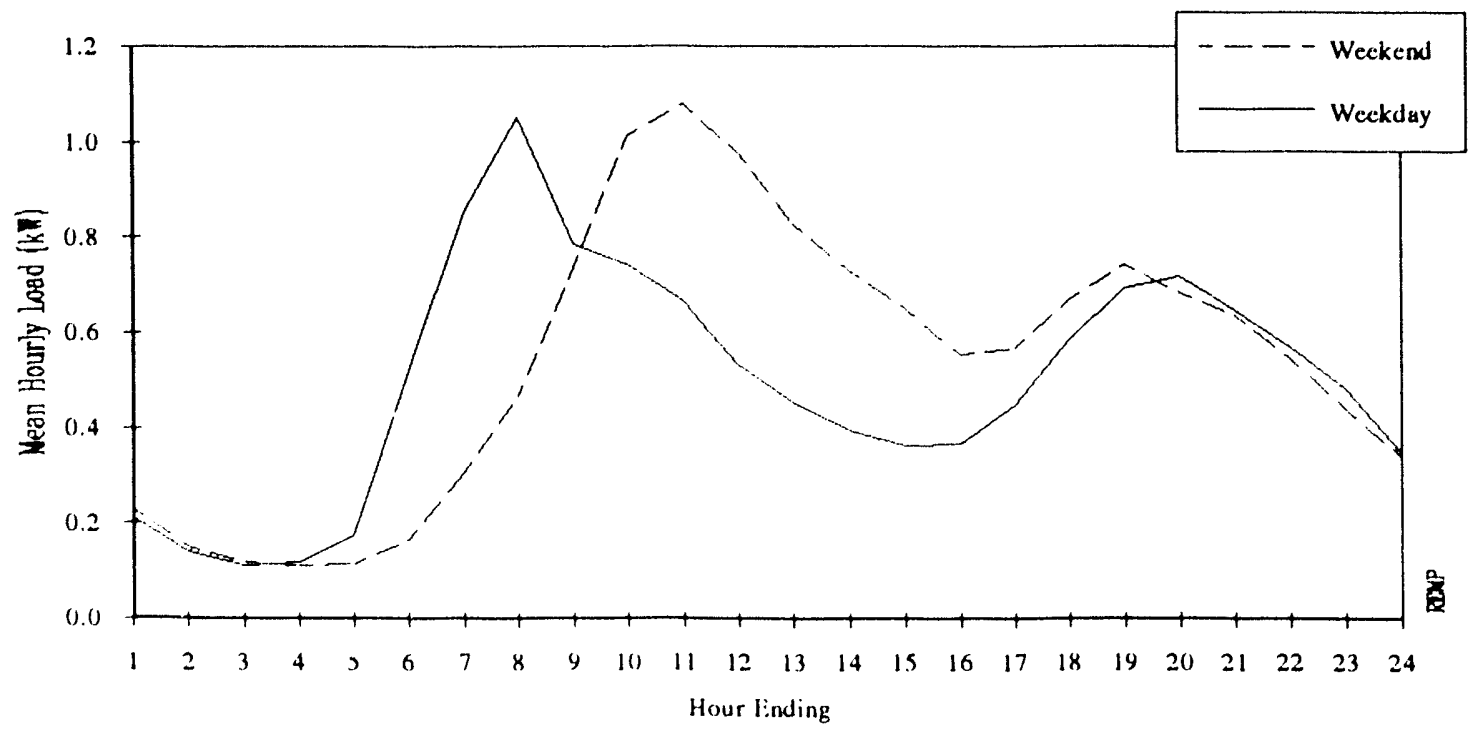


Two effects might explain the sharper peak in the Base and Control homes compared to the other types of homes. First of all, occupants in the Base and Control homes may tend to take their early morning showers at the same time compared to the people in the Post-1978 and MCS homes. A more reasonable explanation centers around the time resolution of the metering equipment. Since the 8:00 a.m. load is the sum of the metered energy use 60 minutes prior to $8: 00 \mathrm{a} . \mathrm{m}$. the hot water energy use for a shower taken at 7:30 a. m. will be reported as 8:00 a.m. 's energy use. As a result, if the MCS and Post-1978 homes have peak loads occurring from, for example, $6: 40$ to $7: 10$, those loads would be reported as occurring partly in the $7: 00$ and partly in the 8:00 a.m. hour. The Base and Control home loads, on the other hand, could peak about 10 minutes earlier (6:30 a.m. to 7:30 a.m.) and so the weekday peak load could be reported in one hour (6:00 a.m.-7:00 a.m.). This would produce a sharper peak load for the Base and Control homes.

\section{JANUARY AND JULY LOAD PROFILES}

Figure 8.5 and Figure 8.6 show hot water average load profiles for the months of January and July for 183 Base homes for weekends and weekdays, respectively. These two plots illustrate the seasonal change in hourly load shapes. Because of the similarity of load shape and magnitude across studies, only the Base weekend and weekday profiles are shown. ${ }^{1}$

On weekends (Figure 8.5), the July hot water load shape is generally similar to the January load shape, with nearly equal loads in the late night and early morning (11:00 p.m.-9:00 a.m.). The morning January peak is about one-third $(0.4 \mathrm{~kW})$ higher than the July morning peak. The difference between the January and July weekend

\footnotetext{
${ }^{1}$ Post-1978 homes were consistently about $.2 \mathrm{~kW}$ higher for both the average weekday and weekend load profiles.
} 
loads is maintained throughout the afternoon and evening, and may represent reduced demand for hot water in July as a result of more summer weekends away from home.

The weekday hot water load shapes for July and January, as shown in Figure 8.6, differ from the weekend load shapes. The weekday afternoon July loads are almost as high as the January loads, possibly because the residents aren't home as much on the weekends, so clothes and dish washing occurs during summer weekday afternoons.

The January weekday load profiles show high morning hot water loads, much higher than evening loads, while in July the morning and evening loads are lower, with the morning loads nearly equal to evening loads. Thus the lovier loads in July are shown to be associated with lower morning peak loads and, to a lesser extent, lower evening loads.

FIGURE 8.5

Mean Residential Hot Water Weekend

Load Profile for Base Homes

(1986-1990)

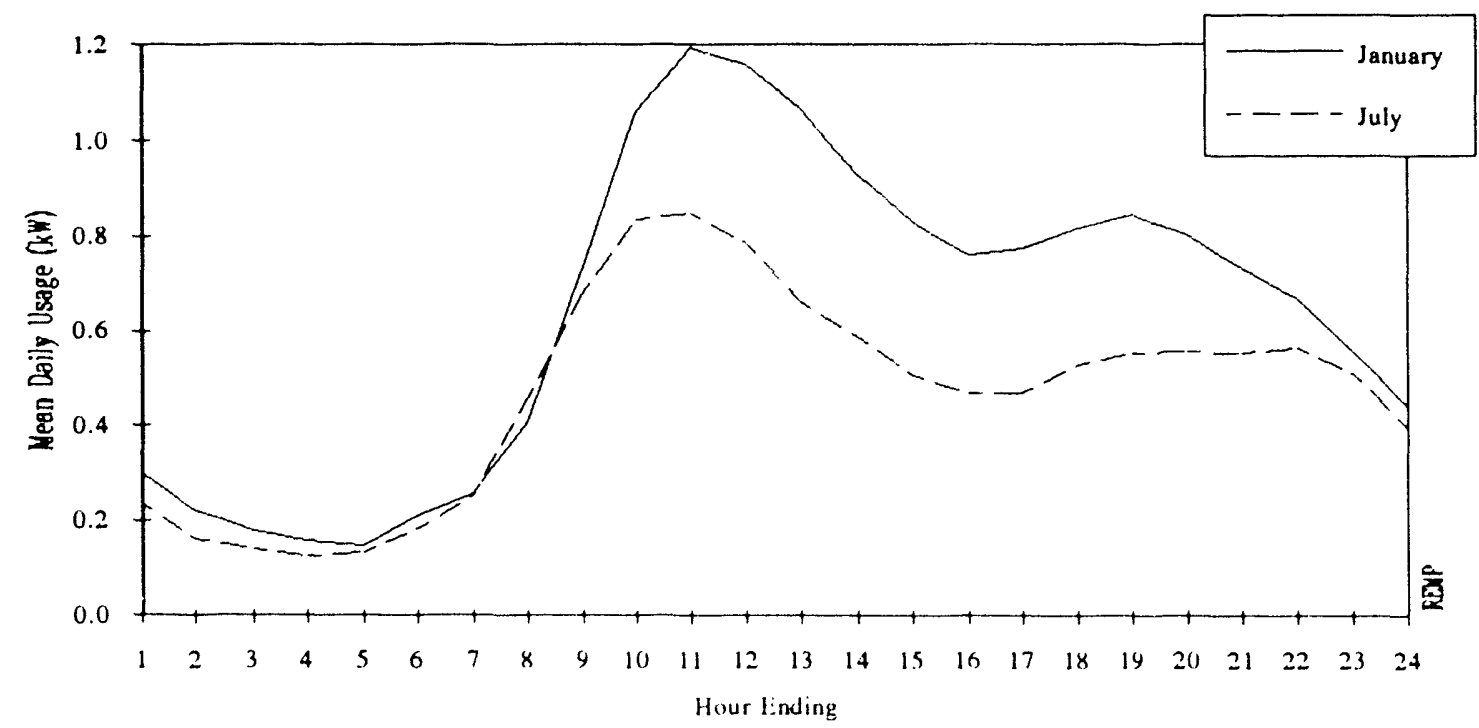


FIGURE 8.6

Mean Residential Hot Water Weekday

Load Profile for Base Homes

(1986-1990)

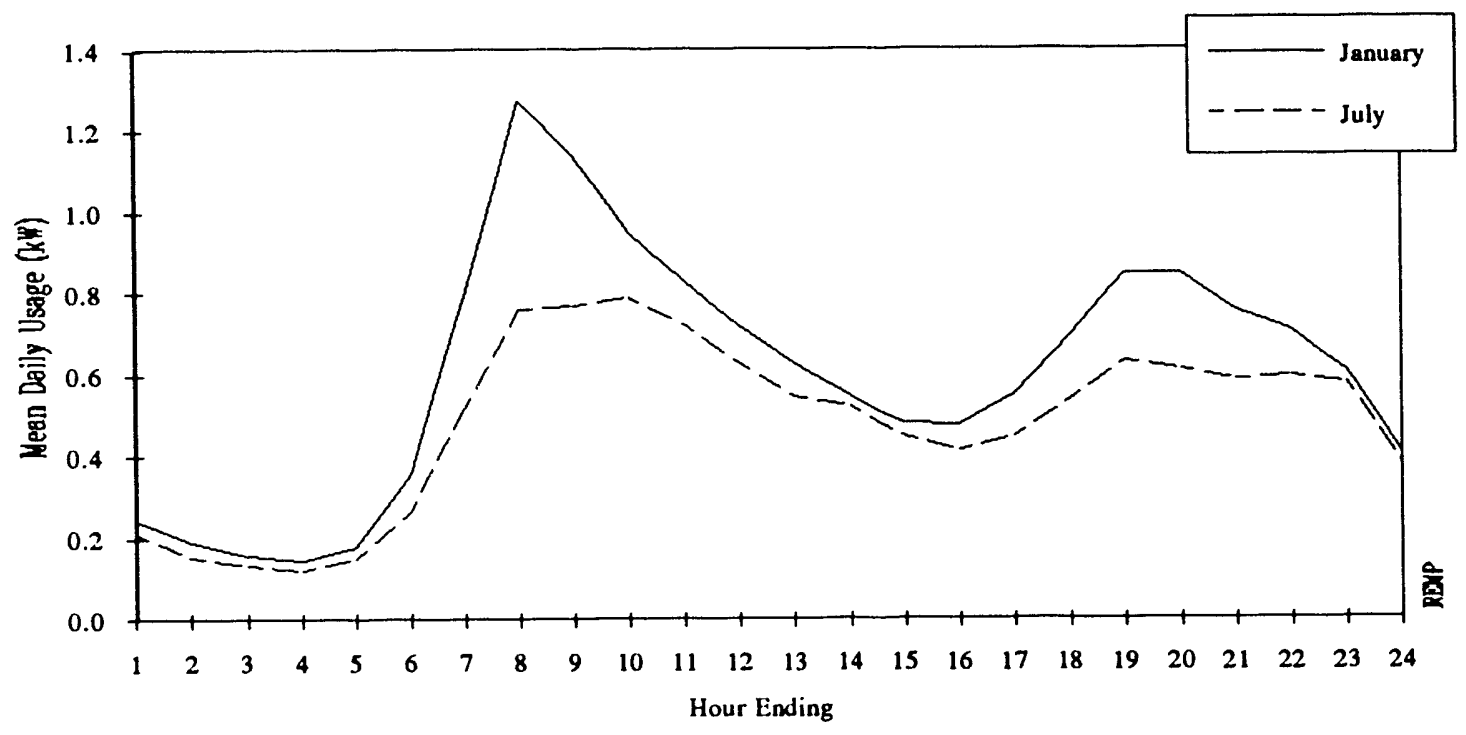




\section{SECTION 9 - PEAK DAY LOAD CHARACTERISTICS}

This section examines the character of the hot water load at peak usage, and makes some observations about the peak loads presented. Two specific times are of interest--the time of the highest hot water load, and the time of the Bonneville system peak load. Information about the hot water load at these two times provides a concise gauge of both the character of hot water peak loads and the contribution of hot water loads to the overall utility system peak load.

Annual and monthly hot water peak loads as well as hot water loads on Bonneville-system seasonal peak days are presented. As in other sections of this report, the annual, month, and day summary statistics are calculated by aggregating the REMP hourly metered data. (See Appendix A on aggregation methodology.)

Three measures of peak are used in this section: hot water coincident peak, Bonneville-system coincident peak, and load factor. The hot water coincident peak is the highest simultaneous hot water usage of all sites considered, or highest aggregate load among those derived by adding together individual site hourly loads. The Bonneville-coincident peak is the average load of all sites at the time of Bonneville system peak. The load factor is the ratio of average load to peak load, and has a value between 0 and 1 (expressed in the Section 9 profiles as a percentage). A higher load factor implies a less peaked load.

The analysis of peak loads is restricted to the 1987 calendar year, the year with the highest number of sites on-line for each study. The number of sites included in a profile is of particular concern when analyzing peak loads. Load diversity decreases as the number of sites decreases, and analyzing just a small number of sites may result in an upward bias of the estimate of coincident peak. This effect is often especially evident when data is used from less than fifteen sites. Accordingly, for this report the 
peak usage analysis is limited to data from the 1987 calendar year, the year with the highest number of sites on-line for each study (Base, Post-1978, MCS, and Control).

\section{ANNUAL PEAK}

Table 9.1 shows the hot water coincident peak load, annual average load, and annual load factor for each type of home in the REMP studies. The peak $\mathrm{kW}$ is compared with the annual average load, which is the annual usage (in $\mathrm{kWh}$ ) divided by the number of hours in the year ( 8760 hours). This table shows that while the annual average load is of similar magnitude across studies, the coincident peak load is consistently higher for newer homes (Post-1978, MCS, and Control), suggesting that there are less diverse usage patterns of hot water in these homes. Note that these higher peak load estimates for newer homes may be biased high due to the small sample size.

\begin{tabular}{|c|c|c|c|c|}
\hline \multicolumn{5}{|c|}{$\begin{array}{c}\text { TABLE } 9.1 \\
\text { ANNUAL HOT WATER PEAK AVERAGES } \\
\text { AND LOAD FACTOR } \\
(1987)\end{array}$} \\
\hline Study & $\begin{array}{l}\text { Coincident } \\
\text { Peak (kW) }\end{array}$ & $\begin{array}{c}\text { Annual } \\
\text { Average }(\mathrm{kW})\end{array}$ & $\begin{array}{l}\text { Annual Load } \\
\text { Factor }\end{array}$ & $\underline{\mathbf{N}}$ \\
\hline Base & 1.56 & .55 & $35.4 \%$ & 183 \\
\hline Post-1978 & 2.07 & .58 & $27.9 \%$ & 25 \\
\hline MCS & 1.83 & .52 & $28.7 \%$ & 53 \\
\hline Control & 2.14 & .52 & $24.2 \%$ & 19 \\
\hline
\end{tabular}

A measure of load diversity is the coincidence factor, which is defined as the ratio of the maximum load for a group to the sum of the individual maximum loads for each member of the group. Since the nameplate reading of residential hot water heaters 
is approximately $4.0 \mathrm{~kW}$, this would indicate a coincidence factor for hot water of slightly more than $40 \%$. This is a relatively high coincidence factor compared to other residential end-use loads.

\section{MONTHLY PEAK PROFILES}

Figures 9.1-9.4 show the average load (AVG), the coincident peak (PEAK), and the resulting load factor (LF) for each calendar month during 1987 for each type of REMP home (Base, Post-1978, MCS, and Control). The plots illustrate the variation in peak loads during the year.

The monthly peak plots show that the coincident peak and average loads are higher in winter than in other seasons. However, the load factor is relatively constant from month to month. This implies that the seasonal variations in peak and average loads are proportional to each other, and the load diversity remains constant through the year. An exception to this observation is the lower peak load in July and/or August. 
FIGURE 9.1

Mean Monthly Residential Hot Water Coincident Peak Load, Average, Load, and Load Factor for Base Homes

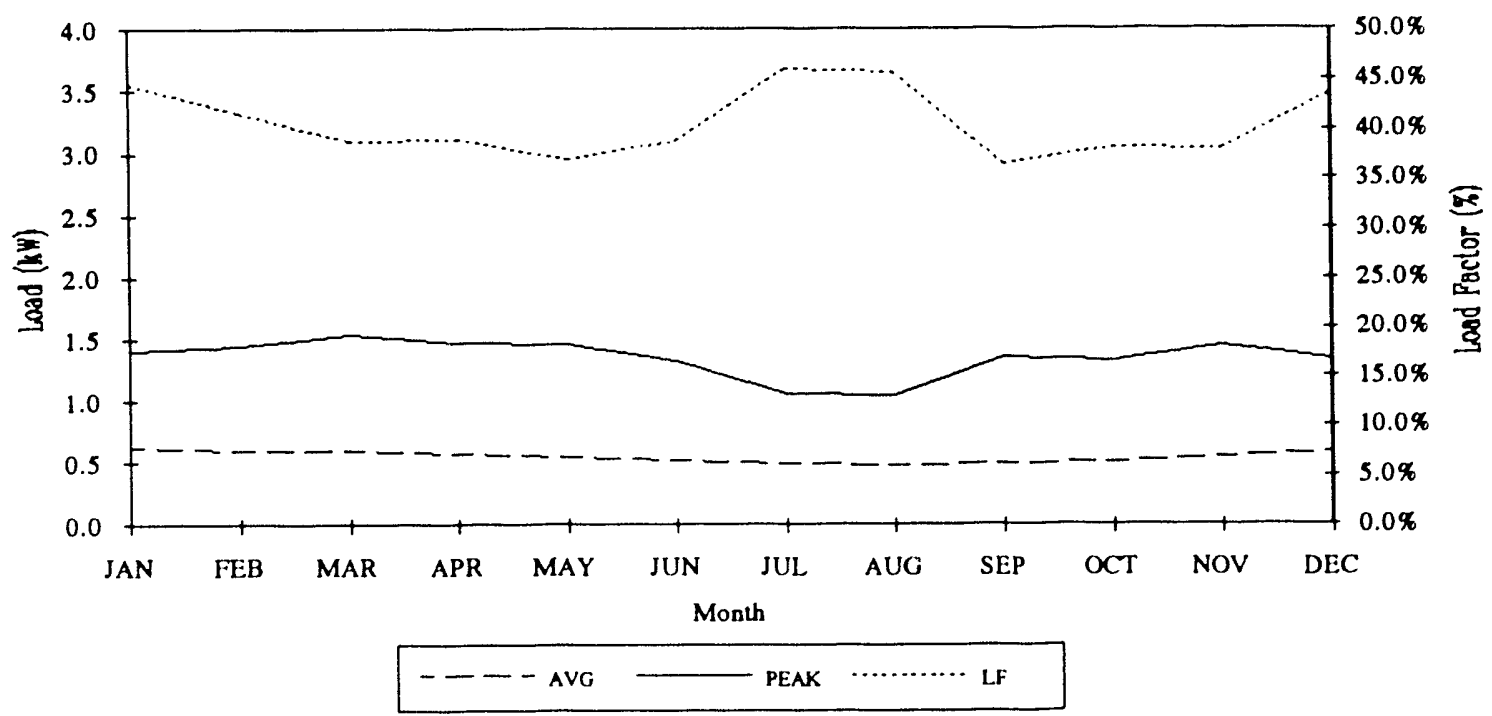

FIGURE 9.2

Mean Monthly Residential Hot Water Coincident Peak Load, Average Load, and Load Factor for Post-1978 Homes

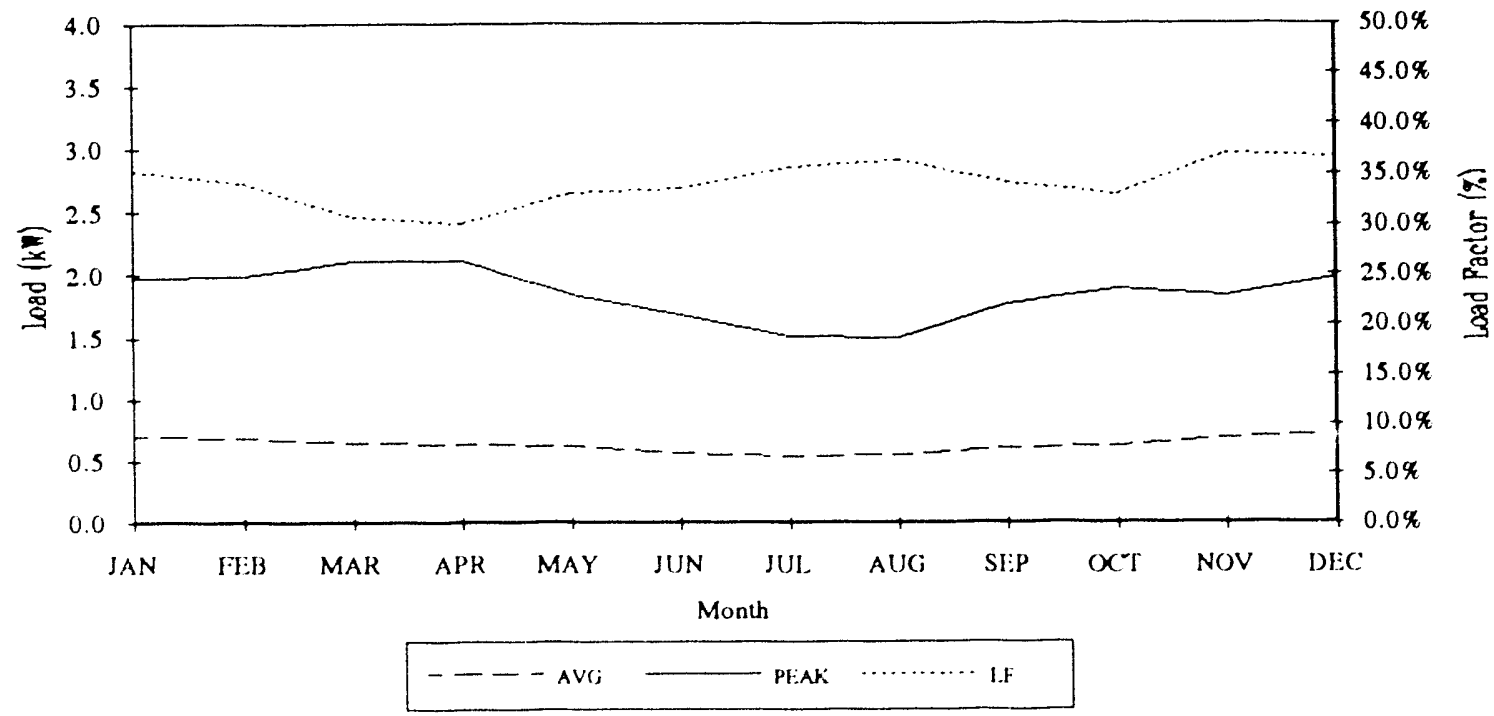


FIGURE 9.3

Mean Monthly Residential Hot Water Coincident Peak Load, Average Load, and Load Factor for MCS Homes

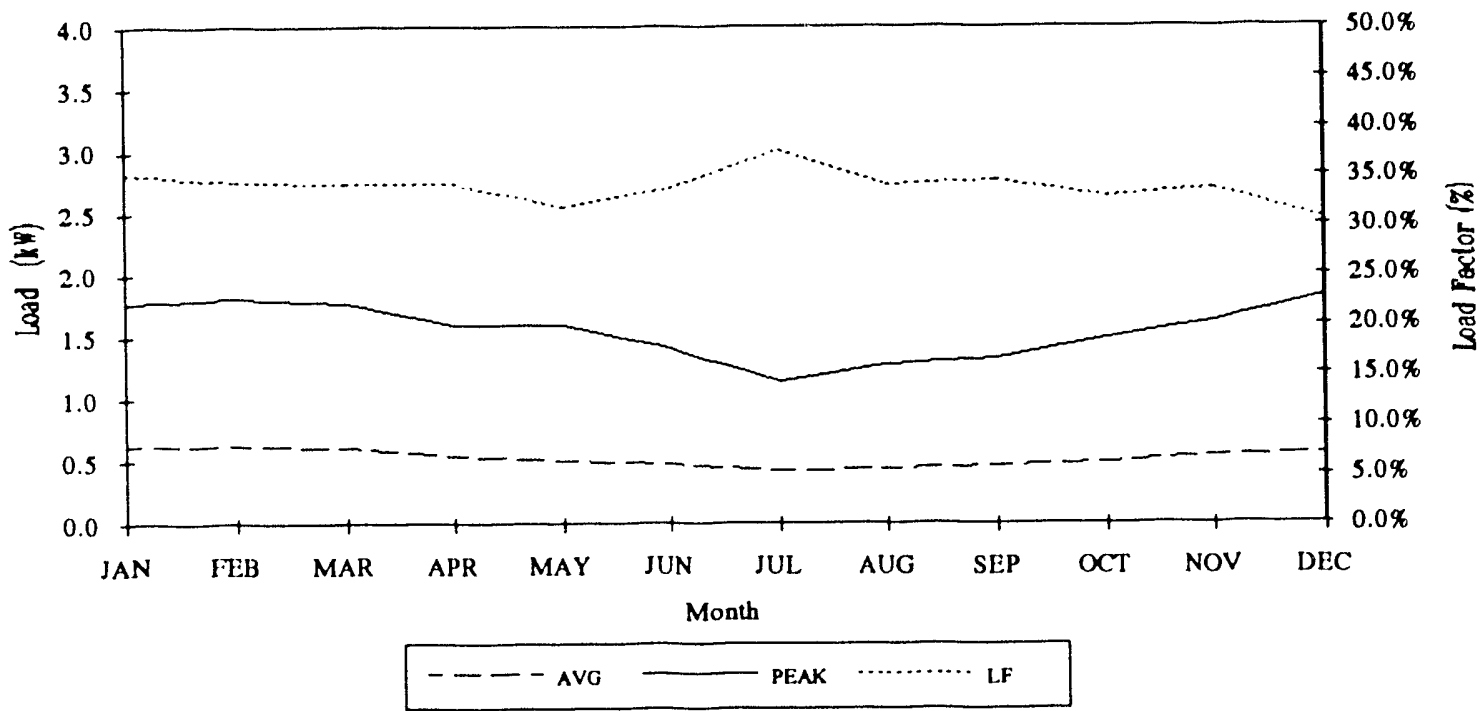

FIGURE 9.4

Mean Monthly Residential Hot Water Coincident Peak Load, Average Load, and Load Factor for Control Homes

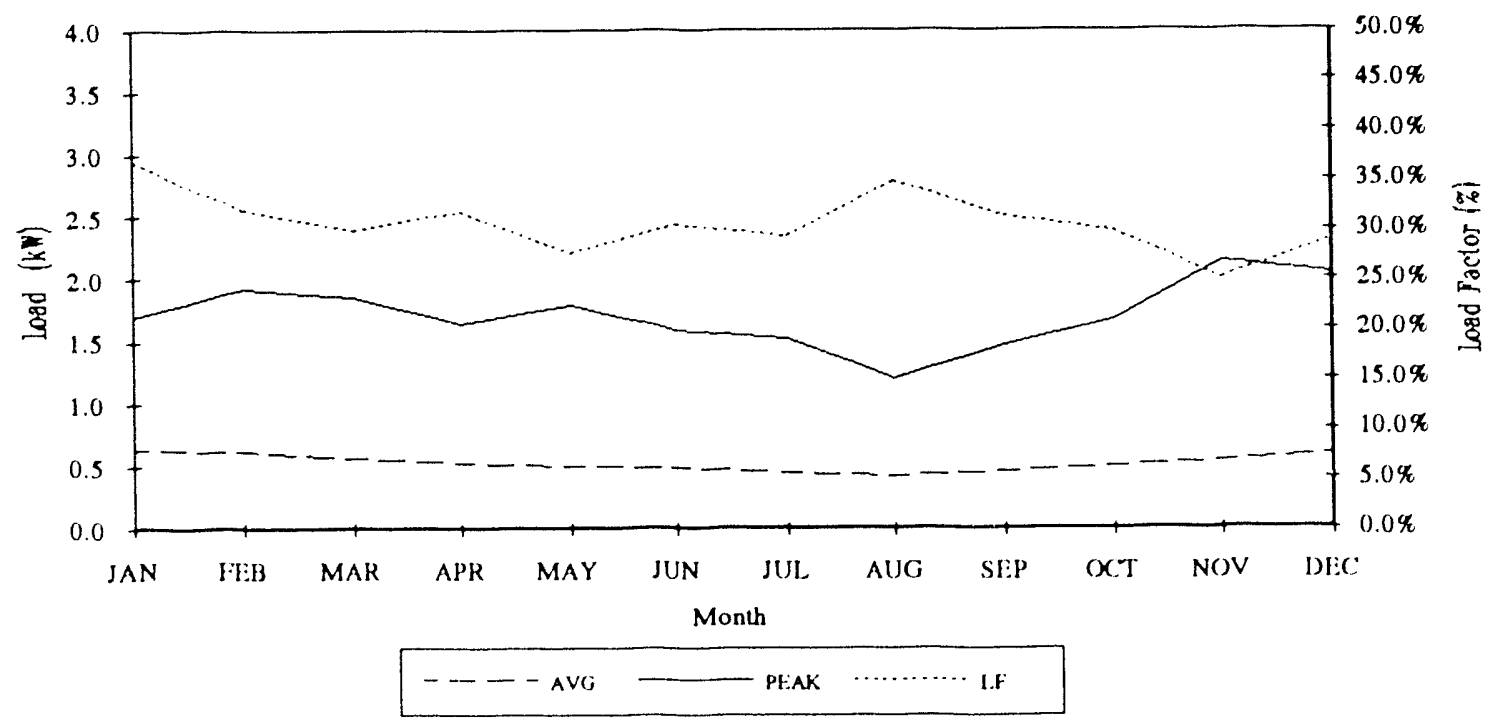




\section{SEASONAL PEAK DAY PROFILES}

Figures 9.5-9.8 include hourly hot water load (HOT WATER) profiles for a Bonneville-system peak winter day and Figures 9.9-9.12 include hourly hot water load profiles for a Bonneville-system peak summer day. Figures 9.5-9.12 also show profiles of the REMP residential load (TOTAL) and the Bonneville system load (SYSTEM) for the peak day.

The winter peak day profiles show a high degree of correspondence among the hot water end use, the total residence load, and the Bonneville system load. The timing of the hot water end-use peak is generally coincident with the total residential load peak. However, comparison with the average load profile for January (see Figures 8.1-8.4) indicates that the peak day hot water load is no higher than on a typical day, whereas the overall residence load is considerably higher. Thus, while the hot water load is a substantial contributor to overall utility peak loads, it is not responsible for increased load on peak days.

In contrast, the summer peak day profiles show less similarity in pattern between the hot water end use, total average residence load, and the Bonneville system peak. Hot water usage is still highest around $8 \mathrm{a} . \mathrm{m}$., while total average residence and Bonneville system loads tend to be higher in the afternoon and evening hours.

The load profiles for the residential group peak days were also examined, by summing across all Base sites on an hour-by-hour basis for the entire year. The total load profile data was then examined to identify the peak winter and peak summer days. These peaks were very similar in shape and magnitude to the Bonneville system peak day profiles, therefore are not shown in this report. 
FIGURE 9.5

Winter Peak Day Hourly Load Profiles

for December 17, 1987 for Base Homes

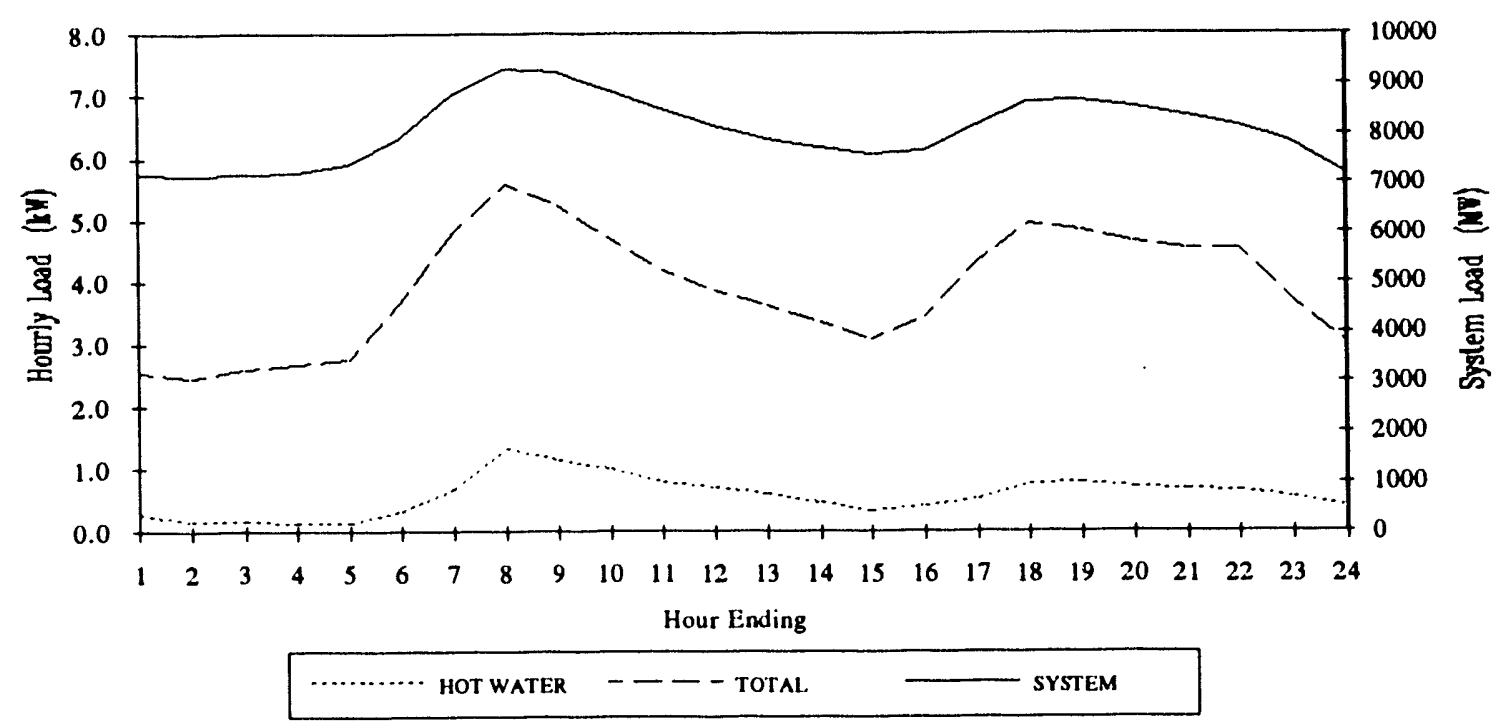

FIGURE 9.6

Winter Peak Day Hourly Load Profiles

for December 17, 1987 for Post-1978 Homes

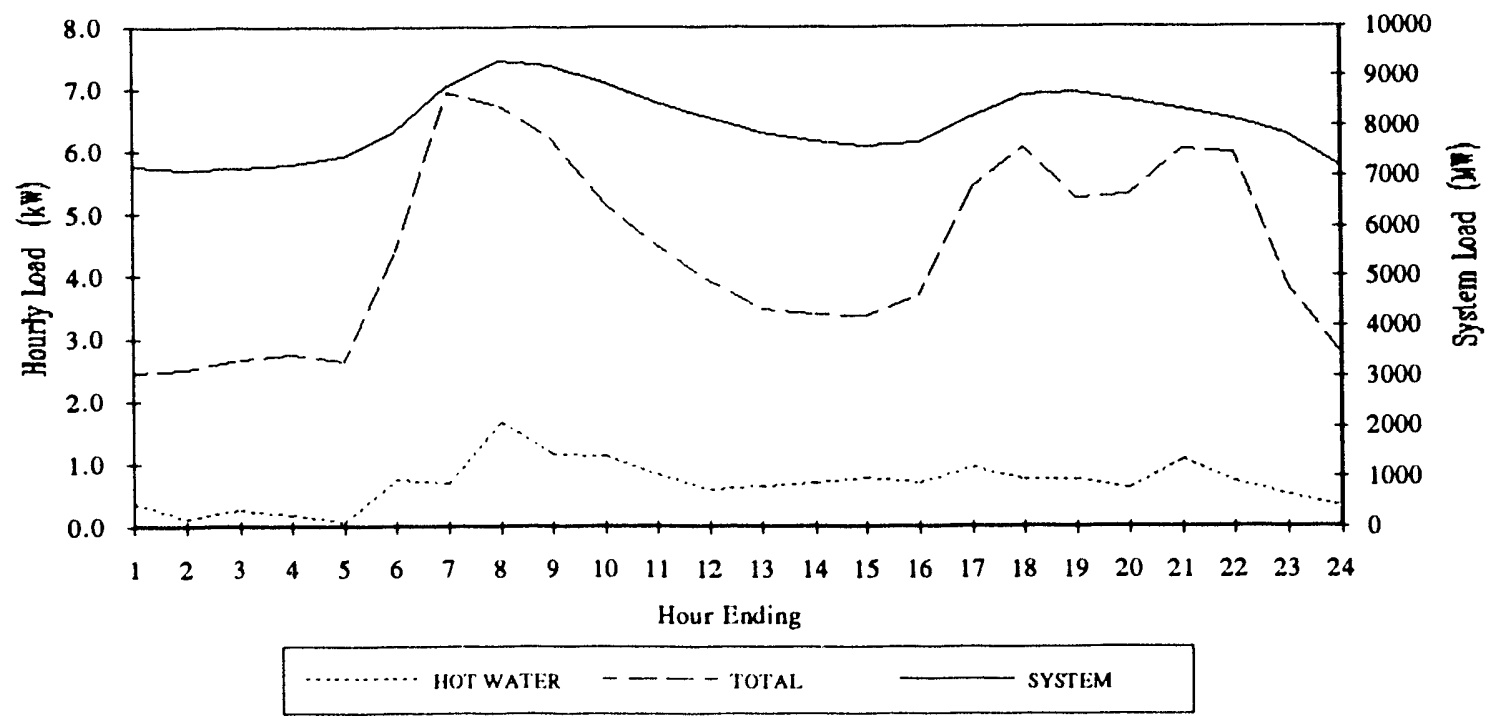


FIGURE 9.7

Winter Peak Day Hourly Load Profiles

for December 17, 1987 for MCS Homes

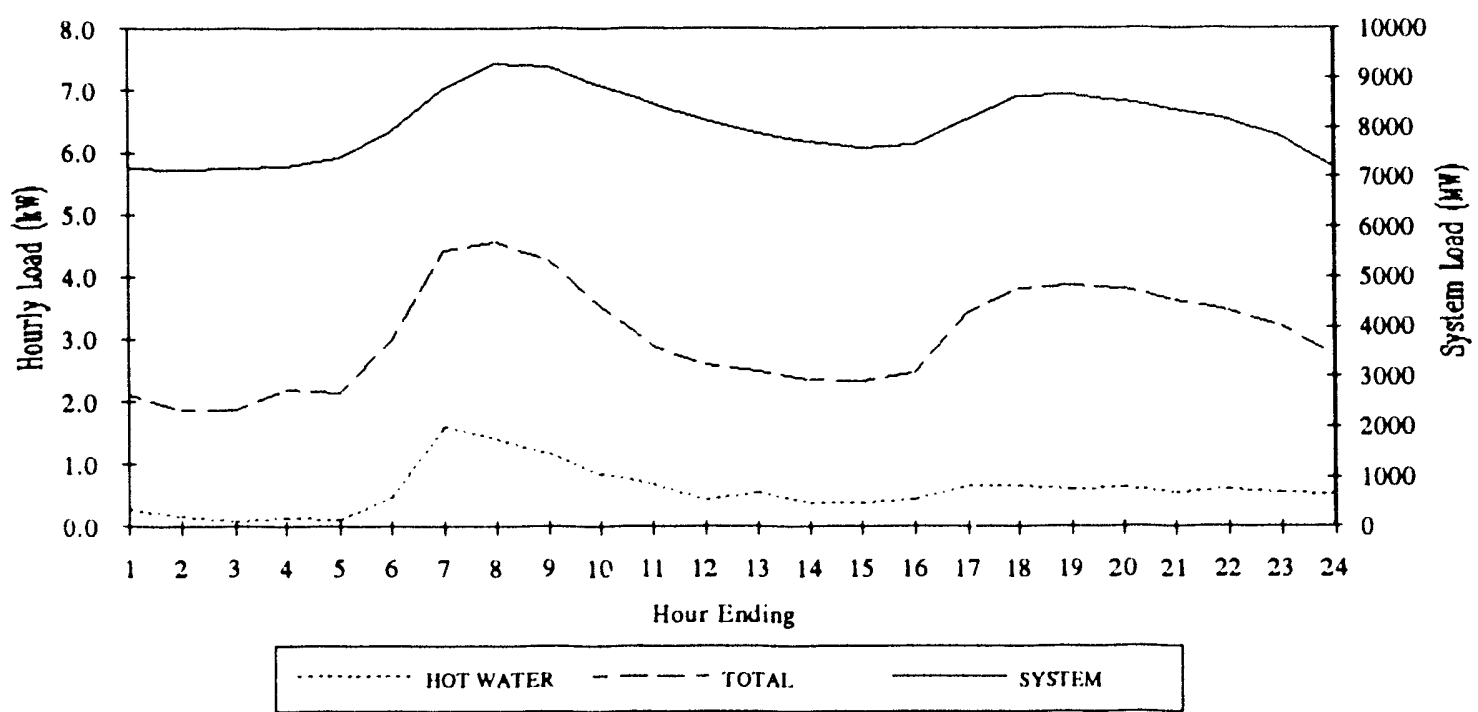

FIGURE 9.8

Winter Peak Day Hourly Load Profiles

for December 17, 1987 for Control Homes

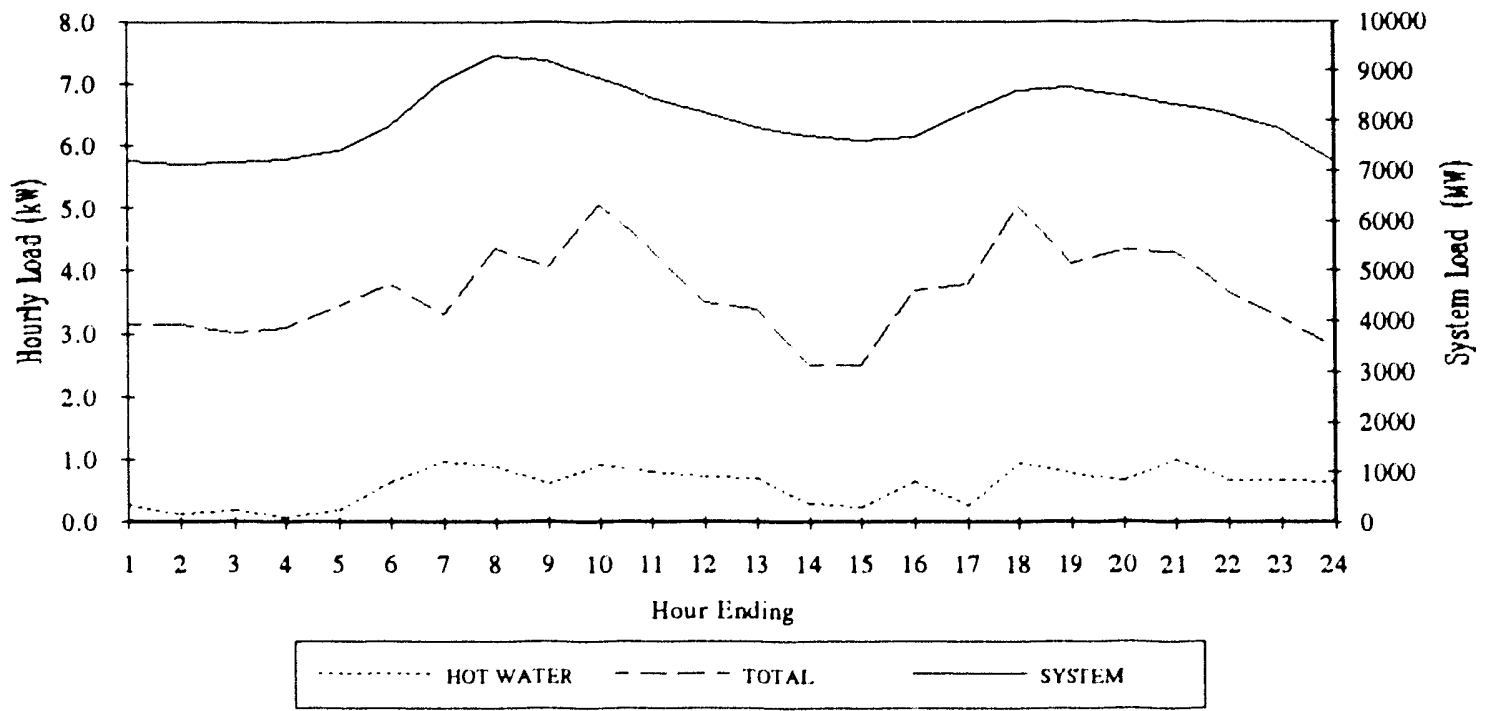


FIGURE 9.9

Summer Peak Day Hourly Load Profiles

for August 31, 1987 for Base Homes

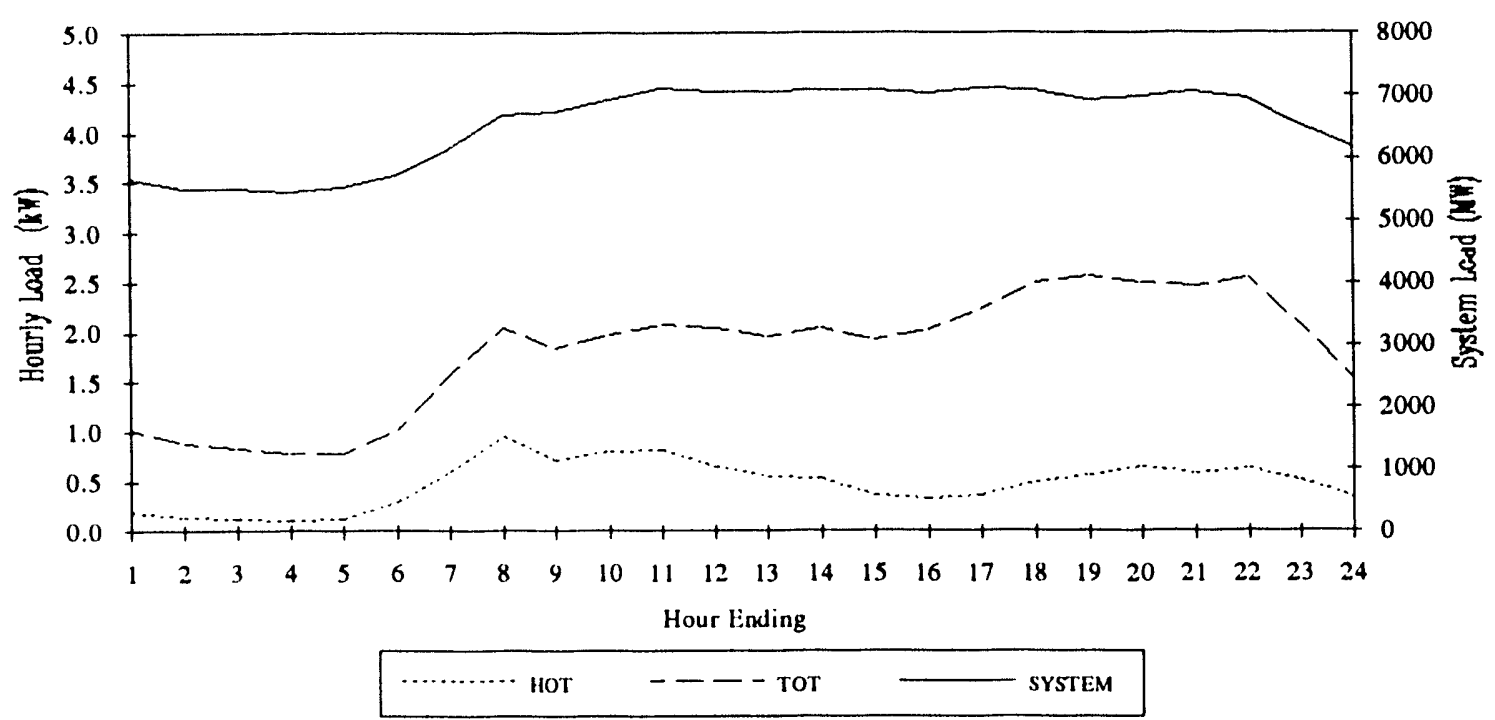

FIGURE 9.10

Summer Peak Day Hourly Load Profiles

for August 31, 1987 for Post-1978 Homes

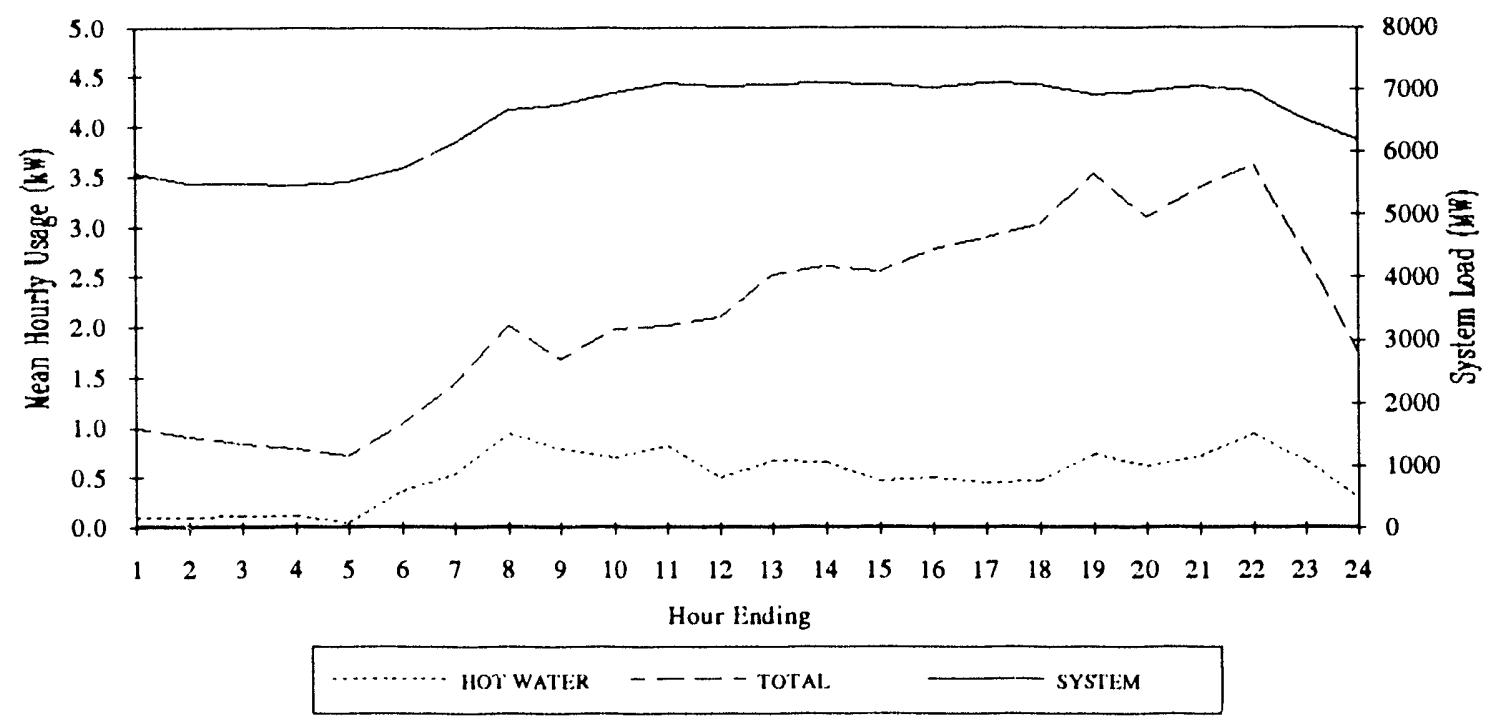


FIGURE 9.11

Summer Peak Day Hourly Load Profiles

for August 31, 1987 for MCS Homes

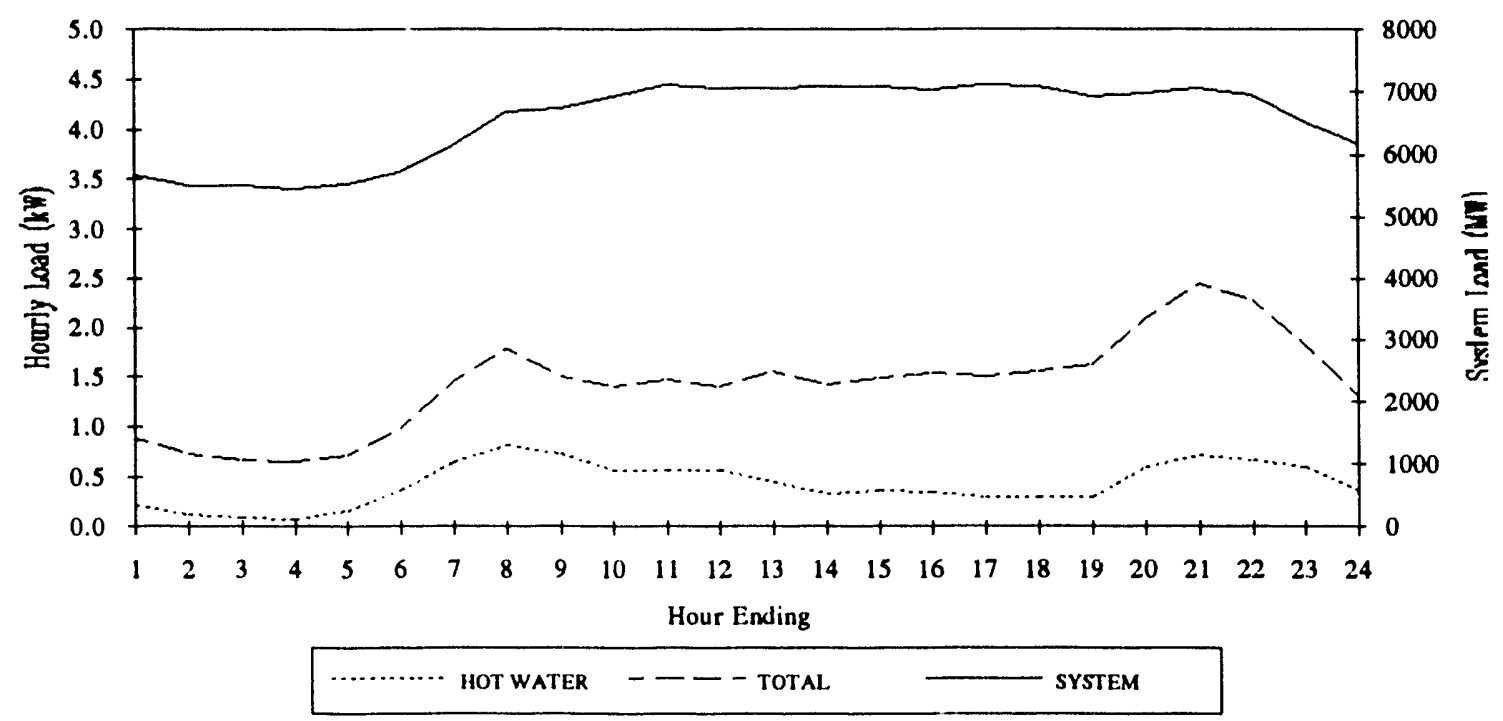

FIGURE 9.12

Summer Peak Day Hourly Load Profiles

for August 31, 1987 for Control Homes

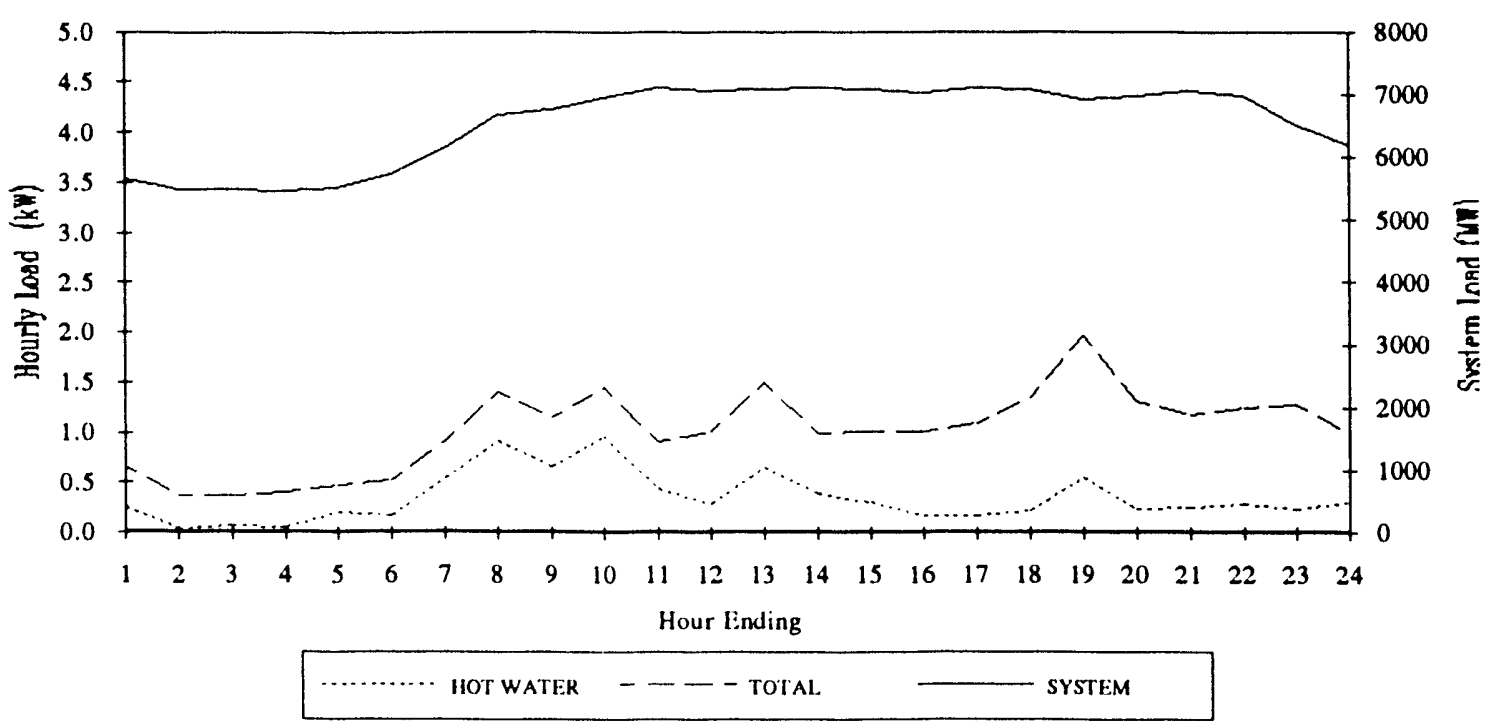




\section{CONTRIBUTION TO BONNEVILLE SYSTEM PEAK}

Table 9.2 shows the hot water (HOT) and total average residence (TOT) hourly load at the time of Bonneville winter and summer system peak, and the percentage that hot water contributes to the residence average total (\%TOT). This table also shows the daily $\mathrm{kWh}$ for respective peak days. In all cases peak hour contribution of hot water to total average residence load is greater than the share for the entire day, implying that hot water usage is more on-peak than off-peak on Bonneville system peak days.

TABLE 9.2

\section{CONTRIBUTION TO BONNEVILLE SYSTEM PEAK} (1987)

\begin{tabular}{|c|c|c|c|c|c|c|}
\hline \multirow[t]{3}{*}{ Group } & \multicolumn{3}{|c|}{ Coincident Peak kW } & \multicolumn{3}{|c|}{ Daily kWh } \\
\hline & \multicolumn{3}{|c|}{ December $17,8: 00$ a.m. } & \multicolumn{3}{|c|}{ December 17} \\
\hline & $\underline{\mathrm{HOT}}$ & TOT & \% TOT & $\underline{\mathrm{HOT}}$ & TOT & \% TOT \\
\hline Base & 1.33 & 5.58 & $23.9 \%$ & 13.89 & 93.1 & $14.9 \%$ \\
\hline Post-1978 & 1.66 & 6.73 & $24.6 \%$ & 16.40 & 105.4 & $15.6 \%$ \\
\hline MCS & 1.42 & 4.57 & $31.0 \%$ & 13.90 & 73.0 & $19.1 \%$ \\
\hline \multirow[t]{2}{*}{ Control } & .89 & 4.37 & $20.4 \%$ & 14.10 & 87.7 & $16.0 \%$ \\
\hline & \multicolumn{3}{|c|}{ August 31.9 p.m. } & \multicolumn{3}{|c|}{ August 31} \\
\hline Base & .81 & 2.08 & $39.0 \%$ & 11.5 & 43.3 & $26.5 \%$ \\
\hline Post-1978 & .82 & 2.01 & $40.5 \%$ & 12.4 & 51.1 & $24.3 \%$ \\
\hline MCS & .57 & 1.47 & $38.8 \%$ & 10.2 & 34.3 & $29.7 \%$ \\
\hline Control & .44 & .91 & $48.6 \%$ & 8.3 & 24.6 & $34.0 \%$ \\
\hline
\end{tabular}




\section{SELECTED BIBLIOGRAPHY}

Bonneville Power Administration. 1990. Draft 1990 Conservation Resource Supply Document. Bonneville Power Administration, Portland, Oregon.

Bonneville Power Administration. 1990. Strategy for Establishing an Energy Efficient Water Heater Program. Draft Final Report. Bonneville Power Administration, Portland, Oregon.

Clear, R. D and D. B. Goldstein. 1980. A Model of Water Heater Energy Consumption and Hot Water Use. LBL-10791. Lawrence Berkeley Laboratory, Berkeley, California.

Ek, C. W. 1982. The Effect of Electric Water heater Tank Insulation Modification and Water Pipe Insulation on Standby Power Consumption. Laboratory Report ERGH-82-35. Bonneville Power Administration, Portland, Oregon.

Ek, C. W. and C. D. Auberg. 1984. "Electric Water Heater Standby Losses: Comparison of Conservation Strategies and their Energy Savings." Proceedings of the 1984 American Council for an Energy Efficient Economy Summer Study on Buildings. American Council for an Energy Efficient Economy, Washington, D.C.

Federal Register. 1977. Vol 42, No. 192, pp. 54109-54119. October 4, 1977.

Geller, H. and J. H. Morrill. 1988. Analysis of Appliance Efficiency Standards in the Pacific Northwest. Bonneville Power Administration, Portland, Oregon.

Natural Resources Defense Council. 1982. A Model Electric Power and Conservation Plan for the Pacific Northwest. Natural Resources Defense Council, Washington, D.C.

Northwest Power Planning Council. 1991. 1991 Northwest Conservation and Electric Power Plan. Final, Vol I; Draft, Vol II. Northwest Power Planning Council, Purtland, Oregon.

Northwest Power Planning Council. 1989. Technical Appendix to Conservation Supply for the 1990 Power Plan. Northwest Power Planning Council, Portland, Oregon.

Pratt, R.G., and B.A. Ross. 1991. Measured Electric Hot Water Standby and Demand Loads from Pacific Northwest Homes (REMP). Draft Final Report. Pacific Northwest Laboratory, Richland, Washington. 
Pratt, R. G., C. C. Conner, E. E. Richman, K. G. Ritland, W. F. Sandusky, and M. E. Taylor. 1989. Description of Electric Energy Use in Single-Family Residences in the Pacific Northwest (ELCAP). DOE/BP-13795-21. Bonneville Power Administration, Portland, Oregon.

Reese, S. P. and H. A. Wall. 1981. Residential Electric Water Heater Conservation Potential. Seattle City Light, Seattle, Washington.

U.S. Department of Energy. 1989. Technical Support Document: Energy Conservation Standards for Consumer Products: Dishwashers, Clotheswashers and Clothesdryers. DOE/CE-0239. U.S. Department of Energy, Washington, D.C.

Windell, P.A. 1988. ELCAP: Residential Sector Sample Design. DOE/BP-13795-16. Bonneville Power Administration, Portland, Oregon. 


\section{APPENDIX A - TEMPORAL AND CROSS-SITE AGGREGATION METHODOLOGY}

Data aggregation is the process of calculating summary statistics of the hourly metered data, over time and across sites. It includes the criterion and processes used to verify individual site data for completeness, and strategies for weighting sites when calculating group statistics. Threc levels of aggregated data are presented in this report on the hot water end use in residences.

The average energy is a single number, representing the total energy used over a specified period of time, for example, a year, and is expressed in kilowatt hours $(\mathrm{kWh})$. Average load can also be presented in terms of average power consumption, or average kilowatts (average $\mathrm{kW}$ ), which is simply $\mathrm{kWh}$ divided by the number of hours. (Note that in some cases. the reported units are watts, where 1000 watts $=1 \mathrm{kWh}$.) For this report, the sequence of calculation is to aggregate the data by site to monthly (or annual) load, and then to calculate the mean usage across sites.

The average load profile is a series of 24 numbers, representing the average loads for each hour of the data, averaged over a specified time period. Average load profiles are constructed for monthly and annual time periods.

The group load profile is the hour-by-hour power usage of a group of sites, calculated for each consecutive hour over a specified time period, and represents the simultaneous power consumption of a group of sites at any given time of day and year. In this report, the group load profile aggregations were used to present peak day load profiles (BPA coincident peak day, and the aggregate peak day for the different groups of homes).

It is important to recognize that average load profiles may differ significantly from the load shape for a typical day. The otherwise spiky nature of hour-to-hour loads tends to smooth out when data are averaged over months or a year. Thus 
behavior patterns apparent when looking at individual days may be greatly concealed by the mathematical averaging over time.

\section{TREATMENT OF MISSING DATA}

A significant issue when aggregating the REMP data is the lack of complete hourly data for most sites. Not only were the site installations staggered over a oneyear period, but equipment failures, homeowner modifications, and other difficulties have resulted in gaps in the data series for virtually every site. The original number of residences has also gradually diminished, from a peak of 405 metered sites in 1987, to the current level of 207 sites early in 1991. The combination of these two factors-missing data and sample attrition--complicate what could otherwise be a simple tabulation of the hourly data to monthly and annual totals. Given the relatively small number of sites, and the considerable variation in magnitude of individual site loads, the addition (or deletion) of a single site's data can significantly alter the average. In turn, this affects hour-to-hour load averages, and apparent trends can result solely from changes in sample composition. On the other hand, restricting the analysis to sites with "complete" data would exclude most sites from the analysis.

The aggregation approach in this report is to limit the analysis to "relatively complete" metered data, with two adjustments which partially compensate for missing data and site attrition. The following is a description of the criteria used to select data for inclusion in the aggregations, and adjustment mechanisms.

\section{DATA SELEC'TION AND INTERPOLATION}

The original database has been verified for completeness on an hour-by-hour basis, but not over an extended period of time, such as an entire month or year. Thus for inclusion in monthly profiles, data for each site was first subject to a data completeness test with two criteria. The result is a data set in which each sites is 
entirely present (or missing) for each calendar year. Thus, the number of sites for aggregations will not change from month to month within the year.

The first completeness criterion is the presence of a minimum number of hours of data per month. Data for a calendar month was acceptable if there were at least 10 weekday and 4 weekend day values for each hour. This threshold level, chosen based on comparisons of several candidate thresholds, is a compromise between being too tight and thus deleting a large fraction of the sites, and being too loose and allowing erratic patterns of missing data to substantially affect the data summarizations.

The second criterion is that data be present for every month in the calendar year. This criterion requires counting the number of months passing the first criterion above, and ensuring that all the calendar months within a year are still present. Otherwise, the calendar year's data for the site is deleted. This criterion is slightly relaxed by allowing linear interpolation of short gaps of data to make a continuous monthly data series. Monthly profiles were derived for missing months, by linear interpolation of adjacent months' profile data, up to a limit of a three-month span, prior to applying the "all months present" criterion. Additionally, the count of interpolated monthly profiles could not exceed four in any calendar year. The effect of the application of this second criterion for data completeness is shown in Table A.1.

A final data screening step is inspection and deletion of unreasonable values. For the hot water end use, 5 sites were dropped due to zero consumption. Further investigation of these sites showed that either the site had converted to another fuel (one site), or the data verification team had flagged the end use as a possible data acquisition problem.

\section{AVERAGE ENERGY AND LOAD PROFILES}

The site monthly profile data passing the data selection criteria (including interpolated monthly profiles) were aggregated to monthly energy, 


\begin{tabular}{|lcrr|}
\hline & \multicolumn{3}{c|}{ TABLE A.1 } \\
& DATA INTERPOLATION & \\
& & \multicolumn{2}{c|}{ Quantity of Data } \\
& Number of Site & Hours & Percent \\
& Years & & $48.5 \%$ \\
no monthly interpolation & 676 & $5,594,295$ & $14.9 \%$ \\
1 month interpolated & 216 & $1,724,047$ & $8.7 \%$ \\
2 months interpolated & 136 & 999,833 & $4.9 \%$ \\
3 months interpolated & 84 & 566,183 & $1.4 \%$ \\
4 months interpolated & 27 & 166,159 & $21.6 \%$ \\
deleted from analysis & 630 & $2,486,168$ & \\
\hline
\end{tabular}

and annual load profile and energy. These are simply the mean of the weekday and weekend monthly profile data (accounting for the number of weekdays and weekends in each month), since at this point there is complete data for each calendar month (no missing values within a calendar year). The annual energy was calculated taking into account the number of days in each month of the year.

The annual energy loads and average load profiles presented in this report are a weighted arithmetic mean of the temporal aggregated site-level data, without regard to any sample weighting to reflect probability of selection or representativeness of the regional population.

\section{CROSS-SITE AGGREGATION AND PROPORTIONAL WEIGHTING}

The cross-site aggregation did incorporate a weighting scheme that reduces year-to-year load variability due to changes in sample composition. The technique is to divide the overall sample into three strata, based on level of usage, and maintain the same ratio of high, medium, and low users for each calendar year. This technique 
provides a simple adjustment for gross changes in average loads, such as abnormal attrition of high users.

The steps in the calculation for all end-uses, including water heating are as follows:

1. Divide the total number of sites so that there are three even-sized strata, based on building total $\mathrm{kWh}$. Each site is thus assigned to stratum 1, 2, or 3, (high, medium, or low consumption) and this assignment is used for all end uses and years, for the site.

2. Calculate a weighting factor for each stratum and end use, based on the fraction of sites in each of the three strata. Note that this weighting factor is not always one-third, since not all sites have every end use, and in fact some end uses have been more prevalent in sites with higher $\mathrm{kWh}$ usage.

3. Calculate the average energy (or load profile) for each stratum, as the simple arithmetic average, using data passing the above described data selection criteria.

4. Calculate the weighted average of the three strata means, using the weighting factors described in Step 2. This overall mean value maintains the original proportions of low, medium, and high users (strata), even when there is disproportional attrition of sites among the strata.

\section{GROUP LOAD PROFILES}

The group load profile aggregation differs in approach from the average energy and load profile calculations. In group load profiles, all the hourly data for the end use are weighted across all sites resulting in the aggregate average power usage for all sites, for each hour of the year.

The site-level data used for this calculation is filtered to retain data for only those months passing the data selection criteria described above. Hours with missing 
data are ignored in subsequent calculations, and no effort is made to interpolate or otherwise estimate values for missing hours. The hourly time series data are then averaged across sites to produce an hour-by-hour average load for each strata, and the overall weighted average for each study group is calculated as for the cross-site aggregations described above.

The number of sites in each group load profile will vary from hour to hour due to missing data. This is a particular concern for studies with a very small number of sites, and in this report the analysis of group load profiles has been restricted to the year where the available number of sites is largest (1987). 


\section{APPENDIX B - COMPANION DATA TABLES}

FIGURES 7.1-7.4

Mean Residential Regional and REMP Annual Loads by End-Use and Study Type (kWh)

\begin{tabular}{|c|c|c|c|}
\hline & & TOTAL & \\
\hline END-USE & REGION & $\underline{\text { REMP }}$ & $\underline{\mathrm{MCS}}$ \\
\hline HWATER & 4365 & 4747 & 448 \\
\hline OTHER & 7368 & 8379 & 780 \\
\hline HVAC & 9820 & 7598 & 4969 \\
\hline TOTAL & 21823 & 20724 & 1725 \\
\hline
\end{tabular}

\begin{tabular}{lccccc}
\multicolumn{1}{c}{ STUDY } & $\begin{array}{c}\text { HOT } \\
\text { WATER }\end{array}$ & OTHER & & HVAC & TOTAL \\
\cline { 2 - 3 } BASE & 4762 & 16945 & 8145 & 21707 \\
POST-1978 & 5266 & 16945 & 8511 & 22211 \\
MCS & 4483 & 12770 & 4969 & 17253 \\
CONTROL & 4527 & 13493 & 7660 & 18020
\end{tabular}

TABLE 7.5

Mean Residential Hot Water Loads by Year and Type of Home Using The Cross Site and Clustered Weighting With All Sites Method

\begin{tabular}{|c|c|c|c|c|c|}
\hline \multirow[b]{2}{*}{ STUDY } & \multicolumn{5}{|c|}{ YEAR } \\
\hline & $\underline{1986}$ & $15 \times 7$ & $\underline{1988}$ & $\underline{1989}$ & $\underline{1990}$ \\
\hline BASE & 4915 & 4776 & 4668 & 4894 & 4558 \\
\hline POST-1978 & 5499 & 5075 & 5420 & 5504 & 4831 \\
\hline MCS & 4433 & 4583 & 4846 & 4664 & 4110 \\
\hline CONTROL & 4294 & 4544 & 4886 & 4634 & 4054 \\
\hline
\end{tabular}


FIGURE 7.6

Mean Residential Hot Water Monthly Loads by Study

\begin{tabular}{|c|c|c|c|c|}
\hline MONTH & BASE & POST-1978 & MCS & CONTROL \\
\hline JAN & 457.2 & 512.7 & 443.5 & 450.0 \\
\hline FEB & 417.8 & 463.6 & 407.1 & 411.5 \\
\hline MAR & 444.5 & 485.2 & 434.1 & 419.9 \\
\hline APR & 414.2 & 468.2 & 390.6 & 388.1 \\
\hline MAY & 406.2 & 450.4 & 377.6 & 378.2 \\
\hline JUN & 367.8 & 400.6 & 328.5 & 334.8 \\
\hline JUL & 353.9 & 381.0 & 315.6 & 310.5 \\
\hline AUG & 346.8 & 387.8 & 314.2 & 305.1 \\
\hline SEP & 347.2 & 375.3 & 330.4 & 324.5 \\
\hline OCT & 373.3 & 418.9 & 366.3 & 360.5 \\
\hline NOV & 392.8 & 431.4 & 391.3 & 376.2 \\
\hline $\mathrm{DEC}$ & 440.7 & 490.9 & 428.1 & 423.1 \\
\hline
\end{tabular}

FIGURES 7.7-7.10

Mean Residential Hot Water Daily Loads by Month and Study

\begin{tabular}{|c|c|c|c|c|c|c|c|c|}
\hline \multirow[b]{2}{*}{ MTH } & \multicolumn{2}{|c|}{ BASE } & \multicolumn{2}{|c|}{ POST-1978 } & \multicolumn{2}{|c|}{$\underline{\mathrm{MCS}}$} & \multicolumn{2}{|c|}{ CONTROL } \\
\hline & WKEND & WKDAY & WKEND & WKDAY & WKEND & WKDAY & WKEND & WKDAY \\
\hline JAN & 15.251 & 14.510 & 17.241 & 16.195 & 15.185 & 13.902 & 15.368 & 14.113 \\
\hline FEB & 15.259 & 14.610 & 16.808 & 16.268 & 15.332 & 14.006 & 15.432 & 14.193 \\
\hline MAR & 14.894 & 14.119 & 16.414 & 15.338 & 14.796 & 13.696 & 14.992 & 12.994 \\
\hline APR & 14.189 & 13.649 & 15.945 & 15.477 & 14.216 & 12.540 & 13.807 & 12.573 \\
\hline MAY & 13.187 & 13.061 & 14.703 & 14.417 & 12.810 & 11.908 & 12.544 & 12.063 \\
\hline JUN & 12.186 & 12.290 & 12.650 & 13.655 & 11.191 & 10.857 & 11.231 & 11.139 \\
\hline JUL & 11.179 & 11.514 & 11.950 & 12.453 & 10.751 & 9.931 & 10.348 & 9.862 \\
\hline AUG & 10.979 & 11.268 & 12.167 & 12.633 & 10.491 & 9.993 & 9.941 & 9.805 \\
\hline SEP & 11.639 & 11.548 & 12.817 & 12.386 & 11.672 & 10.692 & 11.400 & 10.536 \\
\hline OCT & 12.379 & 11.910 & 13.593 & 13.464 & 12.629 & 11.500 & 12.427 & 11.315 \\
\hline NOV & 13.568 & 12.853 & 14.717 & 14.191 & 13.758 & 12.669 & 12.944 & 12.333 \\
\hline DEC & 14.595 & 14.027 & 16.593 & 15.479 & 14.484 & 13.480 & 14.105 & 13.435 \\
\hline
\end{tabular}


FIGURES 8.1-8.4

Mean Residential Hourly Hot Water Load Profiles by Study

\begin{tabular}{|c|c|c|c|c|c|c|c|c|}
\hline \multirow[t]{2}{*}{$\underline{\mathrm{HR}}$} & \multicolumn{2}{|c|}{ BASE } & \multicolumn{2}{|c|}{ POST-1978 } & \multicolumn{2}{|c|}{$\underline{\mathrm{MCS}}$} & \multicolumn{2}{|c|}{ CONTROL } \\
\hline & WKEND & WKDAY & WKEND & WKDAY & WKEND & WKDAY & WKEND & WKDAY \\
\hline 1 & 0.257 & 0.217 & 0.234 & 0.188 & 0.253 & 0.201 & 0.231 & 0.211 \\
\hline 2 & 0.189 & 0.165 & 0.176 & 0.143 & 0.171 & 0.142 & 0.153 & 0.141 \\
\hline 3 & 0.150 & 0.142 & 0.145 & 0.125 & 0.125 & 0.113 & 0.119 & 0.113 \\
\hline 4 & 0.135 & 0.132 & 0.125 & 0.121 & 0.105 & 0.106 & 0.113 & 0.119 \\
\hline 5 & 0.144 & 0.162 & 0.147 & 0.162 & 0.118 & 0.156 & 0.118 & 0.177 \\
\hline 6 & 0.189 & 0.312 & 0.255 & 0.355 & 0.173 & 0.445 & 0.167 & 0.518 \\
\hline 7 & 0.271 & 0.715 & 0.240 & 0.695 & 0.242 & 1.082 & 0.307 & 0.855 \\
\hline 8 & 0.478 & 1.134 & 0.442 & 1.252 & 0.511 & 1.125 & 0.465 & 1.051 \\
\hline 9 & 0.785 & 0.995 & 0.809 & 1.156 & 0.864 & 0.868 & 0.736 & 0.788 \\
\hline 10 & 1.001 & 0.855 & 1.140 & 0.965 & 1.115 & 0.665 & 1.013 & 0.746 \\
\hline 11 & 1.038 & 0.741 & 1.209 & 0.844 & 1.074 & 0.602 & 1.081 & 0.668 \\
\hline 12 & 0.942 & 0.629 & 1.070 & 0.713 & 0.942 & 0.549 & 0.979 & 0.532 \\
\hline 13 & 0.827 & 0.553 & 0.926 & 0.633 & 0.831 & 0.479 & 0.830 & 0.455 \\
\hline 14 & 0.731 & 0.499 & 0.820 & 0.629 & 0.722 & 0.416 & 0.730 & 0.394 \\
\hline 15 & 0.645 & 0.435 & 0.694 & 0.519 & 0.602 & 0.359 & 0.653 & 0.362 \\
\hline 16 & 0.595 & 0.423 & 0.630 & 0.469 & 0.539 & 0.340 & 0.555 & 0.367 \\
\hline 17 & 0.611 & 0.483 & 0.658 & 0.539 & 0.569 & 0.388 & 0.568 & 0.448 \\
\hline 18 & 0.671 & 0.603 & 0.754 & 0.679 & 0.639 & 0.521 & 0.672 & 0.587 \\
\hline 19 & 0.720 & 0.731 & 0.868 & 0.855 & 0.699 & 0.679 & 0.744 & 0.697 \\
\hline 20 & 0.709 & 0.735 & 0.876 & 0.868 & 0.714 & 0.703 & 0.683 & 0.719 \\
\hline 21 & 0.667 & 0.689 & 0.808 & 0.799 & 0.677 & 0.641 & 0.640 & 0.648 \\
\hline 22 & 0.626 & 0.660 & 0.705 & 0.705 & 0.595 & 0.635 & 0.548 & 0.573 \\
\hline 23 & 0.525 & 0.555 & 0.531 & 0.548 & 0.491 & 0.521 & 0.442 & 0.483 \\
\hline 24 & 0.384 & 0.364 & 0.396 & 0.353 & 0.353 & 0.339 & 0.340 & 0.351 \\
\hline
\end{tabular}


FIGURES 8.5-8.6

Mean Residential Hot Water Load Profiles for Base Homes

\begin{tabular}{rcccc} 
& \multicolumn{2}{c}{ WEEKEND } & \multicolumn{2}{c}{ WEEKDAY } \\
HR & $\underline{\text { JAN }}$ & $\underline{\text { JULY }}$ & $\underline{\text { JAN }}$ & $\underline{\text { JULY }}$ \\
& & & & \\
1 & 0.299 & 0.235 & 0.245 & 0.212 \\
2 & 0.221 & 0.161 & 0.190 & 0.154 \\
3 & 0.178 & 0.138 & 0.160 & 0.133 \\
4 & 0.157 & 0.127 & 0.145 & 0.122 \\
5 & 0.148 & 0.131 & 0.178 & 0.150 \\
6 & 0.209 & 0.181 & 0.356 & 0.264 \\
7 & 0.256 & 0.253 & 0.792 & 0.519 \\
8 & 0.409 & 0.457 & 1.274 & 0.761 \\
9 & 0.737 & 0.678 & 1.137 & 0.769 \\
10 & 1.061 & 0.836 & 0.949 & 0.789 \\
11 & 1.194 & 0.850 & 0.830 & 0.724 \\
12 & 1.160 & 0.787 & 0.719 & 0.627 \\
13 & 1.066 & 0.660 & 0.628 & 0.544 \\
14 & 0.930 & 0.588 & 0.546 & 0.522 \\
15 & 0.831 & 0.507 & 0.481 & 0.445 \\
16 & 0.762 & 0.469 & 0.475 & 0.415 \\
17 & 0.774 & 0.467 & 0.548 & 0.446 \\
18 & 0.818 & 0.526 & 0.693 & 0.538 \\
19 & 0.844 & 0.554 & 0.847 & 0.631 \\
20 & 0.803 & 0.556 & 0.846 & 0.612 \\
21 & 0.731 & 0.552 & 0.755 & 0.585 \\
22 & 0.669 & 0.562 & 0.705 & 0.595 \\
23 & 0.556 & 0.511 & 0.606 & 0.577 \\
24 & 0.438 & 0.393 & 0.405 & 0.380
\end{tabular}


FIGURE 9.1-9.4

Mean Residential Hot Water Seasonal Peak Day Profiles by Study (1987)

\begin{tabular}{ccccccc} 
& & BASE & & & POST-1978 & \\
MONTH & AVG & PEAK & LF & $\underline{\text { AVG }}$ & $\underline{\text { PEAK }}$ & $\underline{\text { LF }}$ \\
JAN & 0.627 & 1.409 & $44.5 \%$ & 0.659 & 1.774 & $37.2 \%$ \\
FEB & 0.604 & 1.450 & $41.7 \%$ & 0.636 & 1.719 & $37.0 \%$ \\
MAR & 0.598 & 1.542 & $38.8 \%$ & 0.661 & 1.978 & $33.4 \%$ \\
APR & 0.572 & 1.468 & $39.0 \%$ & 0.635 & 2.075 & $30.6 \%$ \\
MAY & 0.540 & 1.46 .1 & $36.9 \%$ & 0.538 & 1.799 & $29.9 \%$ \\
JUN & 0.513 & 1.321 & $38.8 \%$ & 0.512 & 1.520 & $33.7 \%$ \\
JUL & 0.488 & 1.063 & $45.9 \%$ & 0.483 & 1.413 & $34.2 \%$ \\
AUG & 0.478 & 1.044 & $45.7 \%$ & 0.496 & 1.572 & $31.5 \%$ \\
SEP & 0.491 & 1.352 & $36.3 \%$ & 0.516 & 1.712 & $30.2 \%$ \\
OCT & 0.505 & 1.328 & $38.0 \%$ & 0.565 & 1.804 & $31.3 \%$ \\
NOV & 0.548 & 1.444 & $38.0 \%$ & 0.609 & 1.810 & $33.6 \%$ \\
DEC & 0.587 & 1.345 & $43.7 \%$ & 0.652 & 1.871 & $34.8 \%$ \\
& & & & & & \\
MONTH & $\underline{A V G}$ & $\underline{\text { PEAK }}$ & LF & $\underline{\text { AVG }}$ & $\underline{\text { PEAK }}$ & $\underline{\text { LF }}$ \\
\hline & & & & & & \\
JAN & 0.624 & 1.772 & $35.2 \%$ & 0.626 & 1.698 & $36.9 \%$ \\
FEB & 0.620 & 1.804 & $34.4 \%$ & 0.614 & 1.926 & $31.9 \%$ \\
MAR & 0.607 & 1.771 & $34.3 \%$ & 0.559 & 1.864 & $30.0 \%$ \\
APR & 0.544 & 1.589 & $34.3 \%$ & 0.520 & 1.636 & $31.8 \%$ \\
MAY & 0.510 & 1.595 & $31.9 \%$ & 0.494 & 1.788 & $27.6 \%$ \\
JUN & 0.475 & 1.405 & $33.8 \%$ & 0.486 & 1.595 & $30.5 \%$ \\
JUL & 0.426 & 1.134 & $37.6 \%$ & 0.444 & 1.515 & $29.3 \%$ \\
AUG & 0.434 & 1.277 & $34.0 \%$ & 0.417 & 1.199 & $34.8 \%$ \\
SEP & 0.461 & 1.331 & $34.6 \%$ & 0.457 & 1.461 & $31.3 \%$ \\
OCT & 0.487 & 1.483 & $32.8 \%$ & 0.498 & 1.673 & $29.8 \%$ \\
NOV. & 0.546 & 1.620 & $33.7 \%$ & 0.537 & 2.144 & $25.0 \%$ \\
DEC & 0.556 & 1.827 & $30.5 \%$ & 0.590 & 2.043 & $28.9 \%$ \\
& & & & & &
\end{tabular}


FIGURES 9.5-9.8

Winter Peak Day Hourly Load Profiles

(December 17, 1987)

BASE

POST -1978

MCS

CONTROL

HR SYSTEM HOT TOTAL HOT TOTAL HOT TOTAL HOT TOTAL

$\begin{array}{rlllllllll}1 & 7195 & 0.271 & 2.554 & 0.366 & 2.439 & 0.272 & 2.120 & 0.284 & 3.160 \\ 2 & 7144 & 0.168 & 2.476 & 0.129 & 2.502 & 0.163 & 1.884 & 0.146 & 3.137 \\ 3 & 7167 & 0.182 & 2.590 & 0.262 & 2.677 & 0.082 & 1.863 & 0.188 & 3.028 \\ 4 & 7234 & 0.158 & 2.666 & 0.198 & 2.747 & 0.140 & 2.197 & 0.094 & 3.090 \\ 5 & 7393 & 0.158 & 2.765 & 0.084 & 2.645 & 0.109 & 2.135 & 0.188 & 3.450 \\ 6 & 7920 & 0.341 & 3.684 & 0.767 & 4.410 & 0.472 & 2.972 & 0.649 & 3.789 \\ 7 & 8814 & 0.686 & 4.809 & 0.711 & 5.946 & 1.599 & 4.439 & 0.975 & 3.311 \\ 8 & 9312 & 1.333 & 5.584 & 1.659 & 6.735 & 1.415 & 4.568 & 0.893 & 4.366 \\ 9 & 9232 & 1.132 & 5.229 & 1.159 & 6.199 & 1.173 & 4.272 & 0.623 & 4.078 \\ 10 & 8866 & 1.010 & 4.695 & 1.126 & 5.156 & 0.861 & 3.527 & 0.919 & 5.069 \\ 11 & 8485 & 0.782 & 4.182 & 0.842 & 4.490 & 0.691 & 2.882 & 0.797 & 4.337 \\ 12 & 8166 & 0.727 & 3.865 & 0.588 & 3.934 & 0.442 & 2.586 & 0.732 & 3.487 \\ 13 & 7889 & 0.620 & 3.622 & 0.655 & 3.478 & 0.548 & 2.501 & 0.704 & 3.395 \\ 14 & 7719 & 0.474 & 3.339 & 0.689 & 3.393 & 0.391 & 2.363 & 0.300 & 2.517 \\ 15 & 7589 & 0.343 & 3.091 & 0.784 & 3.373 & 0.381 & 2.335 & 0.236 & 2.515 \\ 16 & 7661 & 0.418 & 3.439 & 0.693 & 3.693 & 0.438 & 2.457 & 0.635 & 3.684 \\ 17 & 8161 & 0.522 & 4.327 & 0.950 & 5.413 & 0.647 & 3.423 & 0.275 & 3.788 \\ 18 & 8619 & 0.757 & 4.934 & 0.759 & 6.064 & 0.651 & 3.801 & 0.943 & 5.046 \\ 19 & 8668 & 0.806 & 4.839 & 0.748 & 5.260 & 0.602 & 3.859 & 0.787 & 4.114 \\ 20 & 8513 & 0.720 & 4.630 & 0.629 & 5.298 & 0.621 & 3.808 & 0.682 & 4.323 \\ 21 & 8358 & 0.698 & 4.524 & 1.081 & 6.018 & 0.555 & 3.618 & 0.982 & 4.318 \\ 22 & 8147 & 0.650 & 4.526 & 0.733 & 5.971 & 0.615 & 3.469 & 0.676 & 3.663 \\ 23 & 7826 & 0.546 & 3.695 & 0.500 & 3.843 & 0.544 & 3.225 & 0.669 & 3.248 \\ 24 & 7170 & 0.389 & 3.009 & 0.318 & 2.723 & 0.517 & 2.743 & 0.655 & 2.763\end{array}$


FIGURES 9.9-9.12

Summer Peak Day Hourly Load Profiles

(August 31, 1987)

BASE POST-1978 $\underline{\text { MCS }}$ CONTROL

\begin{tabular}{rccccccccc} 
HR & SYSTEM & HOT & TOTAL & HOT & TOTAL & HOT & TOTAL & HOT & TOTAL \\
\hline 1 & 5654 & 0.189 & 1.014 & 0.258 & 0.662 & 0.206 & 0.880 & 0.108 & 0.997 \\
3 & 5495 & 0.151 & 0.881 & 0.042 & 0.376 & 0.121 & 0.725 & 0.105 & 0.901 \\
4 & 5496 & 0.127 & 0.838 & 0.073 & 0.378 & 0.091 & 0.662 & 0.118 & 0.835 \\
4 & 5462 & 0.116 & 0.781 & 0.049 & 0.410 & 0.068 & 0.640 & 0.124 & 0.791 \\
5 & 5520 & 0.124 & 0.787 & 0.204 & 0.470 & 0.156 & 0.718 & 0.057 & 0.731 \\
6 & 5727 & 0.302 & 1.015 & 0.171 & 0.513 & 0.364 & 0.991 & 0.368 & 1.038 \\
7 & 6145 & 0.606 & 1.570 & 0.530 & 0.909 & 0.653 & 1.455 & 0.535 & 1.440 \\
8 & 6686 & 0.957 & 2.043 & 0.913 & 1.401 & 0.811 & 1.786 & 0.941 & 2.014 \\
9 & 6746 & 0.721 & 1.841 & 0.657 & 1.144 & 0.728 & 1.506 & 0.787 & 1.689 \\
10 & 6934 & 0.796 & 1.972 & 0.963 & 1.448 & 0.558 & 1.399 & 0.707 & 1.992 \\
11 & 7111 & 0.809 & 2.076 & 0.442 & 0.910 & 0.572 & 1.473 & 0.817 & 2.014 \\
12 & 7058 & 0.651 & 2.041 & 0.283 & 1.005 & 0.560 & 1.403 & 0.501 & 2.100 \\
13 & 7068 & 0.542 & 1.966 & 0.653 & 1.497 & 0.446 & 1.552 & 0.672 & 2.529 \\
14 & 7105 & 0.523 & 2.046 & 0.395 & 1.000 & 0.331 & 1.420 & 0.661 & 2.614 \\
15 & 7090 & 0.370 & 1.930 & 0.303 & 1.014 & 0.369 & 1.488 & 0.463 & 2.558 \\
16 & 7032 & 0.336 & 2.033 & 0.161 & 1.012 & 0.338 & 1.543 & 0.510 & 2.781 \\
17 & 7110 & 0.360 & 2.232 & 0.169 & 1.093 & 0.296 & 1.499 & 0.447 & 2.889 \\
18 & 7086 & 0.501 & 2.499 & 0.215 & 1.352 & 0.297 & 1.551 & 0.463 & 3.021 \\
19 & 6918 & 0.557 & 2.572 & 0.552 & 1.964 & 0.291 & 1.622 & 0.747 & 3.539 \\
20 & 6974 & 0.640 & 2.503 & 0.235 & 1.311 & 0.599 & 2.097 & 0.618 & 3.086 \\
21 & 7057 & 0.589 & 2.465 & 0.252 & 1.185 & 0.712 & 2.441 & 0.721 & 3.406 \\
22 & 6968 & 0.626 & 2.542 & 0.289 & 1.246 & 0.660 & 2.279 & 0.943 & 3.620 \\
23 & 6525 & 0.517 & 2.076 & 0.240 & 1.286 & 0.599 & 1.826 & 0.671 & 2.726 \\
24 & 6183 & 0.350 & 1.535 & 0.296 & 0.996 & 0.361 & 1.297 & 0.304 & 1.746
\end{tabular}



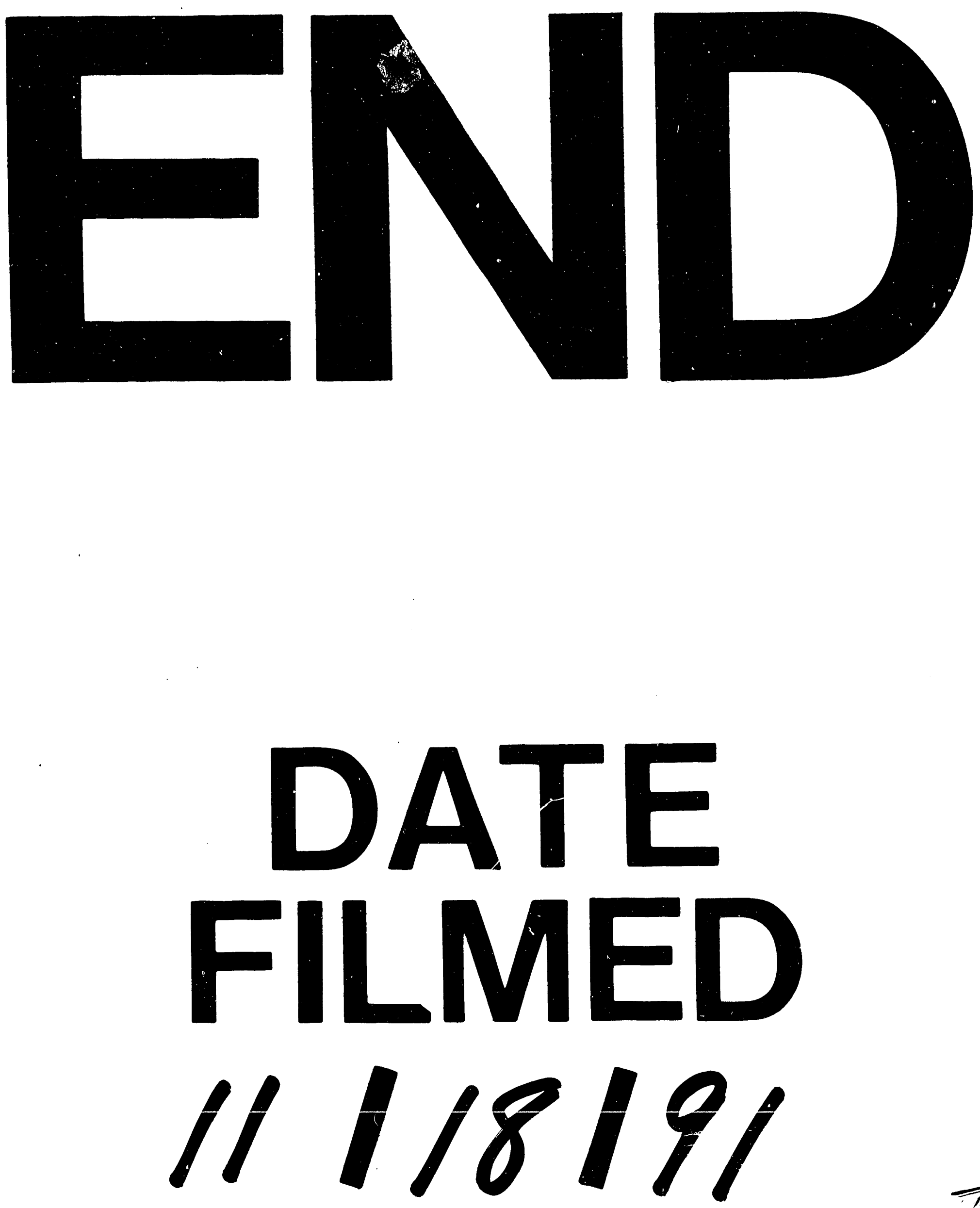


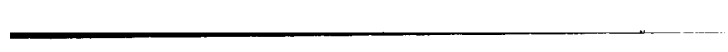

